\title{
Validation of ozone measurements from the Atmospheric Chemistry Experiment (ACE)
}

E. Dupuy ${ }^{1}$, K. A. Walker ${ }^{1,2}$, J. Kar ${ }^{2}$, C. D. Boone ${ }^{1}$, C. T. McElroy ${ }^{2,3}$, P. F. Bernath ${ }^{1,4}$, J. R. Drummond ${ }^{2,5}$, R. Skelton ${ }^{1}$, S. D. McLeod ${ }^{1}$, R. C. Hughes ${ }^{1}$, C. R. Nowlan ${ }^{2}$, D. G. Dufour ${ }^{6}$, J. Zou ${ }^{2}$, F. Nichitiu ${ }^{2}$, K. Strong ${ }^{2}$, P. Baron ${ }^{7}$, R. M. Bevilacqua ${ }^{8}$, T. Blumenstock ${ }^{9}$, G. E. Bodeker ${ }^{10}$, T. Borsdorff ${ }^{11}$, A. E. Bourassa ${ }^{12}$, H. Bovensmann ${ }^{13}$, I. S. Boyd ${ }^{14}$, A. Bracher ${ }^{13}$, C. Brogniez ${ }^{15}$, J. P. Burrows ${ }^{13}$, V. Catoire ${ }^{16}$, S. Ceccherini ${ }^{17}$, S. Chabrillat ${ }^{18}$, T. Christensen ${ }^{19}$, M. T. Coffey ${ }^{20}$, U. Cortesi ${ }^{17}$, J. Davies ${ }^{3}$, C. De Clercq ${ }^{18}$, D. A. Degenstein ${ }^{12}$, M. De Mazière ${ }^{18}$, P. Demoulin ${ }^{21}$, J. Dodion ${ }^{18}$, B. Firanski ${ }^{22}$, H. Fischer ${ }^{9}$, G. Forbes ${ }^{23}$, L. Froidevaux ${ }^{24}$, D. Fussen ${ }^{18}$, P. Gerard ${ }^{18}$, S. Godin-Beekmann ${ }^{25}$, F. Goutail ${ }^{26}$, J. Granville ${ }^{18}$, D. Griffith ${ }^{27}$, C. S. Haley ${ }^{28}$, J. W. Hannigan ${ }^{20}$, M. Höpfner ${ }^{9}$, J. J. Jin ${ }^{29}$, A. Jones ${ }^{30}$, N. B. Jones ${ }^{27}$, K. Jucks ${ }^{31}$, A. Kagawa ${ }^{7,32}$, Y. Kasai ${ }^{7}$, T. E. Kerzenmacher ${ }^{2}$, A. Kleinböhl ${ }^{13,24}$, A. R. Klekociuk ${ }^{33}$, I. Kramer ${ }^{9}$, H. Küllmann ${ }^{13}$, J. Kuttippurath ${ }^{13,25}$, E. Kyrölä̈ ${ }^{34}$, J.-C. Lambert ${ }^{18}$, N. J. Livesey ${ }^{24}$, E. J. Llewellyn ${ }^{12}$, N. D. Lloyd ${ }^{12}$, E. Mahieu ${ }^{21}$, G. L. Manney ${ }^{24,35}$, B. T. Marshall ${ }^{36}$, J. C. McConnell $^{29}$, M. P. McCormick ${ }^{37}$, I. S. McDermid ${ }^{38}$, M. McHugh ${ }^{36}$, C. A. McLinden ${ }^{3}$, J. Mellqvist ${ }^{30}$, K. Mizutani ${ }^{7}$, Y. Murayama ${ }^{7}$, D. P. Murtagh $^{30}$, H. Oelhaf ${ }^{9}$, A. Parrish ${ }^{39}$, S. V. Petelina ${ }^{12,40}$, C. Piccolo ${ }^{41}$, J.-P. Pommereau ${ }^{26}$, C. E. Randall ${ }^{42}$, C. Robert $^{16}$, C. Roth $^{12}$, M. Schneider ${ }^{9}$, C. Senten ${ }^{18}$, T. Steck ${ }^{9}$, A. Strandberg ${ }^{30}$, K. B. Strawbridge ${ }^{22}$, R. Sussmann ${ }^{11}$, D. P. J. Swart ${ }^{43}$, D. W. Tarasick ${ }^{3}$, J. R. Taylor ${ }^{2}$, C. Tétard ${ }^{15}$, L. W. Thomason ${ }^{37}$, A. M. Thompson ${ }^{44}$, M. B. Tully ${ }^{45}$, J. Urban ${ }^{30}$, F. Vanhellemont ${ }^{18}$, C. Vigouroux ${ }^{18}$, T. von Clarmann ${ }^{9}$, P. von der Gathen ${ }^{46}$, C. von Savigny ${ }^{13}$, J. W. Waters ${ }^{24}$, J. C. Witte ${ }^{47,48}$, M. Wolff ${ }^{2}$, and J. M. Zawodny ${ }^{37}$

${ }^{1}$ Department of Chemistry, University of Waterloo, Waterloo, ON, Canada

${ }^{2}$ Department of Physics, University of Toronto, Toronto, ON, Canada

${ }^{3}$ Environment Canada, Downsview, ON, Canada

${ }^{4}$ Department of Chemistry, University of York, Heslington, York, UK

${ }^{5}$ Department of Physics and Atmospheric Science, Dalhousie University, Halifax, Canada

${ }^{6}$ Picomole Instruments Inc., Edmonton, AB, Canada

${ }^{7}$ National Institute of Information and Communications Technology (NICT), Koganei, Tokyo, Japan

${ }^{8}$ Naval Research Laboratory, Washington, D.C., USA

${ }^{9}$ Institut für Meteorologie und Klimaforschung (IMK), Forschungszentrum Karlsruhe (FZK) and Universität Karlsruhe,

Karlsruhe, Germany

${ }^{10}$ National Institute of Water and Atmospheric Research, Lauder, New Zealand

${ }^{11}$ Institut für Meteorologie und Klimaforschung Atmosphärische Umweltforschung (IMK-IFU), Forschungszentrum

Karlsruhe, Garmisch-Partenkirchen, Germany

${ }^{12}$ Institute of Space and Atmospheric Studies, University of Saskatchewan, Saskatoon, SK, Canada

${ }^{13}$ Institut für Umweltphysik (IUP), Universität Bremen, Bremen, Germany

${ }^{14}$ NIWA - Environmental Research Institute, University of Massachusetts, Amherst, MA, USA

${ }^{15}$ Laboratoire d'Optique Atmosphérique, CNRS - Université des sciences et technologies de Lille, Villeneuve d'Ascq, France

${ }^{16}$ Laboratoire de Physique et Chimie de l'Environnement, CNRS - Université d'Orléans, Orléans, France

${ }^{17}$ Instituto di Fisica Applicata "N. Carrara" (IFAC) del Consiglio Nazionale delle Ricerche (CNR), Sesto Fiorentino, Italy

${ }^{18}$ Institut d'Aéronomie Spatiale de Belgique (BIRA-IASB), Bruxelles, Belgium

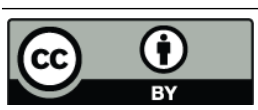

Correspondence to: K. A. Walker (kwalker@atmosp.physics.utoronto.ca)

Published by Copernicus Publications on behalf of the European Geosciences Union. 
${ }^{19}$ Danish Climate Centre, Danish Meteorological Institute, Copenhagen, Denmark

${ }^{20}$ Earth and Sun Systems Laboratory (ESSL), National Center for Atmospheric Research (NCAR), Boulder, CO, USA

${ }^{21}$ Institut d'Astrophysique et de Géophysique, Université de Liège, Liège, Belgium

${ }^{22}$ Science and Technology Branch, Environment Canada, Centre For Atmospheric Research Experiments, Egbert, ON, Canada

${ }^{23}$ Environment Canada Sable Island, Dartmouth, Canada

${ }^{24}$ Jet Propulsion Laboratory (JPL), California Institute of Technology, Pasadena, CA, USA

${ }^{25}$ CNRS - Service d'Aéronomie (SA), Université Pierre et Marie Curie (UPMC) Paris VI, Paris, France

${ }^{26}$ CNRS - Service d'Aéronomie (SA), Verrières-le-Buisson, France

${ }^{27}$ School of Chemistry, University of Wollongong, Wollongong, Australia

${ }^{28}$ Centre for Research in Earth and Space Science, York University, Toronto, ON, Canada

${ }^{29}$ Department of Earth and Space Science and Engineering, York University, Toronto, ON, Canada

${ }^{30}$ Department of Radio and Space Science, Chalmers University of Technology, Göteborg, Sweden

${ }^{31}$ Harvard-Smithsonian Center for Astrophysics, Cambridge, MA, USA

${ }^{32}$ Fujitsu FIP Corporation, Koto, Tokyo, Japan

${ }^{33}$ Ice, Ocean, Atmosphere and Climate (IOAC) Program, Australian Antarctic Division, Kingston, Australia

${ }^{34}$ Earth Observation, Finnish Meteorological Institute, Helsinki, Finland

${ }^{35}$ New Mexico Institute of Mining and Technology, Socorro, NM, USA

${ }^{36}$ GATS, Inc., Newport News, VA, USA

${ }^{37}$ NASA Langley Research Center, Atmospheric Sciences Division, Hampton, VA, USA

${ }^{38}$ Jet Propulsion Laboratory, Table Mountain Facility, Wrightwood, CA, USA

${ }^{39}$ Department of Astronomy, University of Massachusetts, Amherst, MA, USA

${ }^{40}$ Department of Physics, La Trobe University, Victoria, Australia

${ }^{41}$ Atmospheric, Oceanic and Planetary Physics, Oxford University, UK

${ }^{42}$ Laboratory for Atmospheric and Space Physics, University of Colorado, Boulder, CO, USA

${ }^{43}$ National Institute for Public Health and the Environment (RIVM), Bilthoven, The Netherlands

${ }^{44}$ Department of Meteorology, Pennsylvania State University, University Park, PA, USA

${ }^{45}$ Atmosphere Watch Section, Bureau of Meteorology, Melboune, Vic, Australia

${ }^{46}$ Alfred Wegener Institute for Polar and Marine Research, Research Unit Potsdam, Germany

${ }^{47}$ Science Systems and Applications, Inc., Lanham, MD, USA

${ }^{48}$ NASA Goddard Space Flight Center (GSFC), Greenbelt, MD, USA

Received: 1 November 2007 - Published in Atmos. Chem. Phys. Discuss.: 8 February 2008

Revised: 20 November 2008 - Accepted: 20 November 2008 - Published: 16 January 2009 
Abstract. This paper presents extensive bias determination analyses of ozone observations from the Atmospheric Chemistry Experiment (ACE) satellite instruments: the ACE Fourier Transform Spectrometer (ACE-FTS) and the Measurement of Aerosol Extinction in the Stratosphere and Troposphere Retrieved by Occultation (ACE-MAESTRO) instrument. Here we compare the latest ozone data products from ACE-FTS and ACE-MAESTRO with coincident observations from nearly 20 satellite-borne, airborne, balloonborne and ground-based instruments, by analysing volume mixing ratio profiles and partial column densities. The ACEFTS version 2.2 Ozone Update product reports more ozone than most correlative measurements from the upper troposphere to the lower mesosphere. At altitude levels from 16 to $44 \mathrm{~km}$, the average values of the mean relative differences are nearly all within +1 to $+8 \%$. At higher altitudes (45$60 \mathrm{~km}$ ), the ACE-FTS ozone amounts are significantly larger than those of the comparison instruments, with mean relative differences of up to $+40 \%$ (about $+20 \%$ on average). For the ACE-MAESTRO version 1.2 ozone data product, mean relative differences are within $\pm 10 \%$ (average values within $\pm 6 \%$ ) between 18 and $40 \mathrm{~km}$ for both the sunrise and sunset measurements. At higher altitudes $(\sim 35-55 \mathrm{~km})$, systematic biases of opposite sign are found between the ACEMAESTRO sunrise and sunset observations. While ozone amounts derived from the ACE-MAESTRO sunrise occultation data are often smaller than the coincident observations (with mean relative differences down to $-10 \%$ ), the sunset occultation profiles for ACE-MAESTRO show results that are qualitatively similar to ACE-FTS, indicating a large positive bias (mean relative differences within +10 to $+30 \%$ ) in the $45-55 \mathrm{~km}$ altitude range. In contrast, there is no significant systematic difference in bias found for the ACE-FTS sunrise and sunset measurements.

\section{Introduction}

Ozone is a key molecule in the middle atmosphere because it absorbs solar ultraviolet (UV) radiation and contributes to the radiative balance of the stratosphere. Understanding changes occurring in the distribution of ozone in the atmosphere is, therefore, important for studying ozone recovery, climate change and the coupling between these processes (WMO, 2007). To this end, it is important to have continuous high quality measurements of ozone in the stratosphere. Profile measurements from satellite-borne instruments provide height-resolved information that can be used to understand changes in ozone concentrations occurring at different altitudes. For the past two decades, one of the primary sources for ozone profile information has been satellite-borne instruments making solar occultation measurements. The solar occultation technique provides self-calibrating measurements of atmospheric absorption spectra with a high signal-to-noise ratio and good vertical resolution. Thus, to extend this time series of measurements in a consistent way, it is crucial to conduct validation studies that compare the results from new instruments with those from older and more established instruments.

The newest satellite for solar occultation studies is the Atmospheric Chemistry Experiment (ACE). This Canadian-led satellite mission, also known as SCISAT, was launched on 12 August 2003 (Bernath et al., 2005). There are two instruments on-board the spacecraft that provide vertical profiles of ozone and a range of trace gas constituents, as well as temperature and atmospheric extinction due to aerosols. The ACE Fourier Transform Spectrometer (ACE-FTS) (Bernath et al., 2005) measures in the infrared (IR) region of the spectrum and the Measurement of Aerosol Extinction in the Stratosphere and Troposphere Retrieved by Occultation (ACE-MAESTRO) (McElroy et al., 2007) operates in the UV/visible/near-IR. The main objective of the ACE mission is to understand the global-scale chemical and dynamical processes which govern the abundance of ozone from the upper troposphere to the lower mesosphere, with an emphasis on chemistry and dynamics in the Arctic. SCISAT, the platform carrying the ACE-FTS and ACE-MAESTRO, is in a circular low-Earth orbit, with a $74^{\circ}$ inclination and an altitude of $650 \mathrm{~km}$ (Bernath et al., 2005). From this orbit, the instruments measure up to 15 sunrise (hereinafter SR) and 15 sunset (hereinafter SS) occultations each day. Global coverage of the tropical, mid-latitude and polar regions (with the highest sampling in the Arctic and Antarctic) is achieved over the course of one year and the ACE measurement latitude pattern repeats each year. When ACE was launched, there were several solar occultation satelliteborne instruments in operation: Stratospheric Aerosol and Gas Experiment (SAGE) II (Mauldin et al., 1985), SAGE III (SAGE ATBD Team, 2002a), HALogen Occultation Experiment (HALOE) (Russell et al., 1993), Polar Ozone and Aerosol Measurement (POAM) III (Lucke et al., 1999) and SCanning Imaging Absorption spectroMeter for Atmospheric CHartographY (SCIAMACHY) (Bovensmann et al., 1999). The first four instruments only make occultation measurements while SCIAMACHY operates in nadir, limb and occultation modes. Between August and December 2005, the SAGE II, SAGE III, HALOE, and POAM III measurements ended. Currently, ACE-FTS and ACE-MAESTRO are the only satellite-borne instruments operating exclusively in solar occultation mode, while SCIAMACHY provides occultation measurements in addition to its limb and nadir observations. To be able to extend the long-standing record of observations from the SAGE II, SAGE III, POAM III and HALOE instruments, it is important that the ozone measurements provided by ACE-FTS and ACE-MAESTRO be well characterized and their quality thoroughly assessed.

In this paper, we present extensive studies focusing on bias determination for the most recent ozone data products from ACE-FTS (version 2.2 Ozone Update) and ACE-MAESTRO 
(version 1.2). The current ozone data are here compared with measurements from satellite-borne instruments as well as ozonesondes and balloon-borne, airborne and groundbased instruments employing different observation techniques. Section 2 describes the ACE satellite mission, instruments, and the ozone data products. The coincidence criteria and the validation methodology are described in Sects. 3 and 4 , respectively. The comparisons are organized by instrument platform in the following two sections, Sect. 5 for the satellites and Sect. 6 for the ozonesondes, balloon-borne, airborne and ground-based instruments. The overall results are summarized and discussed in Sect. 7 and conclusions are given in Sect. 8.

\section{The ACE instruments and data products}

\subsection{ACE-FTS}

The primary instrument for the ACE mission, the ACEFTS, is a successor to the Atmospheric Trace MOlecule Spectroscopy (ATMOS) experiment (Gunson et al., 1996), an infrared FTS that operated during four flights on the Space Shuttle (in 1985, 1992, 1993 and 1994). ACE-FTS measures high-resolution $\left(0.02 \mathrm{~cm}^{-1}\right)$ atmospheric spectra between 750 and $4400 \mathrm{~cm}^{-1}(2.2-13 \mu \mathrm{m})$ (Bernath et al., 2005). A feedback-controlled pointing mirror is used to target the centre of the Sun and track it during the measurements. Typical signal-to-noise ratios are more than 300 from $\sim 900$ to $3700 \mathrm{~cm}^{-1}$. From the $650 \mathrm{~km}$ ACE orbit, the instrument field-of-view $(1.25 \mathrm{mrad})$ corresponds to a maximum vertical resolution of 3-4 km (Boone et al., 2005). The vertical spacing between consecutive $2 \mathrm{~s}$ ACE-FTS measurements depends on the satellite's orbit geometry during the occultation and can vary from $1.5-6 \mathrm{~km}$. The altitude coverage of the measurements extends from the cloud tops to $\sim 100$ $150 \mathrm{~km}$. The suntracker used by the ACE instruments cannot operate in the presence of thick clouds in the field-of-view. Therefore the profiles do not extend below cloud top level. The lower altitude limit of the profiles is thus generally 8 $10 \mathrm{~km}$, extending in some cases to $5 \mathrm{~km}$, depending on the presence or absence of clouds.

Vertical profiles of atmospheric parameters, namely temperature, pressure and volume mixing ratios (VMRs) of trace constituents, are retrieved from the occultation spectra. This is described in detail in Boone et al. (2005). Briefly, retrieval parameters are determined simultaneously in a modified global fit approach based on the Levenberg-Marquardt nonlinear least-squares method (see Boone et al., 2005, and references therein). The retrieval process consists of two steps. Knowledge of pressure and temperature is critical for the retrieval of VMR profiles. However, sufficiently accurate meteorological data are not available for the complete altitude range of ACE-FTS observations. Therefore, the first step of the retrieval derives atmospheric pressure and tem- perature profiles directly from the ACE-FTS spectra, using microwindows containing $\mathrm{CO}_{2}$ spectral lines. During the second phase of the retrieval process, these profiles are used to calculate synthetic spectra that are compared to the ACEFTS measured spectra in the global fitting procedure to retrieve the VMR profiles of the target species. In the current ACE-FTS dataset (version 2.2 with updates for ozone, $\mathrm{N}_{2} \mathrm{O}_{5}$, and HDO), profiles are retrieved for more than 30 species using spectroscopic information from the HITRAN 2004 line list (Rothman et al., 2005). First-guess profiles are based on the results of the ATMOS mission. It is important to emphasize that the global fitting approach used here does not use the Optimal Estimation Method, hence does not impose constraints based on a priori information. Therefore the retrieval method is not sensitive to the first-guess profiles. Also, averaging kernels are not available for the ACE-FTS retrievals. The altitude range of the ozone retrievals typically extends from $\sim 10 \mathrm{~km}$ to $\sim 95 \mathrm{~km}$. The final results are provided jointly on the measurement (tangent height) grid and interpolated onto a $1 \mathrm{~km}$ grid using a piecewise quadratic method. The latter form is used for all analyses presented in this study. The uncertainties reported in the data files are the statistical fitting errors from the least-squares process and do not include systematic components or parameter correlations (Boone et al., 2005). The mean relative fitting errors are lower than $3 \%$ between 12 and $\sim 65 \mathrm{~km}$ and typically less than $1.5 \%$ around the VMR peak $(30-35 \mathrm{~km})$. A detailed error budget including systematic errors is not currently available for the ACE-FTS data products.

Initial validation comparisons for ACE-FTS version 1.0 ozone retrievals have been reported (Walker et al., 2005; Petelina et al., 2005a; Fussen et al., 2005; McHugh et al., 2005; Kerzenmacher et al., 2005). Version 2.1 ozone was used in the early validation studies for the Microwave Limb Sounder (MLS) on the Aura satellite (hereafter Aura-MLS) by Froidevaux et al. (2006). In these earlier ACE-FTS ozone retrievals (up to and including version 2.2), a set of microwindows from two distinct spectral regions (near $\sim 5 \mu \mathrm{m}$ and $\sim 10 \mu \mathrm{m}$ ) was used. Because of apparent discrepancies in the spectroscopic data for these two regions, the vertical profiles near the stratospheric ozone concentration peak were found to have a consistent low bias of $\sim 10 \%$ in comparisons with other satellite-borne instruments. This was corrected in an update to version 2.2 by removing from the analysis the microwindows in the $5 \mu \mathrm{m}$ spectral region. A consistent set of $37 \mathrm{mi}-$ crowindows around $10 \mu \mathrm{m}$ (from 985 to $1128 \mathrm{~cm}^{-1}$, with the addition of one microwindow at $922 \mathrm{~cm}^{-1}$ to improve results for the interfering molecule CFC-12) is now used for ozone retrievals. This $\mathrm{O}_{3}$ data product, "version 2.2 Ozone Update", is used in the comparisons presented here. These version 2.2 Ozone Update profiles were used in recent validation studies for Aura-MLS (Froidevaux et al., 2008) and the Michelson Interferometer for Passive Atmospheric Sounding (MIPAS) on Envisat (Cortesi et al., 2007). The agreement with Aura-MLS version 2.2 ozone profiles is within 5\% in 
the lower stratosphere (with ACE-FTS ozone VMRs consistently larger than those of Aura-MLS), but degrades with altitude with the largest difference in the upper stratosphere (up to $\sim 25 \%$ ) (Froidevaux et al., 2008). Relative differences with the MIPAS ESA operational ozone v4.62 data products are within $\pm 10 \%$ between 250 and $\sim 2 \mathrm{hPa}(10-42 \mathrm{~km})$ but increase above this range, with ACE-FTS reporting larger VMR values than MIPAS by up to $+40 \%$ around $0.6 \mathrm{hPa}$ ( $\sim 53 \mathrm{~km}$ ) (Cortesi et al., 2007).

\subsection{ACE-MAESTRO}

ACE-MAESTRO is a dual-grating diode-array spectrophotometer that extends the wavelength range of the ACE measurements into the near-IR to UV spectral region (McElroy et al., 2007). It records over a nominal range of 400-1010 nm with a spectral resolution of 1.5-2 $\mathrm{nm}$ for its solar occultation measurements. The forerunner of the ACE-MAESTRO is the SunPhotoSpectrometer instrument which was used extensively by Environment Canada as part of the NASA ER2 stratospheric chemistry research program (McElroy, 1995; McElroy et al., 1995). ACE-MAESTRO uses the same sun tracking mirror as the ACE-FTS, receiving $~ 7 \%$ of the beam collected by the mirror. The ACE-MAESTRO instrument vertical field-of-view is $\sim 1 \mathrm{~km}$ at the limb. The observation tangent altitudes range from the cloud tops to $100 \mathrm{~km}$ with a vertical resolution estimated at better than $1.7 \mathrm{~km}$ (Kar et al., 2007).

The processing of ACE-MAESTRO version 1.2 occultation data is done in two stages and is described in McElroy et al. (2007). In summary, the raw data are converted to wavelength-calibrated spectra, corrected for stray light, dark current and other instrument parameters in the first step. The corrected spectra are then analyzed by a nonlinear least-squares spectral fitting code to calculate slant-path column densities for each spectrum, from which vertical profiles of $\mathrm{O}_{3}$ and $\mathrm{NO}_{2}$ VMRs are subsequently derived. The retrieval algorithm does not require any a priori information or other constraints (McElroy et al., 2007). The inversion routine uses the pressure and temperature profiles and tangent heights from the ACE-FTS data analysis to fix the tangent heights for ACE-MAESTRO. Vertical profiles for the trace gases are determined by adjusting an initial guess (high-vertical-resolution model simulation) using a nonlinear Chahine relaxation inversion algorithm (see McElroy et al., 2007, and references therein). The final profiles are provided both on the tangent grid and linearly interpolated onto a $0.5 \mathrm{~km}$-spacing vertical grid. As is done for ACE-FTS, the latter profiles are used in the analyses presented in this work. Propagation of the spectral fitting errors in the ozone VMR retrievals yield typical errors of $1-2 \%$ between 20 and $40 \mathrm{~km}$ and increasing above and below this range. An error budget including systematic errors has not been produced for the ACE-MAESTRO ozone product. Averaging kernels are not available for the ACE-MAESTRO retrievals.
As described above, ACE-MAESTRO consists of two spectrophotometers and each can provide vertical VMR profiles for ozone. Following the previous validation study of Kar et al. (2007), this work presents only the comparisons made with the Visible-Near-IR (VIS) spectrometer ozone data product. The retrieved profiles from the VIS spectrometer are in good agreement (mean relative differences within $\pm 10 \%$ ) with those obtained from the UV spectrometer over the altitude range where the UV data have good signal-tonoise $(\sim 15-30 \mathrm{~km})$. The VIS profiles provide results over a larger vertical range, necessary for studies in the upper stratosphere and lower mesosphere.

The version 1.2 ACE-MAESTRO data products have been compared with SAGE III, POAM III and ozonesonde observations (Kar et al., 2007). Mean relative differences are generally within $\pm 10 \%$ from $20-40 \mathrm{~km}$. At higher altitudes, there is a significant bias between the SR observations, for which ACE-MAESTRO reports less ozone than the comparison instrument, and the SS observations, which show a large positive bias for ACE-MAESTRO with respect to the coincident measurements (of up to $+30 \%$ around $50 \mathrm{~km}$ ) (Kar et al., 2007). Direct comparison with the ACE-FTS version 2.2 Ozone Update profiles was also performed by Kar et al. (2007) for data obtained in the period March 2004March 2005. The SR comparisons show a low bias of ACEMAESTRO at most altitudes. The mean relative differences are within $\pm 5 \%$ between 22 and $42 \mathrm{~km}$, and increase above and below this range to a maximum value of $-30 \%$ at 15 and $55 \mathrm{~km}$. For the SS comparisons, the mean relative differences remain globally within $\pm 5 \%$ for the Northern Hemisphere occultations, with ACE-MAESTRO VMR values lower than those of ACE-FTS except around $40 \mathrm{~km}$; however, the mean relative differences are larger (within $\pm 10 \%$ ) for the Southern Hemisphere observations, with ACE-MAESTRO showing less ozone than ACE-FTS below $35 \mathrm{~km}$ and more ozone above this altitude (Kar et al., 2007).

\section{Temporal and spatial criteria for coincidences}

The nominal time period chosen for this study extends over 2.5 years from 21 February 2004 to 31 August 2006. The start date is the first day for which routine, reliable measurements were available for both ACE-FTS and ACEMAESTRO. This time period includes the 2004, 2005, and 2006 Canadian Arctic ACE Validation Campaigns (Kerzenmacher et al., 2005; Walker et al., 2005; Sung et al., 2007; Manney et al., 2008; Fraser et al., 2008; Fu et al., 2008; Sung et al., 2009) and the final period of measurements from the SAGE II, SAGE III, POAM III and HALOE instruments. Based on availability of correlative measurements, this time period has been adjusted for some comparisons.

Common coincidence criteria were used to search for correlative observations to compare with ACE-FTS and ACEMAESTRO. In addition to the spatial and temporal criteria 
discussed below, it was also required that there were profiles available for both ACE instruments for each coincidence. This provided a consistent distribution of comparisons for ACE-FTS and ACE-MAESTRO. Coincidence criteria can vary widely between different validation studies. The coincidence criteria used in this study have been chosen to ensure a sufficient number of coincidences in all comparisons while trying to limit the scatter resulting from relaxed coincidence criteria. For satellite comparisons, a maximum time difference of $\pm 2 \mathrm{~h}$ between the ACE observation and the correlative measurement, and maximum latitude and longitude differences of $\pm 5^{\circ}$ and $\pm 10^{\circ}$, respectively, were generally used. All time differences were calculated using Universal Time (UT). The geographic coincidence criteria correspond to maximum distances of $\sim 600 \mathrm{~km}$ at high latitudes and about twice this value near the equator. These distances are of the same order of magnitude as the typical groundtrack distance of an ACE occultation (300-600 km). Note that the measurement density is lower at low latitudes because of the high inclination of the ACE orbit and, therefore, we have significantly fewer coincidences available in the tropics and subtropics. These criteria provide good statistics consisting of a few hundred to several thousand events for most satellite-borne instruments. The list of the correlative datasets, time periods, number of coincidences and mean values of the distance and of the time, latitude and longitude differences is given in Table 1. For the sparser datasets from ozonesondes and airborne, balloon-borne and ground-based instruments, it is more difficult to find coincidences using the criteria listed above. In those cases, a similar fixed distance criterion was used $(800 \mathrm{~km}$ for ozonesondes, 500 to $1000 \mathrm{~km}$ for other ground-based instruments) but the time criterion was relaxed to $\pm 24 \mathrm{~h}$. This was done in an effort to maximize the number of coincident profiles while at the same time avoiding biases in the atmospheric sampling.

To test the sensitivity of the comparison results to the temporal and geolocation criteria of the correlative measurements, we performed comparisons within shorter time periods and smaller geographical regions: typically, comparisons were done for each month of the 2.5-year period and in five latitude bands: four (two in each hemisphere) for mid- and high latitudes (latitudes $30^{\circ}-60^{\circ}$ and $60^{\circ}-90^{\circ}$, respectively) and a larger one for the tropics and subtropics $\left(30^{\circ} \mathrm{S}-30^{\circ} \mathrm{N}\right)$. This analysis was performed for most of the statistical comparisons with satellite-borne instruments and with ozonesondes (not shown). In addition, a detailed check of the time series of the mean relative differences, at each ground-based station, was performed for the study presented in Sect. 6.6. These analyses did not show any systematic latitudinal dependence of the relative differences or apparent temporal trend in the quality of the ACE observations. We also analyzed the dependence of the relative difference profiles on the distance between the measurement pairs and on observation parameters such as the beta angle for occultation instruments or the solar zenith angle for sun-synchronous measurements (not shown). This did not reveal significant systematic biases which might have required the use of narrower coincidence criteria. Finally, we did not find any visible latitude bias between the ACE measurements (e.g., ACE latitudes systematically higher or lower than those of the coincident observations) and the correlative instruments (not shown).

It should be noted that broad criteria such as those defined here may result in multiple coincident observations for a particular ACE occultation, for instance when the ACE orbit footprint is close to the satellite ground-track of the correlative instrument or when the allowed time difference is large (e.g., 24 h). In such cases, each coincident pair (the same occultation measured by ACE-FTS or ACE-MAESTRO paired with a distinct observation from the comparison instrument) is treated as an independent event, except for the statistical comparisons with ozonesondes (see Sect. 6.5) and MicroWave Radiometers (MWRs) (see Sect. 6.9). However, the number of multiple matches did not exceed a few hundred for the largest comparison sets (e.g., for comparisons with SABER), with no more than 6-8 distinct comparison measurements coinciding with a single observation from the ACE instruments.

In a first step, the comparisons with all satellite instruments (Sect. 5) and with the ozonesondes (Sect. 6.5) were made for ACE-FTS or ACE-MAESTRO SR and SS occultations separately. These initial analyses did not show evidence for a systematic SR/SS bias in the ACE-FTS dataset. Therefore, averages over all coincidences - without SR/SS separation - are shown for the ACE-FTS analyses in all sections except Sect. 5.1. Since SR/SS differences can be important for intercomparisons between two solar occultation instruments, the results of the comparisons with SAGE II, HALOE, POAM III and SAGE III (Sect. 5.1) are presented separately for both ACE-FTS and the correlative dataset. For the ACE-MAESTRO measurements, there is a known SR/SS bias (Kar et al., 2007). Thus, we present all of the ACEMAESTRO SR and SS comparisons separately.

Day/night differences in ozone VMR can have an impact on the comparison results in the mesosphere (e.g., Schneider et al., 2005). For the comparisons presented hereafter, we did not routinely use any photochemical model for the ACE measurements to account for these diurnal variations. However, in two cases, a photochemical correction was applied to the correlative data (Sects. 5.4.1 and 5.4.2).

\section{Validation methodology}

The satellite data used in the following comparisons have vertical resolutions ranging from 0.5 to $5 \mathrm{~km}$, which is the same order of magnitude as those of the ACE instruments ( $\sim 3-4 \mathrm{~km}$ for ACE-FTS and better than $1.7 \mathrm{~km}$ for ACEMAESTRO). Therefore, coincident profiles are linearly interpolated onto the ACE vertical grid (with a spacing of $1 \mathrm{~km}$ for ACE-FTS or $0.5 \mathrm{~km}$ for ACE-MAESTRO) for the 
Table 1. Summary of the coincidence characteristics for the instruments (column 1) and data products (column 2) used in the statistical analyses. The full comparison period, latitude range and number of coincidences are presented in columns 3-5. Columns 6-9 give the mean and 1- $\sigma$ standard deviation for: great circle distance, differences in latitude, longitude and time between the ACE and correlative measurements. For instruments which have multiple retrieval codes, these are noted in parentheses in column 1.

\begin{tabular}{|c|c|c|c|c|c|c|c|c|}
\hline Instrument & $\begin{array}{l}\text { Data } \\
\text { version }\end{array}$ & Period & $\begin{array}{l}\text { Latitude } \\
\text { range }\end{array}$ & $\begin{array}{l}\text { Num. } \\
\text { events }\end{array}$ & $\begin{array}{l}\text { Distance } \\
{[\mathrm{km}]}\end{array}$ & $\begin{array}{l}\text { Latitude } \\
\text { diff. }\left[{ }^{\circ}\right]\end{array}$ & $\begin{array}{l}\text { Longitude } \\
\text { diff. }\left[{ }^{\circ}\right]\end{array}$ & $\begin{array}{c}\text { Time } \\
\text { diff. [min] }\end{array}$ \\
\hline SAGE II & v6.20 & $\begin{array}{l}2004 / 08 / 09- \\
2005 / 05 / 06\end{array}$ & $70^{\circ} \mathrm{S}-66^{\circ} \mathrm{N}$ & 229 & $449 \pm 234$ & $-1.4 \pm 1.9$ & $0.1 \pm 5.9$ & $-7 \pm 31$ \\
\hline HALOE & V19 & $\begin{array}{l}2004 / 07 / 05- \\
2005 / 08 / 17\end{array}$ & $53^{\circ} \mathrm{S}-67^{\circ} \mathrm{N}$ & 49 & $382 \pm 222$ & $0.4 \pm 2.2$ & $2.4 \pm 5.8$ & $38 \pm 46$ \\
\hline POAM III & v4 & $\begin{array}{l}2004 / 03 / 16- \\
2005 / 11 / 30\end{array}$ & $\begin{array}{c}86^{\circ} \mathrm{S}-63^{\circ} \mathrm{S} \& \\
55^{\circ} \mathrm{N}-70^{\circ} \mathrm{N}\end{array}$ & 376 & $395 \pm 165$ & $0.6 \pm 3.1$ & $0.5 \pm 5.5$ & $16 \pm 53$ \\
\hline SAGE III & v3.0 & $\begin{array}{l}2004 / 02 / 21- \\
2005 / 10 / 09\end{array}$ & $\begin{array}{c}59^{\circ} \mathrm{S}-37^{\circ} \mathrm{S} \& \\
49^{\circ} \mathrm{N}-80^{\circ} \mathrm{N}\end{array}$ & 648 & $328 \pm 177$ & $-0.0 \pm 2.4$ & $0.3 \pm 5.7$ & $-10 \pm 31$ \\
\hline $\begin{array}{l}\text { OSIRIS } \\
\text { (York) }\end{array}$ & v3.0 & $\begin{array}{l}2004 / 02 / 24- \\
2006 / 08 / 31\end{array}$ & $80^{\circ} \mathrm{S}-86^{\circ} \mathrm{N}$ & 913 & $458 \pm 231$ & $0.2 \pm 2.9$ & $-0.6 \pm 5.6$ & $1 \pm 66$ \\
\hline $\begin{array}{c}\text { OSIRIS } \\
\text { (SaskMART) }\end{array}$ & v2.1 & $\begin{array}{l}2004 / 03 / 02- \\
2006 / 08 / 05\end{array}$ & $79^{\circ} \mathrm{S}-86^{\circ} \mathrm{N}$ & 1219 & $463 \pm 229$ & $0.1 \pm 2.9$ & $-0.6 \pm 5.6$ & $2 \pm 67$ \\
\hline SMR & Chalmers-v2.1 & $\begin{array}{l}2004 / 02 / 21- \\
2006 / 08 / 31\end{array}$ & $82^{\circ} \mathrm{S}-82^{\circ} \mathrm{N}$ & 1161 & $438 \pm 219$ & $0.2 \pm 2.8$ & $-0.2 \pm 5.7$ & $-1 \pm 68$ \\
\hline SABER & $\mathrm{v} 1.06$ & $\begin{array}{l}2004 / 03 / 02- \\
2006 / 07 / 31\end{array}$ & $85^{\circ} \mathrm{S}-85^{\circ} \mathrm{N}$ & 6210 & $366 \pm 158$ & $-0.1 \pm 2.8$ & $-0.2 \pm 5.6$ & $0 \pm 68$ \\
\hline GOMOS & IPF 5.00 & $\begin{array}{l}2004 / 04 / 06- \\
2005 / 12 / 08\end{array}$ & $72^{\circ} \mathrm{S}-80^{\circ} \mathrm{N}$ & 1240 & $317 \pm 122$ & $-0.1 \pm 2.0$ & $0.5 \pm 41.7$ & $54 \pm 438$ \\
\hline $\begin{array}{c}\text { MIPAS } \\
(\text { ESA f.r. })^{\mathrm{a}}\end{array}$ & ESA-v4.62 & $\begin{array}{l}2004 / 02 / 21- \\
2004 / 03 / 26\end{array}$ & $70^{\circ} \mathrm{N}-80^{\circ} \mathrm{N}$ & 138 & $190 \pm 65$ & $-0.5 \pm 1.3$ & $-0.4 \pm 43.7$ & $68 \pm 292$ \\
\hline $\begin{array}{c}\text { MIPAS } \\
(\text { ESA r.r. })^{b}\end{array}$ & ML2PP/5.0 & $\begin{array}{l}2005 / 01 / 27- \\
2006 / 05 / 04\end{array}$ & $85^{\circ} \mathrm{S}-86^{\circ} \mathrm{N}$ & 160 & $401 \pm 225$ & $-0.1 \pm 2.8$ & $0.4 \pm 5.4$ & $96 \pm 210$ \\
\hline $\begin{array}{c}\text { MIPAS } \\
\text { (IMK-IAA) }\end{array}$ & V3O_O3_7 & $\begin{array}{l}2004 / 02 / 21- \\
2004 / 03 / 26\end{array}$ & $30^{\circ} \mathrm{N}-80^{\circ} \mathrm{N}$ & 681 & $\begin{array}{l}276 \pm 146^{\mathrm{c}} \\
315 \pm 159^{\mathrm{d}}\end{array}$ & $\begin{array}{l}-0.2 \pm 1.7^{\mathrm{c}} \\
-0.2 \pm 2.2^{\mathrm{d}}\end{array}$ & $\begin{array}{c}1.8 \pm 9.3^{\mathrm{c}} \\
-2.2 \pm 7.3^{\mathrm{d}}\end{array}$ & $\begin{array}{c}-304 \pm 79^{c} \\
340 \pm 98^{d}\end{array}$ \\
\hline SCIAMACHY & IUP v1.63 & $\begin{array}{l}2004 / 03 / 01- \\
2004 / 12 / 31\end{array}$ & $80^{\circ} \mathrm{S}-80^{\circ} \mathrm{N}$ & 734 & $339 \pm 120$ & $0.6 \pm 2.3$ & $-0.1 \pm 8.3$ & $-84 \pm 233$ \\
\hline Aura-MLS & v 2.2 & $\begin{array}{l}2004 / 09 / 16- \\
2007 / 05 / 23\end{array}$ & $80^{\circ} \mathrm{S}-86^{\circ} \mathrm{N}$ & 3178 & $359 \pm 156$ & $0.4 \pm 2.9$ & $1.5 \pm 5.8$ & $12 \pm 68$ \\
\hline ASUR & $\mathrm{n} / \mathrm{a}$ & $\begin{array}{l}2005 / 01 / 24- \\
2005 / 02 / 07\end{array}$ & $60^{\circ} \mathrm{N}-70^{\circ} \mathrm{N}$ & 39 & $645 \pm 225$ & $0.3 \pm 3.6$ & $1.7 \pm 12.0$ & $208 \pm 113$ \\
\hline Ozonesondes ${ }^{\mathrm{e}}$ & $\mathrm{n} / \mathrm{a}$ & $\begin{array}{l}2004 / 02 / 22- \\
2006 / 08 / 03\end{array}$ & $78^{\circ} \mathrm{S}-83^{\circ} \mathrm{N}$ & 376 & $478 \pm 210$ & $0.4 \pm 3.8$ & $0.1 \pm 4.9$ & $8 \pm 728$ \\
\hline $\begin{array}{c}\text { NDACC } \\
\text { Ozonesondes } \\
\text { + lidars }{ }^{f}\end{array}$ & $\mathrm{n} / \mathrm{a}$ & $\begin{array}{l}2004 / 02 / 21- \\
2006 / 08 / 19\end{array}$ & $71^{\circ} \mathrm{S}-83^{\circ} \mathrm{N}$ & 250 & $305 \pm 135$ & $1.4 \pm 1.1$ & $7.7 \pm 6.5$ & $302 \pm 180$ \\
\hline Eureka DIAL & $\mathrm{n} / \mathrm{a}$ & $\begin{array}{l}2004 / 02 / 21- \\
2006 / 02 / 23\end{array}$ & $76^{\circ} \mathrm{N}-81^{\circ} \mathrm{N}$ & 10 & $279 \pm 123$ & $-1.7 \pm 1.1$ & $-2.4 \pm 10.1$ & $417 \pm 56$ \\
\hline $\begin{array}{l}\text { NDACC } \\
\text { MWRs } \mathrm{g}\end{array}$ & v 5.0 & $\begin{array}{l}2004 / 02 / 08- \\
2006 / 10 / 12\end{array}$ & $51^{\circ} \mathrm{S}-26^{\circ} \mathrm{N}$ & 43 & $709 \pm 243$ & $-0.3 \pm 4.0$ & $0.8 \pm 7.0$ & $35 \pm 345$ \\
\hline
\end{tabular}

a ESA data product for full resolution MIPAS measurements. See text for details.

${ }^{\mathrm{b}}$ ESA data product for reduced resolution MIPAS measurements. See text for details.

c ACE vs. MIPAS daytime measurements.

d ACE vs. MIPAS nighttime measurements.

e Statistical analyses presented in Sect. 6.5.

${ }^{\mathrm{f}}$ Detailed NDACC study described in Sect. 6.6.

g MWRs at Lauder $\left(45^{\circ} \mathrm{S}\right)$ and Mauna Loa $\left(19.5^{\circ} \mathrm{N}\right)$ only. Analysis described in Sect. 6.9. 
comparison. Tests with other interpolation methods (using quadratic or cubic spline), or by comparing at the actual ACE tangent heights, did not yield any systematic differences. For example, the different interpolation methods gave results within a few percent for the Odin/OSIRIS SaskMART dataset (not shown).

Secondly, for high-resolution measurements such as those from ozonesondes or other instruments measuring in situ, it is necessary to smooth the comparison data. Since averaging kernels are not available for the ACE measurements, alternative smoothing methods were employed. In this case, two techniques were used, either a smoothing function was applied or an integration method was used.

For most in situ and high-resolution profile comparisons, smoothing (convolution) functions were created for ACEFTS, consisting of triangular functions of full width at the base equal to $3 \mathrm{~km}$ and centered at the tangent heights of each occultation. This value was chosen to account for the smoothing effect of the limited ACE-FTS vertical resolution ( $\sim 3-4 \mathrm{~km}$ field-of-view), whilst allowing for simplified but valid systematic analysis. Furthermore, it accounts for the vertical spacing of the tangent heights in a retrieved ACEFTS profile. The spacing varies with altitude (including refraction below $\sim 30 \mathrm{~km}$ ) and with the beta angle for the occultation (angle between the satellite orbital plane and the Earth-Sun vector). The minimum spacing is about $1.5 \mathrm{~km}$ at low altitudes for a high-beta occultation and increases to a maximum value of $\sim 6 \mathrm{~km}$ at mesospheric heights for a low-beta event. High-resolution correlative measurements are convolved with these triangular functions for each ACE tangent height $z_{i}$ :

$$
x_{S}\left(z_{i}\right)=\frac{\sum_{j=1}^{n_{h r}} w_{j}\left(z_{j}^{h r}-z_{i}\right) \cdot x_{h r}\left(z_{j}^{h r}\right)}{\sum_{j=1}^{n_{h r}} w_{j}\left(z_{j}^{h r}-z_{i}\right)},
$$

where $x_{s}\left(z_{i}\right)$ is the smoothed mixing ratio for the highresolution instrument at tangent height $z_{i}, x_{h r}$ is the VMR value of the high-resolution profile at altitude $z_{j}^{h r}, w_{j}$ the associated weight (function of $z_{j}^{h r}-z_{i}$ ), and $n_{h r}$ the number of points from the high-resolution profile found in the $3 \mathrm{~km}$ layer centered at $z_{i}$. The resulting smoothed profile is subsequently interpolated onto the $1 \mathrm{~km}$ grid. For ACE-MAESTRO comparisons, the high-resolution profiles are smoothed by convolution with a Gaussian filter of full width at half-maximum (FWHM) equal to $1.7 \mathrm{~km}$, which is the upper limit for the vertical resolution of the instrument. The smoothed profiles are then interpolated onto the ACEMAESTRO $0.5 \mathrm{~km}$ grid. This smoothing technique was used by Kar et al. (2007).

An alternative method is used in some comparisons with ozonesondes and lidars (Sect. 6.6). To account for the higher vertical resolution of the ozonesonde and lidar mea- surements, these profiles are first integrated to obtain partial columns calculated within layers centered at the ACE measurement grid levels (tangent heights). To calculate the partial column corresponding to altitude $z_{i}$, the layer edges are defined as the mid-points between tangent heights $z_{i-1}$ and $z_{i}$ (lower limit) and $z_{i}$ and $z_{i+1}$ (upper limit). Then these partial columns are converted to VMR values attributed to the same tangent heights. The resulting profiles are interpolated onto the ACE-FTS $(1 \mathrm{~km})$ and ACE-MAESTRO $(0.5 \mathrm{~km})$ altitude grids.

Thirdly, for ground-based measurements with lower vertical resolution than the ACE instruments (Fourier Transform IR spectrometers (FTIRs) and MWRs), the ACE-FTS and ACE-MAESTRO profiles are smoothed using the averaging kernels calculated during the ground-based retrieval process, following the method of Rodgers and Connor (2003):

$\boldsymbol{x}_{s}=\boldsymbol{x}_{a}+\mathbf{A}\left(\boldsymbol{x}_{\mathrm{ACE}}-\boldsymbol{x}_{a}\right)$,

where $\boldsymbol{x}_{\mathrm{ACE}}$ is the original ACE profile (ACE-FTS or ACEMAESTRO), $\boldsymbol{x}_{s}$ is the smoothed profile, and $\boldsymbol{x}_{a}$ and $\mathbf{A}$ are the a priori profile and the averaging kernel matrix of the ground-based instrument, respectively.

For the analysis, data are screened to reject either the whole profile or identified low-quality measurements at some altitudes. First, the data from each instrument are filtered according to the recommendations provided by each calibration/processing team. The specific criteria that were used are described in the appropriate subsections of Sects. 5 and 6. The profiles which do not meet the quality requirements are rejected as a whole. Then, altitude levels for which the stated error represents more than $100 \%$ of the profile value, or which exhibit unphysical VMR values - outside of the relatively broad interval of $[-10 ;+20]$ ppmv - are excluded from the analysis. This generally leads to a lower number of comparison pairs at the lowermost and uppermost altitude levels. Negative VMR values are not systematically rejected as they can be produced by the retrieval process as an artifact due to noise in the measurements, especially at altitudes where $\mathrm{O}_{3}$ abundance is naturally low. Finally, an initial comparison step was used to identify and remove erroneous profiles that were not rejected during the aforementioned analysis (a maximum of 5-6 per comparison set). These general filtering criteria were applied to all comparisons given in Sects. 5 and 6.

Differences are calculated for each individual pair of profiles, at the altitude levels where both instruments satisfy the screening criteria described above. The difference at a given altitude $z$ is expressed as

$\delta_{i}(z)=\frac{x_{\mathrm{ACE}}(z)-x_{\mathrm{comp}}(z)}{x_{\mathrm{ref}}(z)}$,

where $x_{\mathrm{ACE}}(z)$ is the VMR at altitude $z$ for ACE (ACE-FTS or ACE-MAESTRO), $x_{\text {comp }}(z)$ the corresponding VMR for the comparison instrument, and $x_{\text {ref }}(z)$ is given by 


$$
\begin{aligned}
x_{\mathrm{ref}}(z) & =1 & & \text { (abs.) } \\
& =x_{\text {comp }}(z) & & \text { (rel.-gb+o3s) } \\
& =\left(x_{\mathrm{ACE}}(z)+x_{\text {comp }}(z)\right) / 2 & & \text { (rel.-others) }
\end{aligned}
$$

The first line is the value of $x_{\text {ref }}(z)$ for absolute difference calculations. The second and third lines give the denominator for calculations of relative differences for the ozonesondes and the ground-based instruments and for all other comparisons, respectively. This difference in the relative difference calculation method is based on the assumption that the in situ high-resolution ozonesonde measurements are a good reference for the comparisons, while satellite-borne measurements are affected by larger uncertainties and a more logical reference is the average of both instruments VMRs (Randall et al., 2003). There are two exceptions. For the comparisons with the Airborne SUbmillimeter Radiometer (ASUR, Sect. 6.1), $x_{\text {ref }}(z)=x_{\mathrm{ACE}}(z)$ was used. In comparisons between ACE and the Global Ozone Monitoring by Occultation of Stars (GOMOS, Sect. 5.4.1) instrument, $x_{\text {ref }}(z)=x_{\mathrm{GOMOS}}(z)$ was used as the denominator. In addition, a different calculation methodology has been used for the comparisons with GOMOS. It is explained in detail in Sect. 5.4.1.

The resulting mean differences (absolute or relative) for a complete set of coincident pairs of profiles are calculated as

$$
\Delta(z)=\frac{1}{N(z)} \sum_{i=1}^{N(z)} \delta_{i}(z)
$$

where $N(z)$ refers to the number of coincidences at altitude $z$ and $\delta_{i}(z)$ is the difference (absolute or relative) for the $i$ th coincident pair calculated using Eq. (3). The mean relative differences are given in percent in the following sections.

In some cases, notably for ACE-MAESTRO, there may seem to be a discrepancy between the apparent differences given by the mean profiles and the sign of the mean relative differences, or between the signs of the mean absolute and relative differences. The reader is reminded that the mean relative differences are not calculated from the mean VMR profiles but from each pair of coincident profiles (Eq. 3). Thus, the mean relative differences can become negative, even though the mean absolute differences are positive, if some profiles exhibit unusually low VMR values at certain altitude levels or if the VMRs for both instruments are of the same magnitude but of opposite signs (e.g., for the comparisons between ACE-MAESTRO and OSIRIS SaskMART, Fig. 10).

Finally, as mentioned in Sect. 2, a full error budget including estimates of the systematic errors is not available for the ACE data products analyzed in this work. Therefore, it is not possible to conduct a full precision validation study. In order to provide the reader with additional information on the significance of the bias and to set an upper limit to the precision of the ACE instruments, we calculate and show the standard deviation of the bias-corrected differences (referred to as "de-biased standard deviation" hereinafter) and the statistical uncertainty of the mean.

The de-biased standard deviation is a measure of the combined precision of the instruments that are being compared (von Clarmann, 2006). It has been used in previous validation studies, for example for POAM III (Randall et al., 2003) or MIPAS (Steck et al., 2007). It is expressed for a given altitude as

$\sigma(z)=\sqrt{\frac{1}{N(z)-1} \sum_{i=1}^{N(z)}\left(\delta_{i}(z)-\Delta(z)\right)^{2}}$,

where $N(z)$ refers to the number of coincidences at altitude $z, \delta_{i}(z)$ is here the difference (absolute or relative) for the $i$ th coincident pair calculated using Eq. (3), and $\Delta(z)$ the mean difference (absolute or relative) calculated from Eq. (4).

The statistical uncertainty of the mean differences (also known as standard error of the mean or SEM) is the quantity that allows the significance of the estimated biases to be judged. It is related to the de-biased standard deviation by

$\operatorname{SEM}(z)=\frac{\sigma(z)}{\sqrt{N(z)}}$.

\section{Comparisons - satellites}

\subsection{Solar occultation instruments}

\subsubsection{SAGE II}

SAGE II (Mauldin et al., 1985) was launched in October 1984 aboard the Earth Radiation Budget Satellite (ERBS) and remained operational until August 2005, thus providing a nearly continuous dataset over 21 years. ERBS was in a $610 \mathrm{~km}$ altitude circular orbit with an inclination of $56^{\circ}$. SAGE II performed two occultation measurements per orbit (1 SR and 1 SS), thus sampling two narrow latitude circles each day. Over the course of a month, observations were recorded with a nearly global coverage between $\sim 80^{\circ} \mathrm{S}$ and $\sim 80^{\circ} \mathrm{N}$.

The SAGE II dataset comprises profiles of $\mathrm{O}_{3}, \mathrm{NO}_{2}, \mathrm{H}_{2} \mathrm{O}$ and aerosol extinction, measured using seven channels centered at wavelengths from 0.385 to $1.02 \mu \mathrm{m}$. The ozone retrievals use data from the center of the Chappuis absorption band measured by the $0.603 \mu \mathrm{m}$ channel. The retrieval algorithm is described in detail by Chu et al. (1989).

Data versions prior to version 6.00 have been the subject of several publications, including an extensive study of version 5.96 in the first Stratospheric Processes And their Role in Climate assessment report (SPARC, 1998). In 2000, a major revision of the retrieval algorithm corrected long-standing data issues (version 6.00). Version 6.00 was used in detailed comparisons with HALOE (Morris et al., 2002) and several other instruments (Manney et al., 2001). Subsequent improvements, versions 6.10 and 6.20 , were made and have 

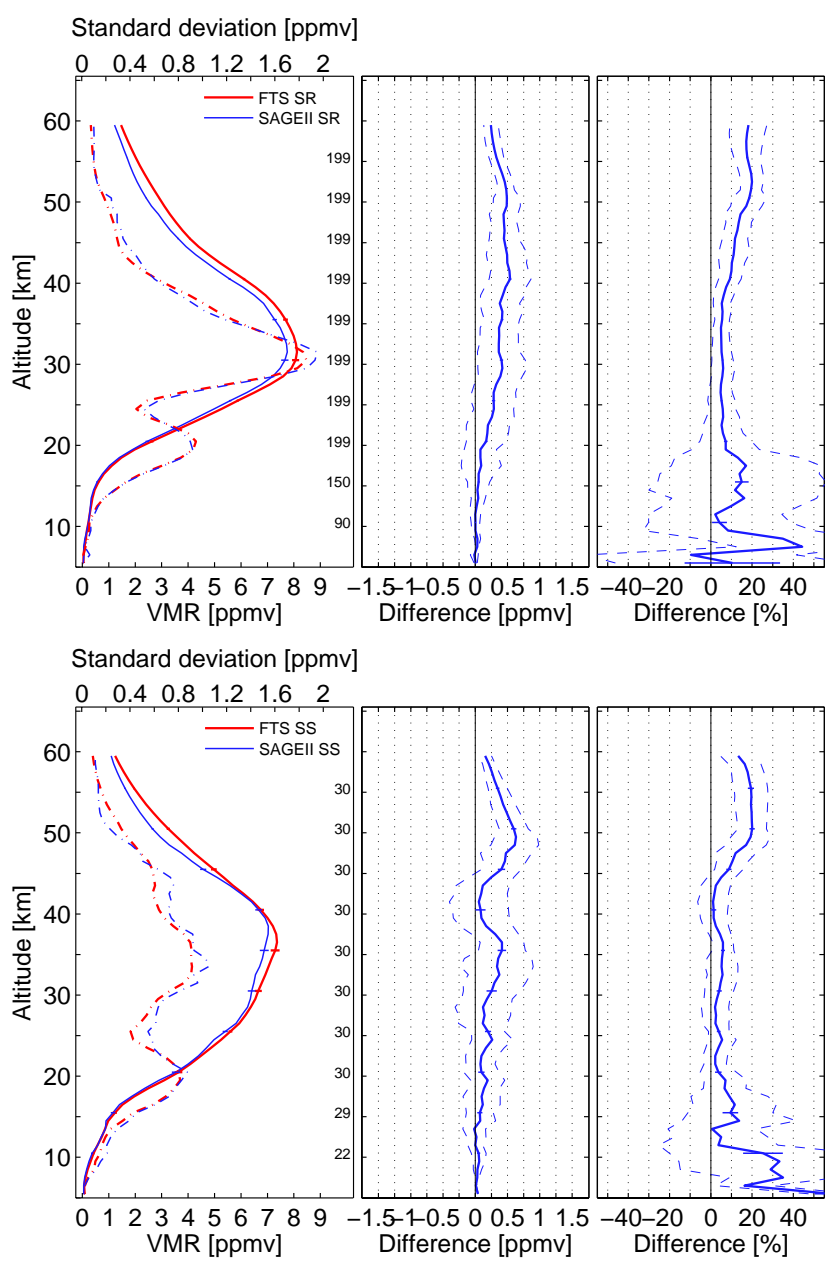

Fig. 1. Mean profiles and differences for the ACE-FTS - SAGE II coincidences. Results are shown for ACE-FTS SR (top panel) and SS (bottom panel) observations. In each panel: Left: Mean VMR profiles from ACE-FTS and SAGE II (solid lines) and associated $1-\sigma$ standard deviations (dot-dashed lines). The standard error - or uncertainty - of the mean (standard deviation divided by the square root of the number of profiles) is shown every $5 \mathrm{~km}$ as horizontal error bars on the VMR profiles. Note that in some figures they are smaller than the profile line width and cannot be distinguished. The number of coincident pairs used is given every $5 \mathrm{~km}$. Middle: Mean absolute differences (ACE-FTS-SAGE II) in ppmv (solid line), with corresponding de-biased standard deviations (dashed line), and standard error (uncertainty) of the mean reported as error bars. Right: Mean relative differences in percent (solid line) shown as $2 \times($ ACE-FTS-SAGE II)/(ACE-FTS+SAGE II), de-biased standard deviations of the mean relative differences (dashed line), and standard error (uncertainty) of the mean (error bars).

been extensively validated (Wang et al., 2002; Kar et al., 2002; Iyer et al., 2003; Randall et al., 2003; P. H. Wang et al., 2006). The current version (version 6.20) shows good agreement with correlative measurements within $\pm 5 \%$ above $\sim 18 \mathrm{~km}$. At lower altitudes, the relative differences increase, with a persistent low bias of $-10 \%$ or more below $\sim 10 \mathrm{~km}$ (e.g., Borchi et al., 2005; Nazaryan and McCormick, 2005; Froidevaux et al., 2008). This version (v6.20) was used for the comparisons with ACE-FTS and ACE-MAESTRO.

Applying the coincidence criteria $\left( \pm 2 \mathrm{~h}, \pm 5^{\circ}\right.$ in latitude and $\pm 10^{\circ}$ in longitude), we found 229 matches in the period between August 2004 and early May 2005. Among these, 199 correspond to SR occultations for both instruments, and 30 to both SS observations. The ACE-FTS comparison results are shown in Fig. 1 for the SR/SR (top panel) and the SS/SS (bottom panel) comparisons. ACE-FTS reports consistently higher ozone values than SAGE II at all altitudes. The mean relative differences are within +10 to $+17 \%$ in the range $12-18 \mathrm{~km}$, which is comparable to the low bias of SAGE II ozone values previously reported (e.g., Borchi et al., 2005; P. H. Wang et al., 2006). They are within 0 to $+10 \%$ between 18 and $42 \mathrm{~km}$ for both SR and SS events, with average values of about +5 and $+6 \%$ for SR and SS, respectively. Above $42 \mathrm{~km}$, both SR and SS comparisons show larger positive differences of up to $+20 \%$. Comparisons for SS events yield generally smaller mean relative difference values, notably around $12 \mathrm{~km}$ and in the range $38-44 \mathrm{~km}(<3 \%)$. Below $\sim 18 \mathrm{~km}$, the de-biased standard deviation of the mean relative differences is large (within 30 to $60 \%$ for SR and within 20 to $50 \%$ for SS), which is explained by the lower number of coincident pairs and by the large natural variability of the ozone field at these altitudes. Above $18 \mathrm{~km}$, the de-biased standard deviation of the mean relative differences remains lower than $10 \%$ for both SR and SS events up to the top of the comparison range. Note also that there is high consistency shown by the standard deviation of the ACE-FTS and SAGE II mean profiles, which confirms that both instruments sounded airmasses with similar variability. Finally, the observed differences are statistically significant as shown by the very small values of the standard errors of the mean.

Figure 2 shows the comparisons between the SAGE II and ACE-MAESTRO ozone retrievals for the ACE-MAESTRO SR (top panel) and SS (bottom panel) profiles, respectively. For the SR cases, the agreement is very good between 15 and $55 \mathrm{~km}$ with mean relative differences within $\pm 3 \%$ throughout, except near $20 \mathrm{~km}$. For the ACE-MAESTRO SS events, the agreement is again quite good (within $\pm 5 \%$ between 16 and $45 \mathrm{~km}$ ), except for a significant positive bias between $45-55 \mathrm{~km}$, reaching a maximum of $+17 \%$ at $54 \mathrm{~km}$. This is much larger than the SR bias at these altitudes. In contrast to ACE-FTS, the relatively large standard errors of the mean relative differences for the ACE-MAESTRO comparisons show that the observed biases are only marginally significant: below $20 \mathrm{~km}$ for both SR and SS events, and in the upper stratosphere for the SS comparisons. The standard deviation of the mean VMR profiles shows a noticeable scatter of the ACE-MAESTRO VMR values, also reflected in the de-biased standard deviation of the mean absolute and relative differences. These are within 30 to $70 \%$ for the SR comparisons and within 10 to $50 \%$ for the SS comparisons. 

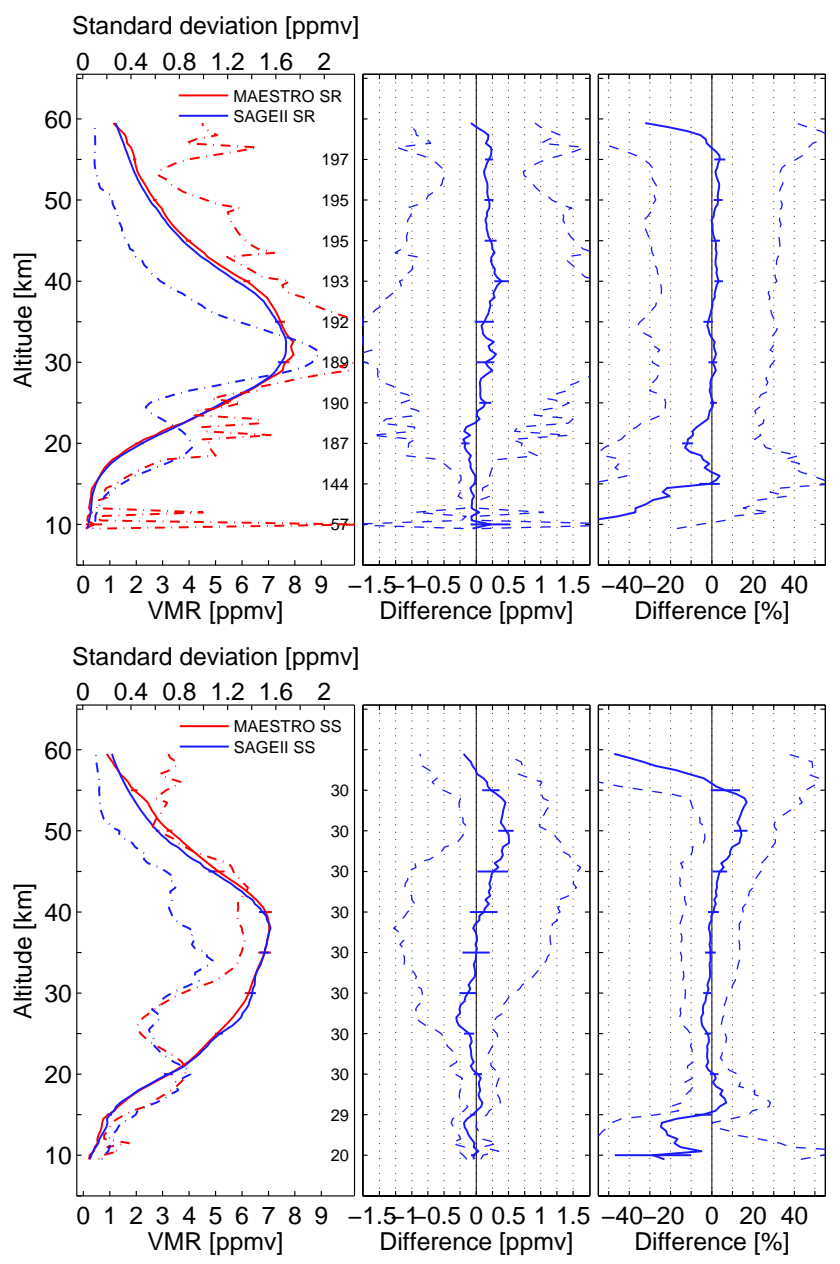

Fig. 2. Same as Fig. 1, but for the comparisons between ACEMAESTRO and SAGE II. Top: comparison with ACE-MAESTRO SR observations; bottom: comparison with ACE-MAESTRO SS observations.

The estimated biases in the stratosphere found for ACEFTS and ACE-MAESTRO are comparable to these found in previous validation studies for SAGE II. Note also that this analysis provides an incomplete test of biases in the ACE (or SAGE II) datasets since the ACE SR (SS) occultations are all coincident with SAGE II SR (SS) occultations.

\subsubsection{UARS/HALOE}

The Upper Atmosphere Research Satellite (UARS) (Reber et al., 1993) was deployed from the Space Shuttle Discovery in September 1991. The satellite circled the Earth at an altitude of $585 \mathrm{~km}$ with an orbital inclination of $57^{\circ}$. HALOE (Russell et al., 1993) remained in operation until November 2005 and performed two occultation measurements per orbit. A nearly-global latitude range $\left(75-80^{\circ} \mathrm{S}\right.$ to $\left.75-80^{\circ} \mathrm{N}\right)$ was sampled in about 36 days.

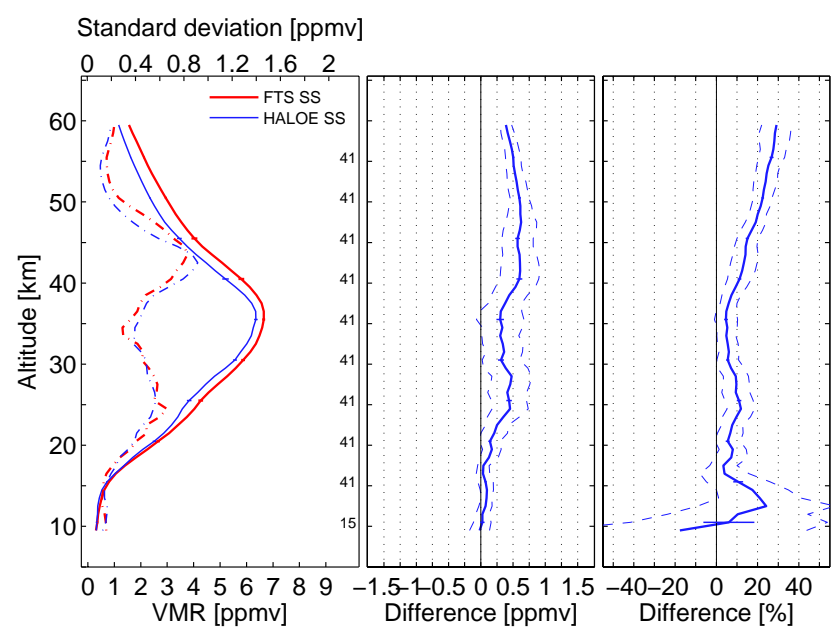

Fig. 3. Same as Fig. 1, but for the comparisons between ACE-FTS and HALOE. Because of the limited number of SR comparisons, results are shown for ACE-FTS SS observations only.

HALOE observations used 8 channels to measure infrared absorption bands between 2.45 and $10.04 \mu \mathrm{m}$, providing VMR profiles of trace constituents (including $\mathrm{O}_{3}, \mathrm{H}_{2} \mathrm{O}, \mathrm{NO}_{2}$, and $\mathrm{CH}_{4}$ ) with a vertical resolution of $\sim 2 \mathrm{~km}$. $\mathrm{O}_{3}$ profiles are retrieved with an onion-peeling scheme from the $9.6 \mu \mathrm{m}$ channel, which provides an accurate product from the upper troposphere to the mesopause (Russell et al., 1993).

Extensive validation studies have been conducted for previous versions of the HALOE dataset (e.g., for version 17: Brühl et al., 1996; for version 18: Bhatt et al., 1999). The latest version, version 19 (hereinafter V19) has also been compared to numerous correlative measurements. Good agreement, to within $\sim 10 \%$, was found in comparisons with various satellite-borne instruments for the mid-latitudes in November 1994 (Manney et al., 2001). Differences of 4 to $11 \%$ were found between HALOE V19 and SAGE II version 6.10 throughout the stratosphere (Randall et al., 2003). The differences with the POAM III version 3 ozone profiles were typically smaller than $5 \%$ and always within $\pm 10 \%$ (Randall et al., 2003). Comparisons with the MIPAS IMKIAA version V3O_O3_7 retrievals show a global agreement within $10 \%$ in the middle and upper stratosphere (Steck et al., 2007). The agreement of the HALOE V19 O $\mathrm{O}_{3}$ profiles with the most recent release (version 2.2) of the Aura-MLS ozone data product is $\sim 5 \%$ between 68 and $2 \mathrm{hPa}(\sim 20-42 \mathrm{~km})$ but degrades to $15 \%$ at 100 and $147 \mathrm{hPa}(\sim 15$ and $\sim 14 \mathrm{~km}$, respectively), with Aura-MLS values larger than the HALOE values (Froidevaux et al., 2008). In this study, we use the HALOE V19 ozone retrievals.

In the comparisons, only 49 pairs of coincident profiles were found using $\pm 2 \mathrm{~h}, \pm 5^{\circ}$ in latitude and $\pm 10^{\circ}$ in longitude for the coincidence criteria. As for SAGE II, there are no SR/SS collocations, but only SR/SR and SS/SS events 


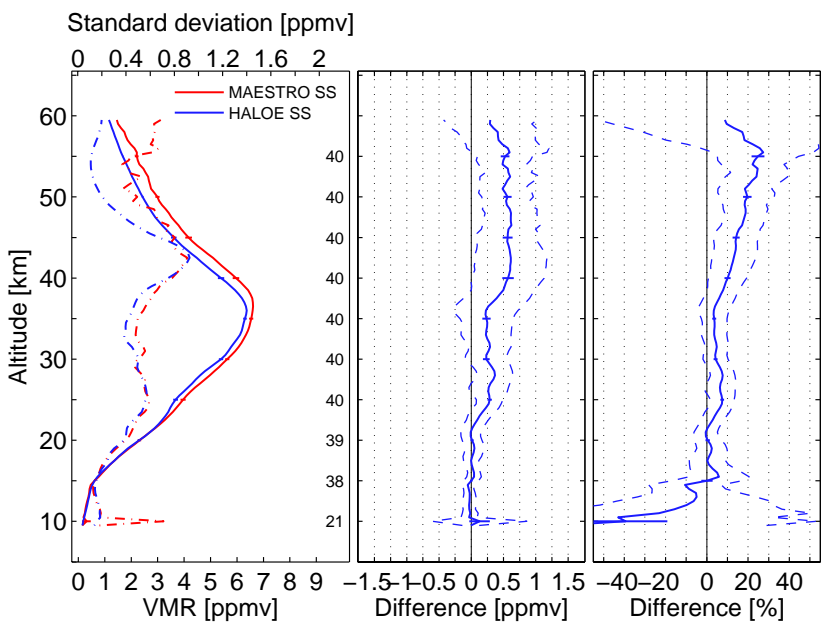

Fig. 4. Same as Fig. 1, but for the comparisons between ACEMAESTRO and HALOE. Because of the limited number of SR comparisons, results are shown for ACE-MAESTRO SS observations only.

(respectively 8 and 41 coincidences). In Fig. 3, we present the results for the SS/SS comparisons only, because of the limited number of coincidences for the SR events. The ACEFTS mixing ratios exhibit a positive bias over most of the altitude range. Mean relative differences for the SS comparisons are within +4 to $+13 \%$ in the range $15-42 \mathrm{~km}$, increasing to about $+28 \%$ at $60 \mathrm{~km}$. These larger positive mean relative differences are similar to those noted with SAGE II and are a persistent feature in most of the profile comparisons presented in this paper. The de-biased standard deviation of the mean relative differences remains small at all altitudes above $\sim 17 \mathrm{~km}$ ( $<8 \%$ throughout). As for SAGE II, the standard errors of the mean show that the observed differences are statistically significant.

The ACE-MAESTRO comparisons were also done separately for SR and SS events. As for ACE-FTS, only the comparison between ACE-MAESTRO SS and HALOE SS results is shown (Fig. 4). For this comparison, there is good agreement between $12 \mathrm{~km}$ and $40 \mathrm{~km}$, with mean relative differences within 0 to $+10 \%$ ( $+5 \%$ on average). The mean relative differences increase thereafter to a maximum of about $+27 \%$ near $55 \mathrm{~km}$. This is generally similar to the ACE-FTS - HALOE comparison shown above. Contrary to the comparisons with SAGE II, there is little discrepancy in the standard deviations of the ACE-MAESTRO and HALOE mean VMR profiles, except above $45 \mathrm{~km}$. The de-biased standard deviations of the mean relative differences are larger than those found for ACE-FTS but remain within $10 \%$ between 15 and $\sim 50 \mathrm{~km}$.

\subsubsection{POAM III}

POAM III (Lucke et al., 1999) was launched in March 1998 onboard the fourth Satellite Pour l'Observation de la Terre (SPOT-4) in a sun-synchronous orbit, with an altitude of $833 \mathrm{~km}$, an inclination of $98.7^{\circ}$ and ascending node crossing at 22:30 (local time). It is a solar occultation instrument able to provide high-resolution $(\sim 1 \mathrm{~km})$ vertical profiles of $\mathrm{O}_{3}$, $\mathrm{NO}_{2}, \mathrm{H}_{2} \mathrm{O}$ and aerosol extinction using nine filter channels from 0.353 to $1.02 \mu \mathrm{m}$. POAM III measured in high latitude ranges throughout the year $\left(\sim 55^{\circ}-71^{\circ} \mathrm{N}\right.$ and $\left.\sim 63^{\circ}-88^{\circ} \mathrm{S}\right)$, with satellite sunrises in the Northern Hemisphere and satellite sunsets in the Southern Hemisphere. POAM III was operational from April 1998 to early December 2005.

Briefly, the retrieval algorithm for POAM III consists of a spectral inversion for species separation, followed by the limb (vertical) inversion. Ozone is retrieved primarily from the $0.603 \mu \mathrm{m}$ channel where the Chappuis absorption dominates the total optical depth between 15 and $60 \mathrm{~km}$.

The retrieval and error budget for the version 3 (v3) data products are described in detail in Lumpe et al. (2002). The ozone v3 retrievals have been extensively compared and validated using observations from aircraft, balloon and satelliteborne instruments (see Randall et al., 2003, and references therein). They were shown to be highly accurate from 13 to $60 \mathrm{~km}$ with a typical agreement of $\pm 5 \%$. A possible slight bias of $\sim 5 \%$ was noted between the SR (Northern Hemisphere) and SS (Southern Hemisphere) profiles, and a high bias (up to $0.1 \mathrm{ppmv}$ ) was found below $12 \mathrm{~km}$ (Randall et al., 2003). For these comparisons, we use version 4 (hereinafter v4) of the POAM III retrievals. This version was improved to account for problems in the POAM III v3 retrievals, due in part to unexpected instrument degradation over the course of the mission. Comparative studies similar to those conducted with v3 show that the general conclusions of Randall et al. (2003) can be applied to POAM III v4 ozone data (http://eosweb.larc.nasa.gov/PRODOCS/poam3/ documents/poam3_ver4_validation.pdf).

The quality flag implemented for the POAM III v4 $\mathrm{O}_{3}$ product (http://eosweb.larc.nasa.gov/PRODOCS/poam3/ documents/poam3_ver4_documentation.pdf) was used for data screening: altitude levels with non-zero values of the quality flag were excluded from the calculations. We used $\pm 2 \mathrm{~h}, \pm 5^{\circ}$ in latitude and $\pm 10^{\circ}$ in longitude for the coincidence search. A total of 376 coincidences was found in the comparison period, with about $1 / 3$ in the Northern Hemisphere (POAM III SR) and the remainder in the Southern Hemisphere (POAM III SS).

Results are shown in Fig. 5 for the ACE-FTS SR (top) and SS (bottom) occultations. Mean relative differences are within $\pm 10 \%$ ( +2 to $+5 \%$ on average) between $\sim 12$ and $\sim 42 \mathrm{~km}$ for both SR and SS. In particular, the ACEFTS SS/POAM III SS results show an excellent agreement with mean relative differences within $\pm 3 \%$ in the range $23-$ $41 \mathrm{~km}$ and de-biased standard deviation of the mean relative 
differences lower than 5\%. These are indicative of a good combined precision for these events and therefore imply low random errors for the ACE-FTS retrievals. The largest differences are found for the ACE-FTS SR/POAM III SS comparisons (109 coincidences, with mean relative differences within 0 to $+13 \%$ ). Below $16 \mathrm{~km}$, ACE-FTS measures consistently less ozone than POAM III, with large mean relative differences corresponding to mean absolute differences of less than $0.1 \mathrm{ppmv}$. The de-biased standard deviation of the mean relative differences is lower than $8 \%$ (SR/SS and SS/SR) and $15 \%$ (SR/SR and SS/SS) between about 12 and $42 \mathrm{~km}$. Above $42 \mathrm{~km}$, mean relative differences increase to a maximum of $+34 \%$ around $60 \mathrm{~km}$. The largest mean relative differences are found for the ACE-FTS SR/POAM III SS events in the range $42-48 \mathrm{~km}$ and for the ACE-FTS SS/POAM III SR pairs ( $\sim 230$ coincidences) above $42 \mathrm{~km}$. In each panel of Fig. 5, a discrepancy in the mean relative difference profiles can be seen, notably at high altitudes. However, when comparing all ACE-FTS SR profiles against POAM III (top panel) and all ACE-FTS SS profiles against POAM III (bottom panel), the resulting differences between the ACEFTS SR and SS observations are always lower than 1-2\% (not shown). Therefore the observed differences should not be interpreted as showing a SR/SS bias of the ACE-FTS data.

The ACE-MAESTRO and POAM III comparisons were done by Kar et al. (2007) using measurements from February 2004 to September 2005. This slightly shorter comparison period did not significantly lower the number of coincidences. Therefore, a short summary will be given but the reader is referred to the analysis of Kar et al. (2007) for more information and to their Figs. $6 \mathrm{a}$ and $6 \mathrm{~b}$ for illustration of the results. ACE-MAESTRO SR events show consistently smaller VMRs from $20-50 \mathrm{~km}$ when compared to POAM III SR or SS profiles, with mean relative differences within -5 to $-15 \%$. The comparison of the ACE-MAESTRO SS profiles with POAM III yields mean relative differences within $\pm 10 \%$ in the altitude range $\sim 18-40 \mathrm{~km}$, with smallest values (within $\pm 4 \%$ from $20-35 \mathrm{~km}$ ) for the comparisons of ACE-MAESTRO SS and POAM III SR. Above $\sim 40 \mathrm{~km}$, the ACE-MAESTRO SS profiles show larger ozone values than POAM III (up to $+20 \%$ for POAM III SR and $+30 \%$ for POAM III SS). As for SAGE II or HALOE, the shape of the relative difference profile above $\sim 45 \mathrm{~km}$ for the ACEMAESTRO SS events is qualitatively similar to the results obtained for ACE-FTS at high altitudes. Here also, the debiased standard deviation of the mean relative differences is larger than that found for ACE-FTS, within 10 to $25 \%$ over the comparison altitude range (18-40 km) (Kar et al., 2007).

\subsubsection{SAGE III}

SAGE III was an upgraded version of SAGE II and was launched in December 2001 aboard the Russian Meteor-3M satellite. The satellite is in a sun-synchronous orbit at an altitude of $1000 \mathrm{~km}$, with an inclination of $99.3^{\circ}$ and an as-

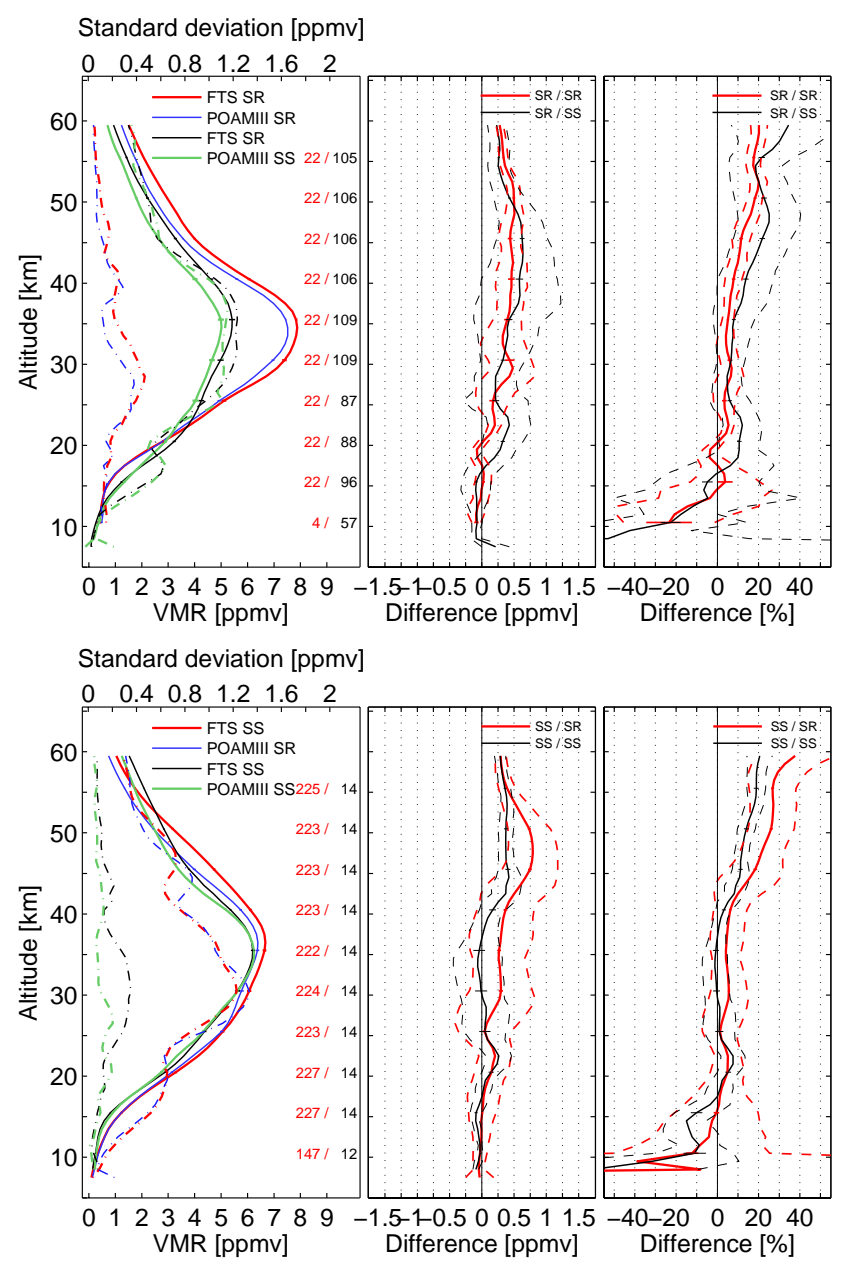

Fig. 5. Mean profiles and differences for the ACE-FTS - POAM III coincidences. Results are shown for ACE-FTS SR (top panel) and SS (bottom panel) observations. In each panel: Left: Mean VMR profiles from ACE-FTS and POAM III (solid lines) and associated 1- $\sigma$ standard deviations (dot-dashed lines). POAM III SR (blue) mean profiles are paired with ACE-FTS (red) mean profiles and POAM III SS (green) are paired with ACE-FTS (black) mean profiles. The standard error (uncertainty) of the mean is shown every $5 \mathrm{~km}$ by error bars on the VMR profiles. The number of coincident pairs used is given every $5 \mathrm{~km}$. Middle: Mean absolute differences (ACE-FTS-POAM III) in ppmv (solid line), with corresponding de-biased standard deviations (dashed line), and standard error (uncertainty) of the mean reported as error bars. The ACE-FTS-POAM III SR and ACE-FTS-POAM III SS differences are shown in red and black, respectively. Right: Mean relative differences in percent (solid line) shown as $2 \times$ (ACEFTS-POAM III)/(ACE-FTS+POAM III), de-biased standard deviations of the mean relative differences (dashed line), and standard error (uncertainty) of the mean (error bars). The colour scheme used is the same as that used in the middle panel.

cending node crossing at 09:00 (local time). SAGE III used solar and lunar occultation as well as limb scatter to make measurements in 87 spectral channels (at wavelengths from 

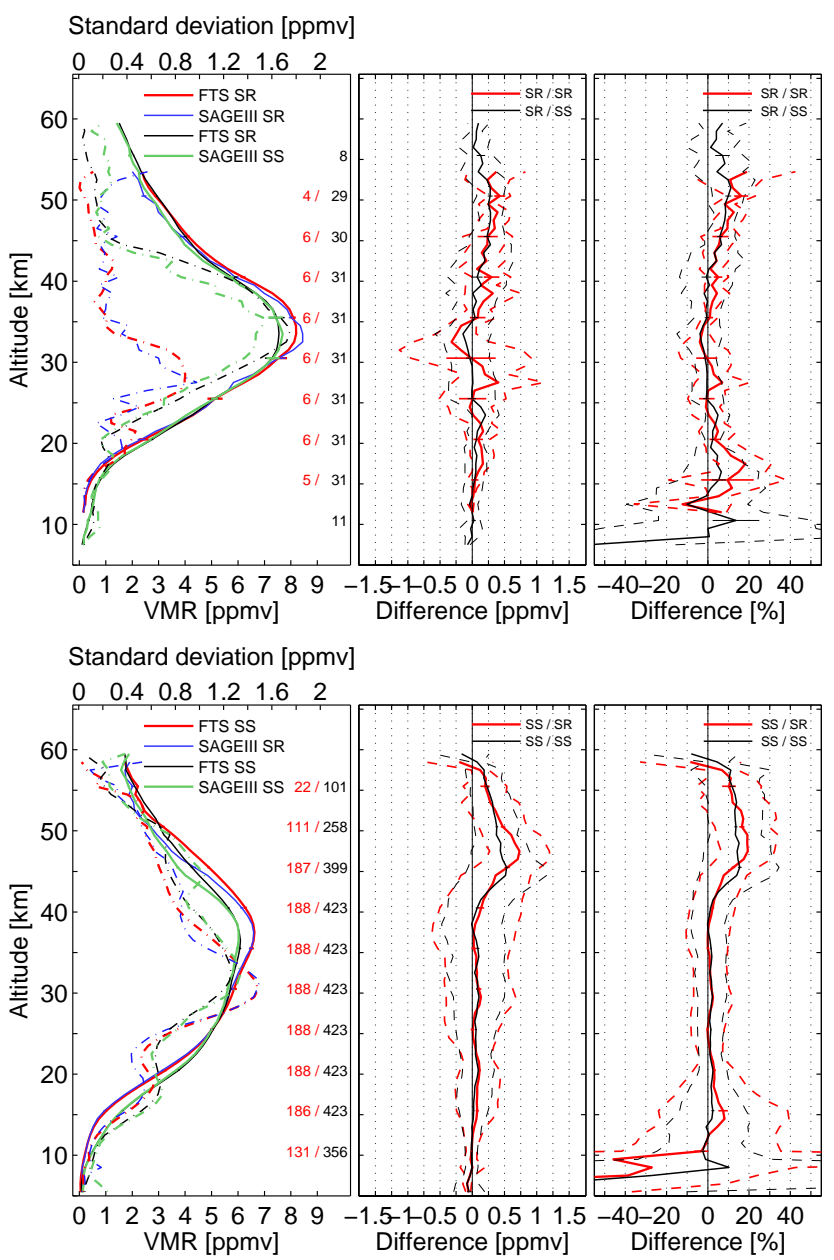

Fig. 6. Same as Fig. 5, but for the comparisons between ACE-FTS and SAGE III. Results are shown for ACE-FTS SR observations (top panel) and ACE-FTS SS observations (bottom panel).

280 to $1035 \mathrm{~nm}$ ) using a grating spectrometer (SAGE ATBD Team, 2002a). The solar occultation observations produced high-resolution $(\sim 1 \mathrm{~km})$ profiles of $\mathrm{O}_{3}, \mathrm{NO}_{2}, \mathrm{H}_{2} \mathrm{O}$ and aerosol extinction. The SAGE III solar occultation measurements occured at high latitudes in the Northern Hemisphere $\left(45^{\circ} \mathrm{N}-80^{\circ} \mathrm{N}\right.$, satellite SS) and at mid-latitudes in the Southern Hemisphere $\left(60^{\circ} \mathrm{S}-25^{\circ} \mathrm{S}\right.$, satellite SR). This provided increased opportunities for measurements coincident with ACE occultation events, particularly in the Northern Hemisphere. SAGE III took measurements from May 2002 through December 2005.

Two different processing algorithms have been used for SAGE III ozone retrievals in the upper troposphere and the stratosphere. One is a SAGE II type (least-squares) algorithm using only a few wavelengths and the second one employs a multiple linear regression (MLR) technique to retrieve ozone number densities from the Chappuis absorption band (SAGE ATBD Team, 2002b). The recent study of H. J. Wang et al. (2006), using the latest release (version 3.0) of the retrievals, showed that both products are essentially similar from 15 to $40 \mathrm{~km}$. When compared to correlative measurements, the SAGE II type retrievals provide better precision above $40 \mathrm{~km}$ and do not induce artificial hemispheric biases in the upper stratosphere, whereas the MLR retrieval yields slightly better accuracy in the upper troposphere/lower stratosphere (UT/LS) region. Comparisons with ozonesondes, SAGE II and HALOE show that the estimated precision of SAGE III for the least-squares (SAGE II type) retrieval algorithm is better than $5 \%$ between 20 and $40 \mathrm{~km}$ and $\sim 10 \%$ at $50 \mathrm{~km}$, and the accuracy is $\sim 5 \%$ down to $17 \mathrm{~km}$. In particular, excellent agreement was found with SAGE II from 15 to $50 \mathrm{~km}$, with ozone values reported by SAGE III systematically larger than those of SAGE II by only $2-3 \%$. Below $17 \mathrm{~km}$, SAGE III ozone VMR values are systematically larger than those of the comparison instruments, by $10 \%$ at $13 \mathrm{~km}$ (H. J. Wang et al., 2006). We use version 3.0 of the ozone data product from the SAGE II type algorithm for the comparisons detailed hereafter.

Of the solar occultation instruments, the most coincidences were found with SAGE III (648 events). There is very good overall agreement between ACE-FTS and SAGE III, as shown in Fig. 6. Mean relative differences are within $\pm 6 \%$ from 12-42 km (except for the ACE-FTS SR/SAGE III SR results at $17 \mathrm{~km}$ ) and generally smaller than $\pm 2 \%$. Above $42 \mathrm{~km}$, ACE-FTS reports larger VMRs than SAGE III (by up to $+20 \%$ ). This is consistent with other comparisons presented in this study. There is no significant difference between the ACE-FTS SR and SS comparisons below $42 \mathrm{~km}$. Above this altitude, the SR results show slightly smaller mean relative differences (by -2 to $-6 \%$ ) but are based on a considerably lower number of coincidences. Based on these comparisons, there does not appear to be a systematic SR/SS bias in the ACE-FTS retrievals. The de-biased standard deviation of the mean relative differences is within $15 \%$ at all altitudes but often smaller than $6 \%$, a value comparable to the estimated precision of the SAGE III retrievals. This could mean that the ACE-FTS contribution to the combined random errors of the comparison is very small.

As for POAM III, comparisons of ACE-MAESTRO with SAGE III were conducted by Kar et al. (2007) using narrower geographic criteria (maximum distance of $500 \mathrm{~km}$ ) and will not be reproduced here. Mean relative differences within $\pm 5 \%$ are found between 15 and $\sim 40 \mathrm{~km}$ for the larger samples (ACE-MAESTRO SS/SAGE III SR and ACE-MAESTRO SS/SAGE III SS). Above this range, the ACE-MAESTRO SS profiles exhibit a large positive bias with mean relative differences of up to $+30 \%$, larger than those found for ACE-FTS. The de-biased standard deviation of the mean relative differences is quite large (within 10 to $20 \%$ ), which suggests that the ACE-MAESTRO spectral fitting errors to not entirely account for the random errors of the retrieval. For the ACE-MAESTRO SR measurements, the mean relative differences are consistently within -5 to 
$-15 \%$ in the altitude range $28-55 \mathrm{~km}$, with smaller values of the de-biased standard deviation $(<7 \%)$ compared to the SS events. This is shown in Figs. 5a and 5b of Kar et al. (2007).

\subsection{Odin}

The Swedish-led Odin satellite, launched in February 2001, is in a sun-synchronous, near-terminator orbit at $\sim 600 \mathrm{~km}$ with a $97.8^{\circ}$ inclination and an ascending node crossing at 18:00 (local time) (Murtagh et al., 2002). This orbit provides the limb-scanning instruments with latitudinal coverage in the orbit plane from $82.2^{\circ} \mathrm{N}$ to $82.2^{\circ} \mathrm{S}$. Odin serves both astronomy and aeronomy objectives and, while in normal operation, it shares time equally between aeronomy and astronomy measurements. The stratospheric mode (measured for one day out of every three) scans the Earth's limb from 7 to $70 \mathrm{~km}$ with a vertical speed of $0.75 \mathrm{~km}$ per second.

\subsubsection{Odin/OSIRIS}

The Optical Spectrograph and InfraRed Imager System (OSIRIS) is one of the two instruments on Odin. It measures limb-scattered solar radiance in the spectral range 280$810 \mathrm{~nm}$ with $\sim 1 \mathrm{~nm}$ resolution (Llewellyn et al., 2004). The instrument's vertical field-of-view is $\sim 1 \mathrm{~km}$ at the tangent point. OSIRIS provides approximately 30 ozone profiles per orbit over the sunlit hemisphere (about 60 profiles per orbit during orbital equinox periods).

There are presently two versions of the OSIRIS ozone data product. The retrieval algorithm for the first product is developed and maintained at York University (Toronto, Canada). It applies the inversion technique developed by Flittner et al. (2000) and McPeters et al. (2000) to OSIRIS radiances measured at three wavelengths in the Chappuis absorption band (von Savigny et al., 2003). The resulting ozone number density profiles, version 3.0 (v3.0), are provided from $10-46 \mathrm{~km}$ with a $2 \mathrm{~km}$ spacing. The York v3.0 data products are described in Haley and Brohede (2007). The major change in the York v3.0 data product is the correction of a pointing drift affecting the previous retrieval versions. Total error estimates for the $\mathrm{O}_{3}$ retrievals are $6 \%$ at about $24 \mathrm{~km}$, increasing to $\sim 14 \%$ at $10 \mathrm{~km}$ and $33 \%$ at $44 \mathrm{~km}$ (Haley and Brohede, 2007). These will be referred to as the "York retrievals" hereinafter. There were two previous releases of the York ozone product (v1.2 and v2.4), yielding very similar results (agreement better than 3\%). Version 1.2 has been validated against coincident ozonesonde and satellite measurements (Petelina et al., 2004, 2005a). These comparisons showed a good agreement of the OSIRIS York data product with correlative measurements, within $\pm 7 \%$ over the altitude range $16-32 \mathrm{~km}$. Recently, v3.0 data were validated against Odin/SMR, POAM III, balloon-borne and ground-based instruments. An overall low bias of the York retrievals, generally of about $-15 \%$ ( -0.3 to $-0.7 \mathrm{ppmv}$ depending on the

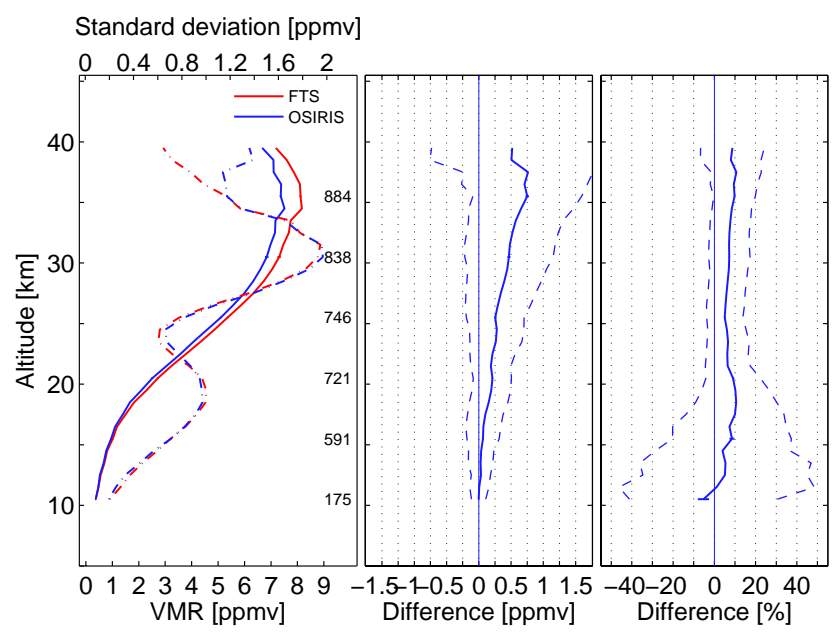

Fig. 7. Mean profiles and differences for the ACE-FTS - OSIRIS (York) coincidences. Results for ACE-FTS SR and SS observations are combined. Left: Mean VMR profiles from ACE-FTS and OSIRIS (York) (solid lines) and associated 1- $\sigma$ standard deviations (dot-dashed lines). The standard error (uncertainty) of the mean is shown every $5 \mathrm{~km}$ using error bars on the VMR profiles. The number of coincident pairs is given every $5 \mathrm{~km}$. Middle: Mean absolute differences (ACE-FTS-OSIRIS (York)) in ppmv (solid line), with corresponding de-biased standard deviations (dashed line), and standard error (uncertainty) of the mean reported as error bars. Right: Mean relative differences in percent (solid line) shown as $2 \times($ ACE-FTS-OSIRIS (York))/(ACE-FTS+OSIRIS (York)), debiased standard deviations of the mean relative differences (dashed line), and standard error (uncertainty) of the mean (error bars).

altitude), was found in the range $10-35 \mathrm{~km}$ (Brohede et al., 2007; Jégou et al., 2008).

The second OSIRIS ozone retrieval algorithm, SaskMART, is developed and maintained at the University of Saskatchewan (Saskatoon, Canada). We also compare the ACE-FTS and ACE-MAESTRO ozone profiles with version 2.1 (v2.1) of this product (hereinafter "SaskMART retrievals"). The SaskMART algorithm combines information from the Chappuis and the Hartley-Huggins bands to infer the ozone number density from the cloud tops to the lower mesosphere. It is described by Roth et al. (2007) and uses a Multiplicative Algebraic Reconstruction Technique (MART) and the SASKTRAN radiative transfer model (Bourassa et al., 2007). SaskMART zonal mean profiles were compared with SAGE II v6.20 and SAGE III v3.0 $\mathrm{O}_{3}$ profiles by Roth et al. (2007). Results show an overall agreement within $\pm 5 \%$ for SAGE II and $\pm 10 \%$ for SAGE III from $20-40 \mathrm{~km}$, with OSIRIS reporting less ozone over most of the altitude range. Comparisons with SAGE II, using the complete OSIRIS SaskMART dataset over the full altitude range of the retrievals $(10-60 \mathrm{~km})$, were conducted by Degenstein et al. (2008). The results show very good agreement with SAGE II, with mean relative differences within $\pm 2 \%$ 


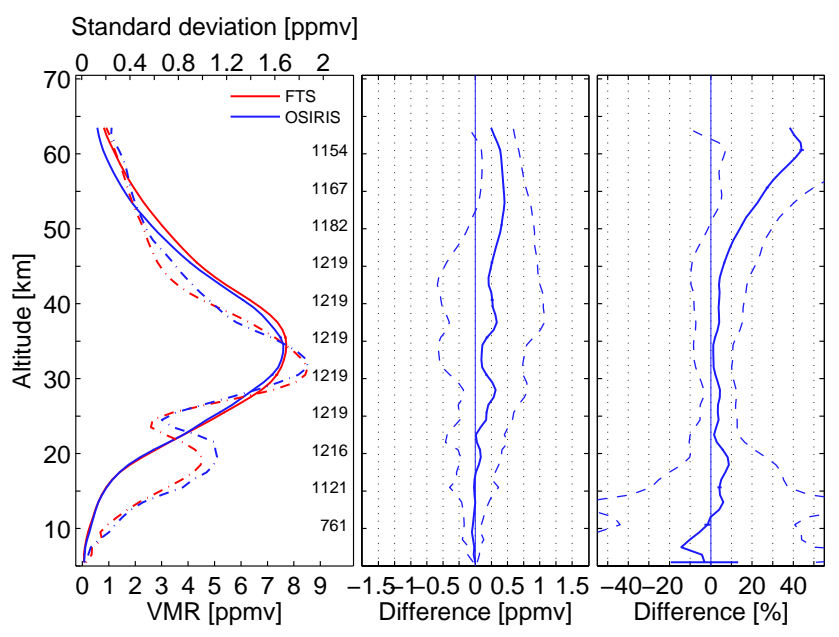

Fig. 8. Same as Fig. 7, but for the comparisons between ACE-FTS and OSIRIS (SaskMART).

between 18 and $53 \mathrm{~km}$, and a substantial low bias below and above this range ( $-20 \%$ at $58 \mathrm{~km}$ ) (Degenstein et al., 2008).

For OSIRIS, the ACE-FTS profiles were first compared with the York retrievals (Fig. 7). Following the developers' recommendation, only profiles for which the measurement response is greater than 0.9 (i.e., where $90 \%$ or more of the information content comes from the observation and not from the a priori (Rodgers, 2000)) were included in the analysis. Furthermore, the data were screened to exclude altitude levels for which the estimated vertical resolution is $>5 \mathrm{~km}$. A total of 913 coincidences was found with criteria of $\pm 2 \mathrm{~h}, \pm 5^{\circ}$ in latitude and $\pm 10^{\circ}$ in longitude. As explained in Sect. 3, results for ACE-FTS will now be given for averages over all coincident events, with no SR/SS separation. ACE-FTS consistently reports more ozone than the OSIRIS York retrievals except at the lowermost altitudes (11-12 km). Above $12 \mathrm{~km}$, the mean relative differences are within +4 to $+11 \%$ throughout, with largest values at 18 and at $37 \mathrm{~km}(\sim+11 \%)$. Here also, the standard error values are very small, indicating that the observed differences are statistically significant. These are, however, compatible with other validation studies of the York v3.0 retrievals. The debiased standard deviation of the mean relative differences is lower than $15 \%$ above $20 \mathrm{~km}$ and increases below this altitude. Note again the very good consistency of the standard deviations of the ACE-FTS and York mean VMR profiles (as seen in most comparisons presented in this work).

Results of the comparison of ACE-FTS with the SaskMART retrievals are presented in Fig. 8. In these comparisons, the ACE-FTS VMR values are also consistently larger than those of OSIRIS, but with better agreement (with mean relative differences within $\pm 6 \%$ ) in the altitude range 9-45 km. Above $45 \mathrm{~km}$ mean relative differences increase, up to $+44 \%$ at $60 \mathrm{~km}$. The de-biased standard deviation of
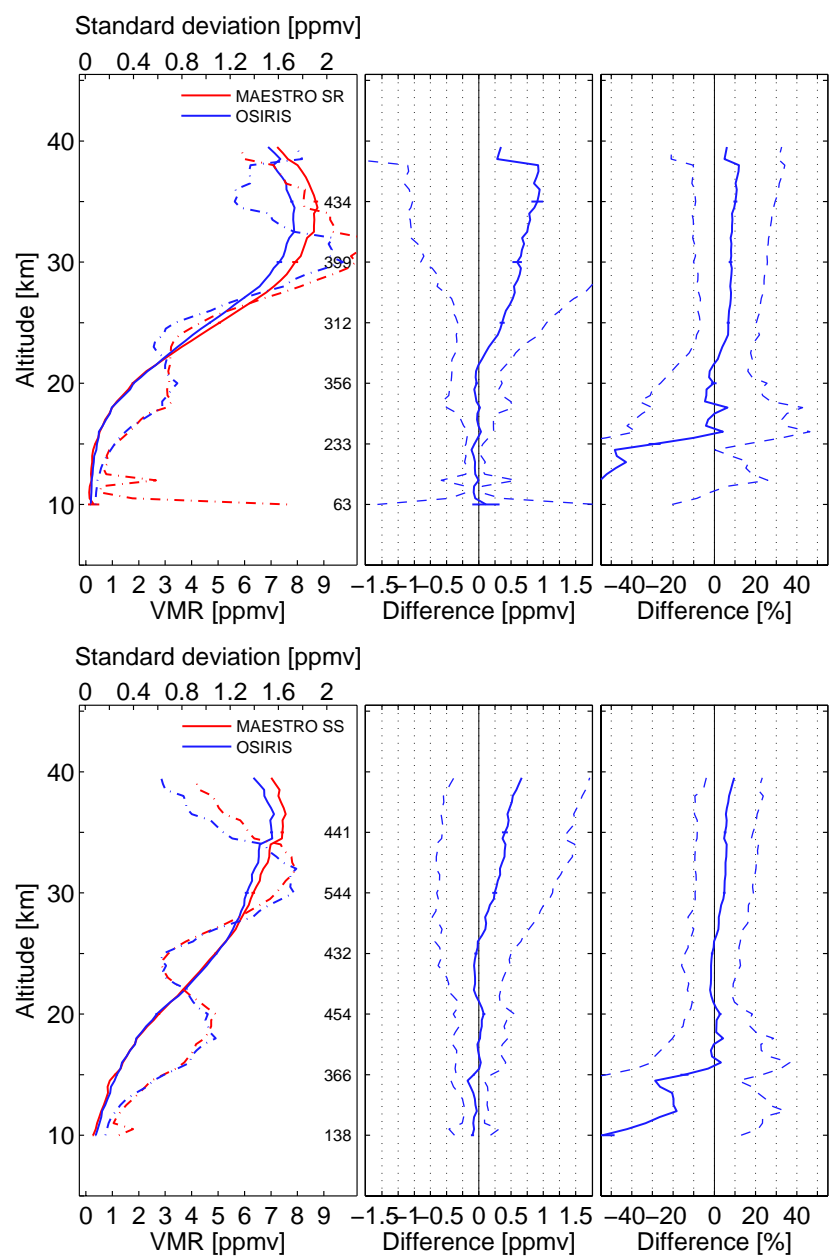

Fig. 9. Same as Fig. 1, but for the comparisons between ACEMAESTRO and OSIRIS (York). Top: comparison with ACEMAESTRO SR observations; bottom: comparison with ACEMAESTRO SS observations.

the mean relative differences remains lower than $20 \%$ at all altitudes between 18 and $55 \mathrm{~km}$. Considering the low bias previously noted in the comparisons of OSIRIS SaskMART with SAGE II and SAGE III, this suggests that this large positive difference may be the combination of the persistent high bias of ACE-FTS between $\sim 45$ and 55-60 km and of a low bias of the SaskMART retrievals above $\sim 50 \mathrm{~km}$.

Figure 9 shows the results of the comparison between ACE-MAESTRO and the York retrievals, for ACEMAESTRO SR (top panel) and SS (bottom panel) occultations. For both types of events, the mean relative differences are within $\pm 5 \%$ between 16 and $26 \mathrm{~km}$ and within +6 to $+12 \%$ between 26 and $40 \mathrm{~km}$. However, the ACEMAESTRO SR profiles around $37 \mathrm{~km}$ seem to have a larger positive bias compared to the SS profiles, which is opposite to the known SR/SS bias seen with the solar occultation comparisons. The reason for this is not clear at this time. 
For ACE-MAESTRO, the de-biased standard deviation of the mean relative differences is larger than for ACE-FTS, with values within 10 to $25 \%$ found above $18 \mathrm{~km}$. The de-biased standard deviation of the mean relative differences is slightly smaller for the SS comparisons than for the SR events, but by less than 2-3\%. Since these are an estimate of the combined precision of the instruments, the comparison of the results for ACE-FTS and for ACE-MAESTRO could indicate that ACE-MAESTRO retrievals have a noticeably poorer precision than those of ACE-FTS.

The comparison results for ACE-MAESTRO and OSIRIS SaskMART retrievals are shown in Fig. 10 for ACEMAESTRO SR (top) and SS (bottom) events. The agreement is quite good for the SR events, with mean relative differences within $\pm 7 \%$ over the altitude range $18-59 \mathrm{~km}$. For ACE SS events, ACE-MAESTRO ozone mixing ratios have a large positive bias between 40 and $60 \mathrm{~km}$, similar to comparisons with most other instruments. However, the maximum mean relative difference of $\sim 15 \%$ near $53 \mathrm{~km}$ is somewhat smaller than the corresponding positive bias for ACE-FTS at this altitude. A SR/SS bias in ACE-MAESTRO ozone measurements can be seen, particularly in the upper stratosphere. The fact that the mean relative differences at the uppermost levels are negative while the mean absolute differences are small but positive is due to very low VMR values in the ACEMAESTRO retrievals for more than half ( $\sim 240$ out of $\sim 450)$ of the coincident events. The de-biased standard deviation of the mean relative differences for the comparison of ACEMAESTRO with the SaskMART retrievals is very similar to the York comparisons, with a minimum of $\sim 10 \%$ and a maximum of $\sim 28 \%$ in the altitude range $18-50 \mathrm{~km}$, for both the SR and SS events.

\subsubsection{Odin/SMR}

The Sub-Millimetre Radiometer (SMR) is the second instrument on board the Odin satellite. It uses four tunable heterodyne radiometers to observe thermal limb emission from atmospheric molecules, in the frequency range $486-581 \mathrm{GHz}$. In the stratospheric mode, SMR measures several species related to stratospheric ozone processes in two frequency bands centered at $501.8 \mathrm{GHz}$ and $544.6 \mathrm{GHz}$, namely $\mathrm{O}_{3}, \mathrm{HNO}_{3}$, $\mathrm{ClO}$ and $\mathrm{N}_{2} \mathrm{O}$ (Urban et al., 2005).

The current best ozone data product for SMR is version 2.1 of the operational processing developed at the Chalmers University of Technology, Gothenburg, Sweden (hereinafter Chalmers-v2.1). It uses the observations of a weak $\mathrm{O}_{3}$ line near $501.5 \mathrm{GHz}$ to retrieve ozone VMRs mainly in the stratosphere (above $\sim 17-18 \mathrm{~km}$ at mid-latitudes), with a retrieval scheme based on the Optimal Estimation Method (Rodgers, 2000). The vertical resolution achieved is on the order of $2.5-3.5 \mathrm{~km}$ below $\sim 40-45 \mathrm{~km}$. Chalmers-v2.1 and two previous operational ozone data products (v1.2 and v2.0) were compared with ozonesondes and with the MIPAS ozone profiles retrieved with the ESA Level 2 processor prototype

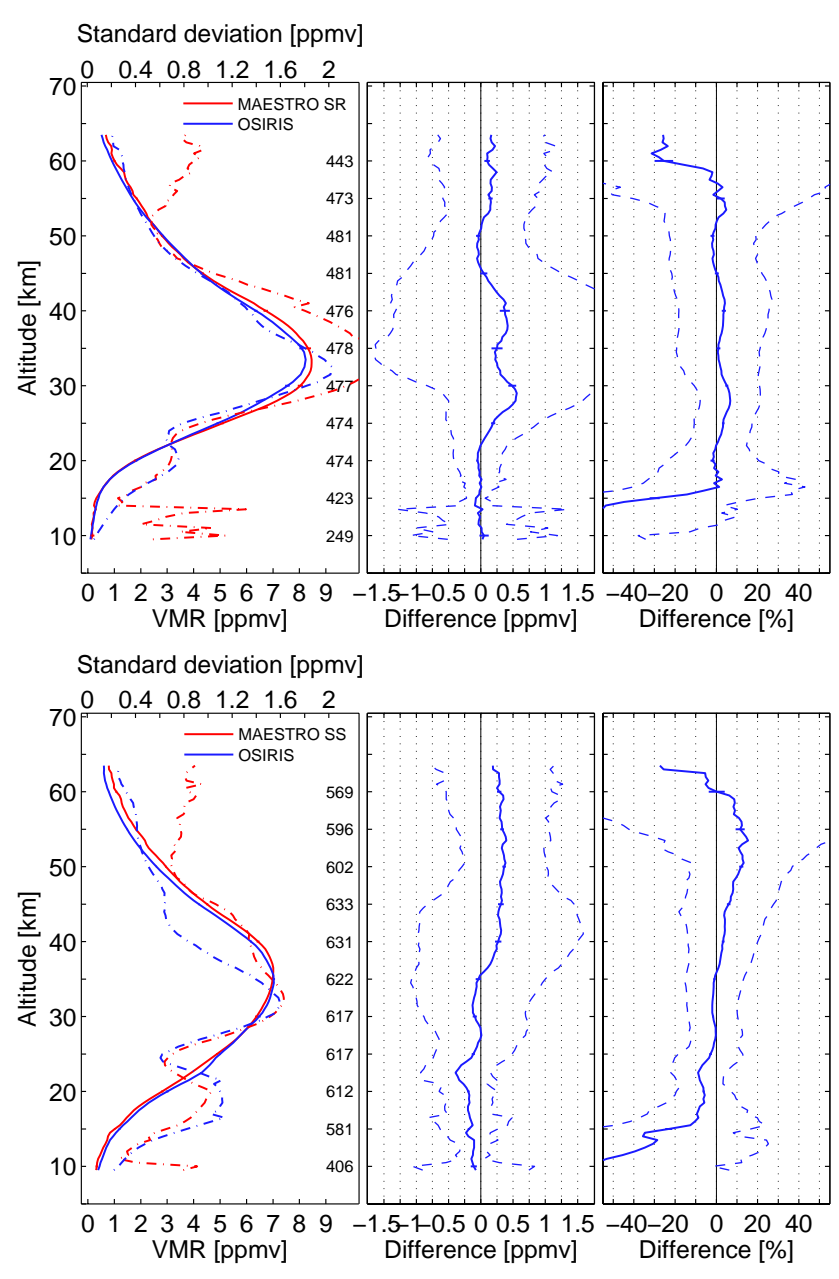

Fig. 10. Same as Fig. 1, but for the comparisons between ACEMAESTRO and OSIRIS (SaskMART), for the ACE-MAESTRO SR (top panel) and SS (bottom panel) events.

(Raspollini et al., 2006) version 4.61 in the recent study of Jones et al. (2007). The SMR ozone v2.1 is very similar to the older versions in the altitude range $20-45 \mathrm{~km}$, but is significantly improved below $20 \mathrm{~km}$ and above $\sim 45 \mathrm{~km}$. Comparisons with MIPAS show relative differences of about $-10 \%$ (smaller than $0.4 \mathrm{ppmv}$ ) between 17 and $55 \mathrm{~km}$, with SMR reporting VMR values systematically smaller than those of MIPAS. Absolute differences with ozonesonde measurements are typically within \pm 0.3 ppmv below $27 \mathrm{~km}$, but the SMR ozone VMRs are smaller than the ozonesonde measurements in the tropics around $30 \mathrm{~km}$ (by more than $10 \%$ or 0.9 ppmv; Jones et al., 2007). We used the Chalmers-v2.1 SMR ozone data product for the comparisons with the ACE instruments.

The comparisons were made with coincidence criteria of $\pm 2 \mathrm{~h}, \pm 5^{\circ}$ in latitude and $\pm 10^{\circ}$ in longitude. Following the recommendations of the retrieval team, only SMR data with a profile quality flag value of 0 were used at altitude levels 


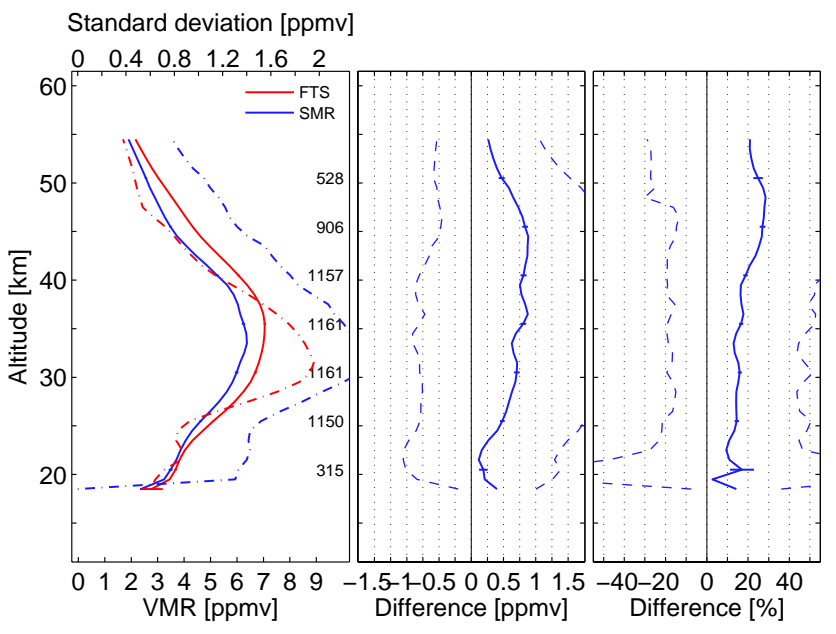

Fig. 11. Same as Fig. 7, but for the comparisons between ACE-FTS and SMR.

where measurement response was greater than 0.9 (see Urban et al., 2005, for a description of the measurement response and the quality flag). The vertical range was limited to altitudes where the SMR measurements have a good signal-to-noise ratio $(\sim 20-55 \mathrm{~km})$. A total of 1161 coincidences was found in the comparison period. The results are presented in Fig. 11. Between 20 and $\sim 55 \mathrm{~km}$, ACE-FTS consistently reports more ozone than SMR. The mean relative differences are within +2 to $+13 \%(0.5 \mathrm{ppmv})$ below $\sim 25 \mathrm{~km}$ and within +13 to $+20 \%$ between 25 and $41 \mathrm{~km}$. In the altitude range $41-55 \mathrm{~km}$, the mean relative differences are larger (within +20 to $+30 \%$ ), which is consistent with the other comparisons presented in this study. Here, the debiased standard deviation of the mean relative differences is very large, within 30 to $60 \%$ between 20 and $55 \mathrm{~km}$. The large positive bias is consistent with previous validation studies for SMR, and the large de-biased standard deviations of the mean relative differences may indicate that the SMR instrument has a relatively limited precision since such large values are not found in most other comparisons.

Similar comparisons were conducted with ACEMAESTRO and are presented in Fig. 12. Overall, the mean relative differences for the SR and SS events are similar and comparable to those of ACE-FTS. Mean relative differences are within $\pm 10 \%$ below $25 \mathrm{~km}$ and within +10 to $+20 \%$ in the altitude range $\sim 25-44 \mathrm{~km}(25-40 \mathrm{~km})$ for the ACE-MAESTRO SR (SS) events. The ACE-MAESTRO SR data show more ozone below $33 \mathrm{~km}$ than the SS data, which translates into larger values of the mean relative differences (by up to $+5 \%$ ) with SMR at these altitudes. A larger positive bias is also observed in the ACE-MAESTRO - SMR comparisons between 40 and $\sim 50 \mathrm{~km}$, with a maximum mean relative difference of about $+28 \%$. For both SR and SS comparisons, the de-biased standard deviation

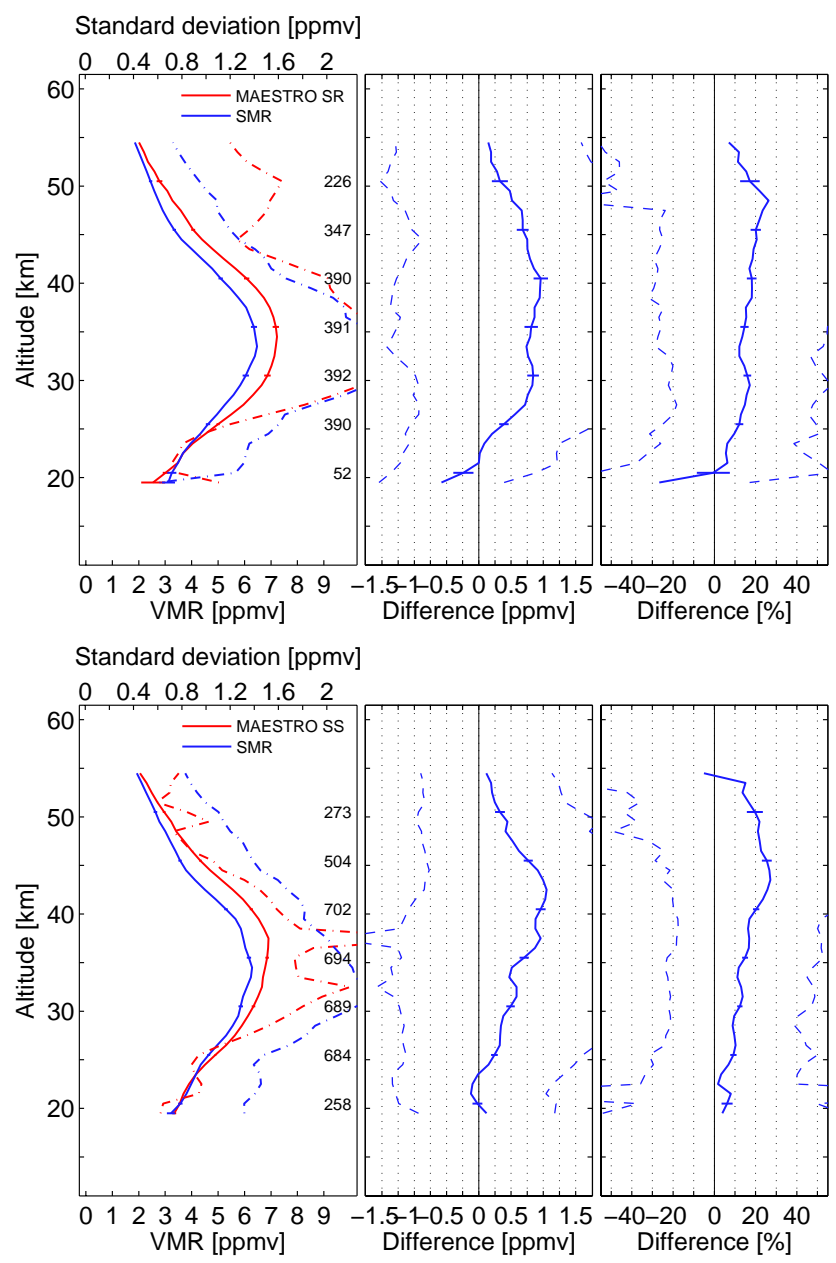

Fig. 12. Same as Fig. 1, but for the comparisons between ACEMAESTRO and SMR. Top: comparison with ACE-MAESTRO SR observations; bottom: comparison with ACE-MAESTRO SS observations.

of the mean relative differences is comparable to that found for ACE-FTS (within 30 to $60 \%$ over the altitude range $25-44 \mathrm{~km}$ ). Above $50 \mathrm{~km}$, the mean relative differences rapidly decrease and become smaller than $+5 \%$ at the top of the comparison range $(\sim 55 \mathrm{~km})$.

\subsection{TIMED/SABER}

The Sounding of the Atmosphere using Broadband Emission Radiometry (SABER) instrument is one of the four instruments onboard the Thermosphere, Ionosphere, Mesosphere Energetics and Dynamics (TIMED) satellite. TIMED was launched in December 2001 into an orbit with an altitude of $\sim 625 \mathrm{~km}$ and an inclination of $74^{\circ}$ (Russell et al., 1999). The latitude coverage alternates between $54^{\circ} \mathrm{S}-82^{\circ} \mathrm{N}$ and $82^{\circ} \mathrm{S}-$ $54^{\circ} \mathrm{N}$, and the local time coverage is $\sim 22 \mathrm{~h}$ in about 60 days. SABER uses ten channels in the near- and mid-IR spectral 
region $(1.27-15 \mu \mathrm{m})$ to perform broadband limb emission measurements of pressure, temperature, the $\mathrm{O}_{2}\left({ }^{1} \Delta\right)$ and $\mathrm{OH}$ Meinel volume emission rates, as well as VMR profiles for $\mathrm{CO}_{2}, \mathrm{O}_{3}$ and $\mathrm{H}_{2} \mathrm{O}$. The retrieval code takes into account non-local thermodynamic equilibrium (non-LTE) effects in the emissions measured above $\sim 55 \mathrm{~km}$ (Mertens, 2001). The ozone profiles are retrieved from the $9.6 \mu \mathrm{m}$ channel, in the vertical range $\sim 12-\sim 100 \mathrm{~km}$ with a vertical spacing of $\sim 0.4 \mathrm{~km}$.

The temperature and wind data have been used extensively for comparisons and scientific publications (e.g., Sica et al., 2008; Forbes et al., 2006; Petelina et al., 2005b; Mertens et al., 2004). However, at the time of writing, there are no published comparisons for the SABER trace gas data. The present study thereby constitutes the first large-scale intercomparison for the SABER ozone dataset. The SABER $\mathrm{O}_{3}$ data product available at the time of writing, version 1.06 (hereinafter v1.06), is used for the comparisons. A new version (v1.07) is currently being developed, but the reprocessing was not completed in time for this analysis. Version 1.07 should show significant changes in the SABER temperature and ozone retrievals. For $\mathrm{O}_{3}$, it should yield lower VMR values (by a few percent) in the stratosphere and a larger decrease (by $10 \%$ or more) in the mesosphere (B. T. Marshall, personal communication).

Results for the ACE-FTS and SABER comparisons are shown in Fig. 13. The shape of the difference profile is significantly different from the comparisons presented above. A total of 6210 coincidences was found between ACE-FTS and SABER with the criteria: $\pm 2 \mathrm{~h}$ and $\pm 5^{\circ}$ and $\pm 10^{\circ}$ for the latitude and longitude differences, respectively. Narrower coincidence criteria did not induce significant changes in the results. Good agreement is found in the altitude range 19$46 \mathrm{~km}$, with mean relative differences within $\pm 7 \%$. ACEFTS reports less ozone than SABER around the peak in ozone VMR (31-42 km), but shows larger VMRs around $20 \mathrm{~km}$ and at altitudes between 42 and $56 \mathrm{~km}$. Below $19 \mathrm{~km}$ and above $56 \mathrm{~km}$, the $\mathrm{O}_{3}$ VMRs measured by ACE-FTS are systematically lower than those of SABER. Note that the standard deviation of the SABER mean VMR profile is always larger than that of ACE-FTS, with largest discrepancy found below $25 \mathrm{~km}$. The de-biased standard deviation of the mean relative differences is within 13 to $30 \%$ between 19 and $50 \mathrm{~km}$. The expected decrease in the ozone VMR for the SABER v1.07 ozone data product should significantly reduce the discrepancies, notably in the mesospheric part of the comparison range. However, the reasons for this particular behavior cannot be explained at this time.

The comparisons of the ACE-MAESTRO retrievals with the SABER ozone profiles are shown in Fig. 14. Large mean relative differences are found at the top and at the bottom of the altitude range for both the SR and the SS events (below $\sim 20 \mathrm{~km}$ and above $\sim 52 \mathrm{~km}$ ). Between 20 and $52 \mathrm{~km}$, the ACE-MAESTRO SR profiles show good agreement with SABER (Fig. 14, top panel), with mean relative

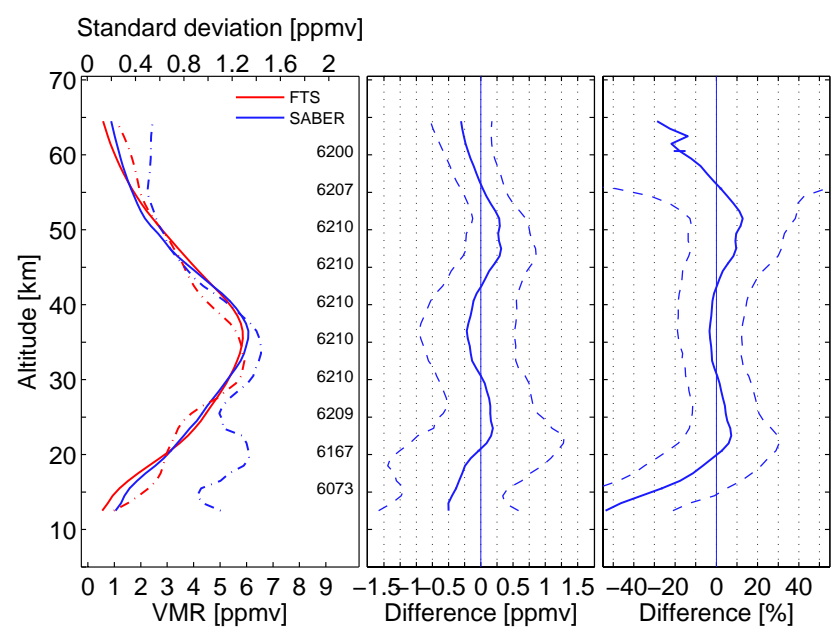

Fig. 13. Same as Fig. 7, but for the comparisons between ACE-FTS and SABER.

differences within $\pm 7 \%$ and decreasing with increasing altitude above $27 \mathrm{~km}$. The corresponding de-biased standard deviation values are within 20 to $40 \%$ in the altitude range $20-52 \mathrm{~km}$. The mean relative difference profile for the SS occultations (Fig. 14, bottom panel) is closer in shape to the results found for ACE-FTS, with values within $\pm 4 \%$ between 20 and $42 \mathrm{~km}$ and de-biased standard deviations of the mean relative differences comparable to, but slightly smaller than for the SR events (within 15 to 30\%). Between 42 and $54 \mathrm{~km}$, ACE-MAESTRO SS measurements show VMR values significantly larger than those of SABER, with mean relative differences of up to $+16 \%$ around $48 \mathrm{~km}$. As was found for the comparisons between ACE-MAESTRO and OSIRIS SaskMART in Sect. 5.2.1, the mean relative differences at the uppermost level of the comparison vertical range are negative for ACE-MAESTRO SS occultations. This is also explained by unusually low values of the retrieved ACE-MAESTRO VMRs.

\subsection{Envisat}

The ESA Environmental Satellite (Envisat) was launched in March 2002 into a quasi-polar, sun-synchronous orbit at an altitude of $800 \mathrm{~km}$, with an inclination of $98.6^{\circ}$ and an ascending node crossing at 22:00 (local time). For most of the onboard sensors, this allows complete coverage of the Earth in one to three days. Three of the ten instruments are dedicated to atmospheric chemistry: the GOMOS, MIPAS and SCIAMACHY instruments.

\subsubsection{Envisat/GOMOS}

GOMOS is a stellar occultation instrument, that has been in operation since the launch of Envisat (see Kyrölä et al., 2004, and references therein). It is a UV/visible/near-IR grating 


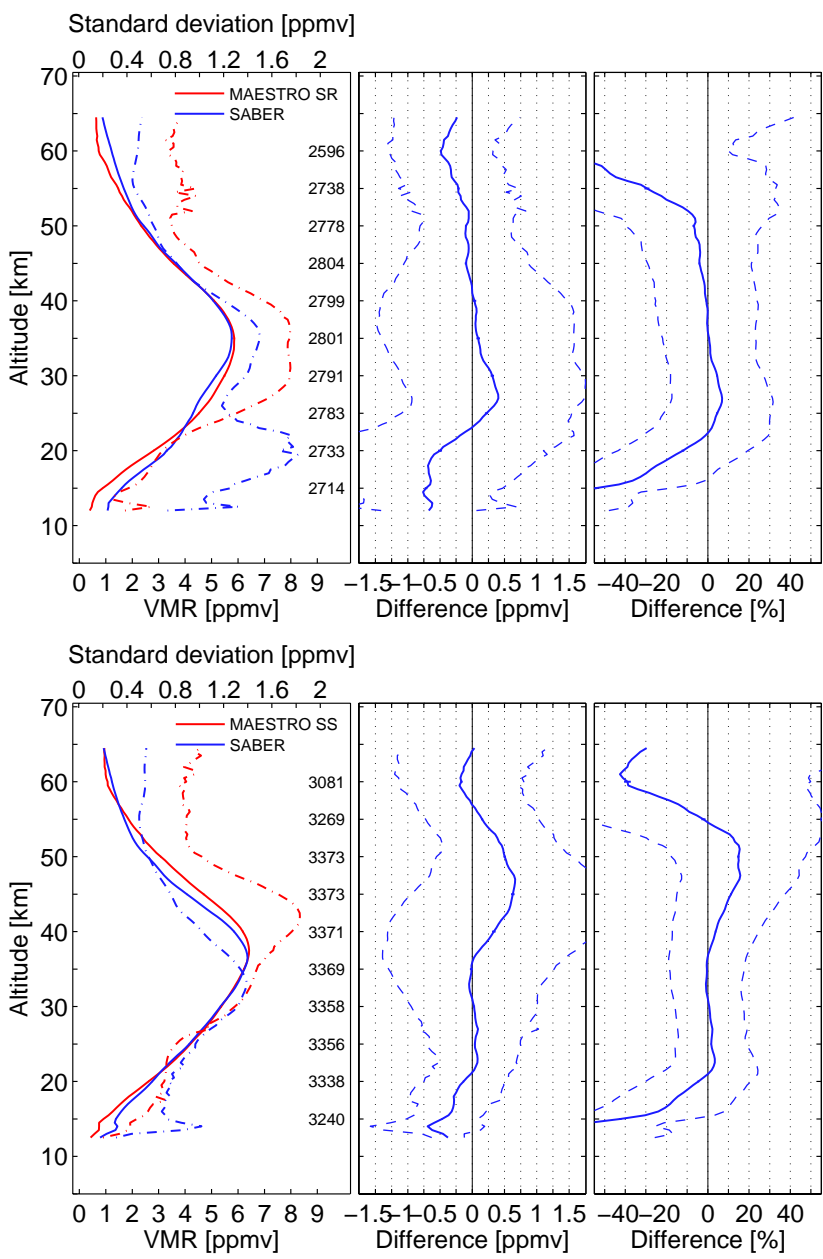

Fig. 14. Same as Fig. 1, but for the comparisons between ACEMAESTRO and SABER. Top: comparison with ACE-MAESTRO SR observations; bottom: comparison with ACE-MAESTRO SS observations.

spectrometer that can measure about 100000 star occultations per year with a vertical sampling of better than $1.7 \mathrm{~km}$. From these observations, atmospheric concentration profiles are retrieved for $\mathrm{O}_{3}, \mathrm{NO}_{2}, \mathrm{NO}_{3}, \mathrm{H}_{2} \mathrm{O}, \mathrm{O}_{2}, \mathrm{Na}, \mathrm{OClO}$ and stratospheric aerosols. The range of latitudes sampled by GOMOS depends on the suitable stars available during each orbit and thus varies throughout the year. GOMOS sounds the atmosphere at different local solar times depending on the position of the star that is being observed.

The ozone measurements are made in the $250-687 \mathrm{~nm}$ spectral range. GOMOS ozone profiles are produced using a two step retrieval process (Kyrölä et al., 2004, 2006). First, the spectral inversion uses a nonlinear Levenberg-Marquardt method to fit the refraction-corrected atmospheric spectra simultaneously at all wavelengths. Then, the onion-peeling method is used to perform the vertical inversion to obtain profiles. The typical altitude range of the GOMOS ozone re- trievals is $15-100 \mathrm{~km}$. The GOMOS precision is strongly influenced by the star magnitude and temperature as both can impact the signal-to-noise ratio of the measured spectra. The daytime (bright-limb) occultations suffer from additional noise from scattered solar light. Because of this, the comparisons shown here will be restricted to nighttime (dark-limb) observations. The GOMOS ozone profiles have been validated using measurements from ozonesondes, lidars and MWRs (Meijer et al., 2004). Between 14 and $64 \mathrm{~km}$, the differences were found to be $2.5-7.5 \%$ with GOMOS measuring less ozone than the comparison instrument. In comparisons with MIPAS and SCIAMACHY, the agreement for GOMOS dark limb profiles was $-5 \%$ from $20-50 \mathrm{~km}$ and $+1 \%$ from $20-40 \mathrm{~km}$, respectively (Bracher et al., 2005). The level 2 data product used for these comparisons was version 6.0a. Version IPF 5.00 is used for the comparisons with ACE-FTS and the difference between these versions is expected to be less than $1-2 \%$.

The approach taken for the GOMOS comparisons differs from that used for the other satellite instruments. Instead of calculating the mean of the relative differences for the GOMOS and ACE-FTS comparisons, the weighted median difference is determined. This approach, used in earlier GOMOS validation studies (e.g., Fussen et al., 2005), was adopted because outliers in either dataset can significantly influence the results of the comparison. The weighted median difference, $m$, is calculated by minimizing the expression,

$D(m)=\sum_{i} w_{i} \cdot\left|x_{\mathrm{ACE}}(i)-x_{\mathrm{GOMOS}}(i)-m\right|$,

with respect to $m$, where $x_{\mathrm{ACE}}(i)$ and $x_{\mathrm{GOMOS}}(i)$ are the profile values at a given altitude, for coincidence $i$ and for ACEFTS and GOMOS, respectively, and $w_{i}$ is the weighting factor, equal to the inverse of the combined estimated experimental errors from ACE-FTS and GOMOS. Figure 15 shows the dependence of the weighted median difference at $24.5 \mathrm{~km}$ on the number of collocated events and the spatial and temporal coincidence criteria used for the comparisons. From these results, it can be seen that a larger dataset improves the statistical significance although a slight linear bias is apparent. Using criteria of $\pm 12 \mathrm{~h}$ and $500 \mathrm{~km}, 1240$ pairs of collocated profiles were identified for the comparisons.

Because both datasets extend into the mesosphere (60$80 \mathrm{~km}$ ), we have used the Simulation of Chemistry, Radiation, and Transport of Environmentally important Species (SOCRATES) model to correct the GOMOS data for diurnal variations between the observation time and the local sunset or sunrise. SOCRATES is a two-dimensional chemistryclimate model which extends from the surface to the lower thermosphere. The version used here is optimized to study the heat budget and the photochemistry in the mesosphere (Chabrillat and Fonteyn, 2003; Kazil et al., 2003). Because the present study requires a precise representation of the chemical composition at sunrise and sunset, the model was run with a photochemical time step of 5 min over a whole 

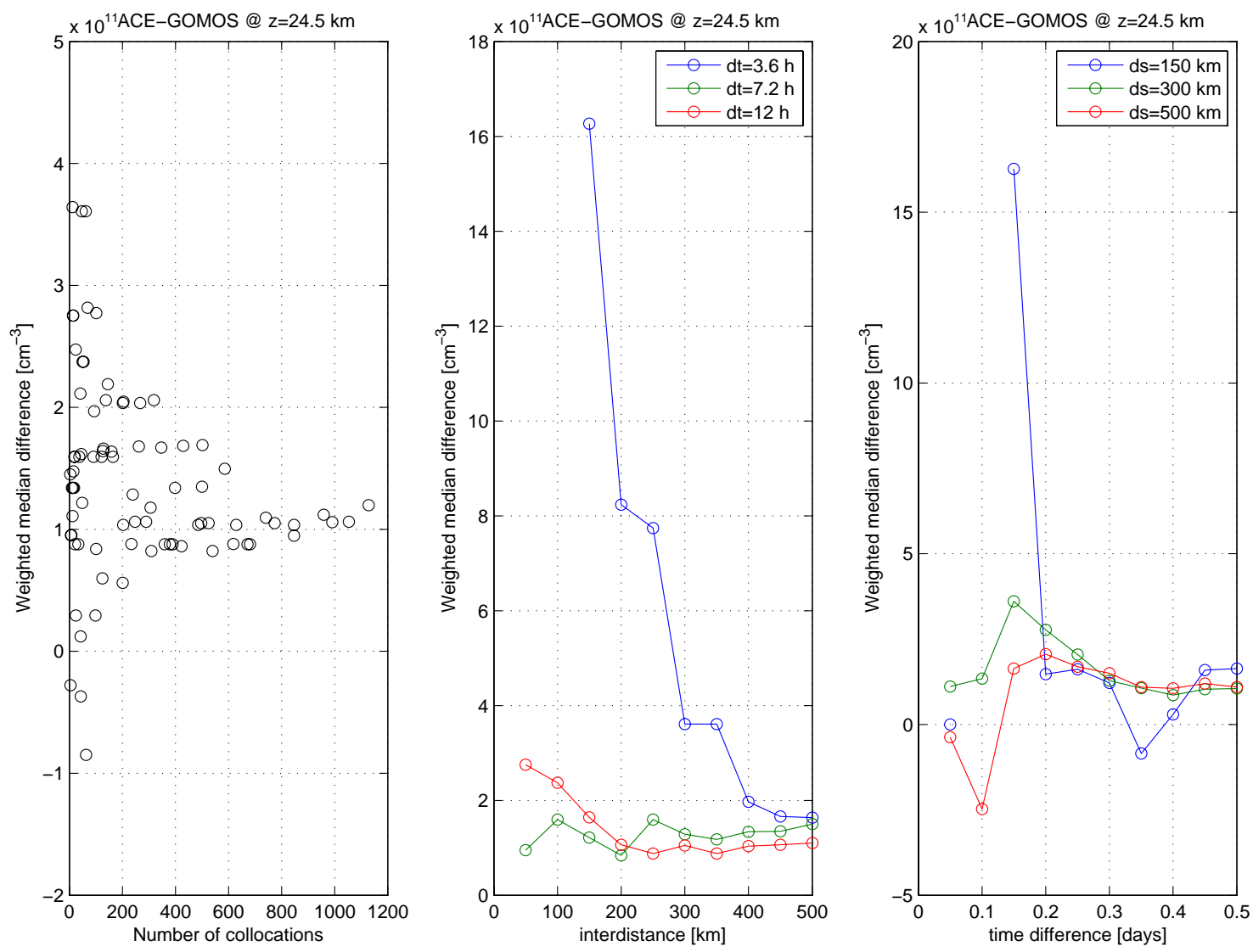

Fig. 15. Dependence of the weighted median difference, $m$, on the ACE-FTS - GOMOS coincidence characteristics. In panels from left to right: variation of $m$ relative to the number of coincident events, to the distance between the measurements and to the time difference. The altitude shown is $24.5 \mathrm{~km}$.

year with solar flux conditions representative of the year 2004. Each GOMOS observation was scaled by the modeled ratio between ozone density at local sunset or sunrise and ozone density at the observation time.

The results of the ACE-FTS - GOMOS comparisons are presented in Fig. 16. The differences shown in Fig. 16 were calculated after applying the photochemical correction from the SOCRATES model. A good agreement (median relative differences within $\pm 10 \%$ ) can be observed in the stratosphere $(15-40 \mathrm{~km})$ with a slight positive bias increasing slowly with altitude. However, there exists a larger bias (up to $+40 \%$ ) between 40 and $60 \mathrm{~km}$, similar to other comparisons. Above $60 \mathrm{~km}$, the positive bias increases strongly when comparing the ACE-FTS and corrected GOMOS profiles. Without applying the photochemical correction, ACEFTS reports significantly less ozone than GOMOS (with median relative differences down to about $-80 \%$, not shown). Because of the photochemical correction method used and the low ozone number densities, it is difficult to draw conclusions about the accuracy of the ACE-FTS profiles in the mesosphere based on these relative differences.
The GOMOS observations have better vertical resolution than the ACE-FTS profiles. Thus, we also performed an additional qualitative comparison. Since the ACE-FTS retrievals do not produce averaging kernels, an empirical triangular smoothing function was therefore applied to the GOMOS data. This was done to degrade their vertical resolution (from initial values of 0.3 to $1.7 \mathrm{~km}$ ) in order to minimize the differences between the median profiles. The agreement between both datasets was considerably improved, as seen in Fig. 16. However, this result was obtained using a convolution function with a FWHM of $10.5 \mathrm{~km}$, which could indicate that the effective resolution of the ACE-FTS measurements is larger than $10 \mathrm{~km}$ in the upper mesosphere.

\subsubsection{Envisat/MIPAS}

MIPAS is a mid-IR Fourier transform emission spectrometer designed to perform global-scale continuous (day/night) limb-sounding measurements of VMR profiles for a range of atmospheric species (Fischer et al., 2008). For this purpose, it acquires spectra in five frequency bands over the range $685-2410 \mathrm{~cm}^{-1}(14.6-4.15 \mu \mathrm{m})$. Global measurements are 

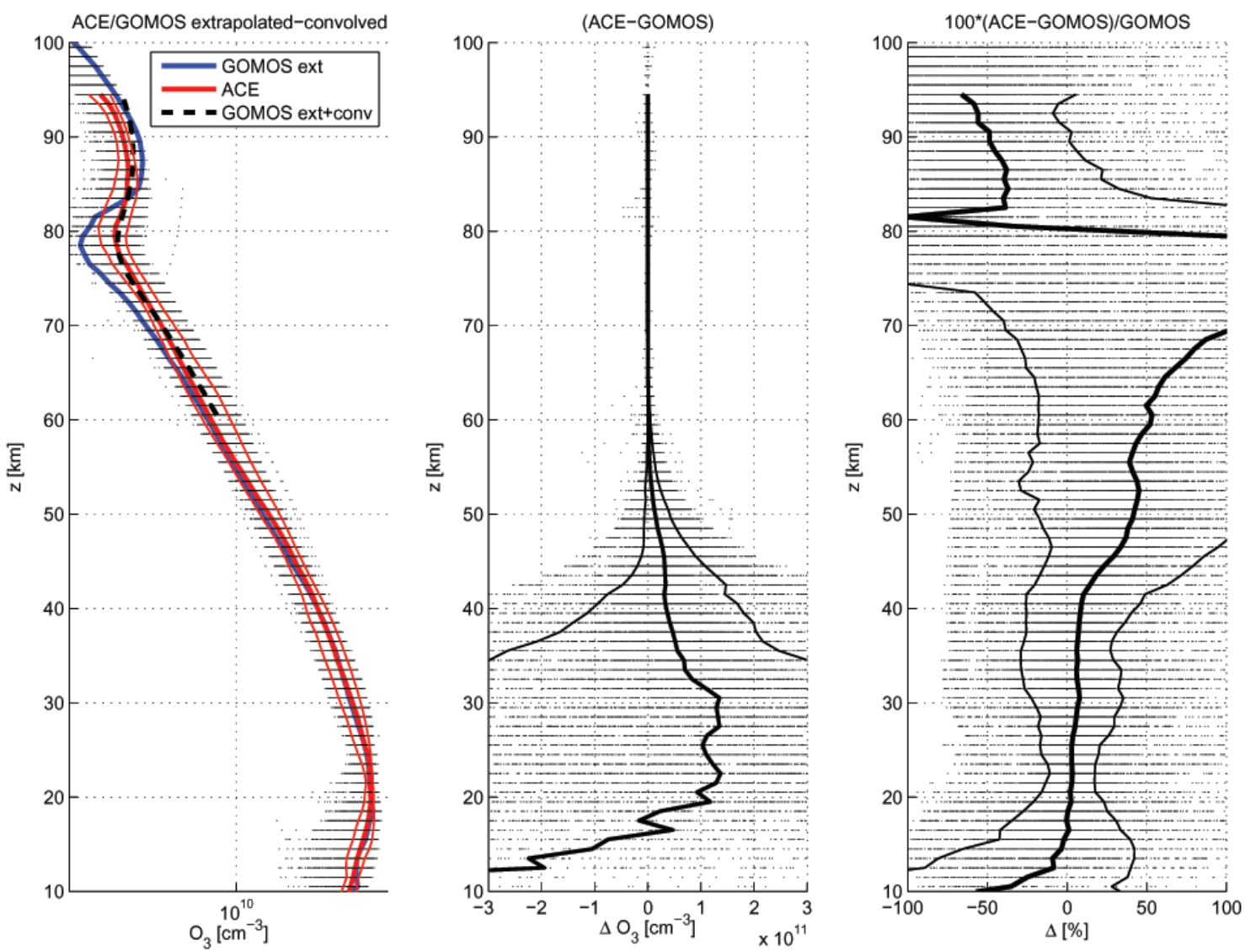

Fig. 16. Weighted median profiles and differences for the ACE-FTS and GOMOS coincidences. Left: Number density weighted median profiles (thick red) and associated 16 and 84 percentiles (thin red) for ACE-FTS. For GOMOS, the weighted median profile photochemically corrected by the SOCRATES model ("extrapolated" or "ext", thick blue line) and the weighted median profile convolved with the empirical triangular function ("convolved" or "conv", dashed black line) are shown. Middle: Weighted median profile (thick line) and associated 16 and 84 percentiles (thin lines) for the absolute differences between the ACE-FTS and the photochemically corrected GOMOS profile (ACEFTS-GOMOS) in $\mathrm{cm}^{-3} \times 10^{11}$. Right: Weighted median profile and 16 and 84 percentiles for the median relative differences between ACE-FTS and the photochemically corrected GOMOS profiles expressed as (ACE-FTS-GOMOS)/GOMOS [\%].

achieved every day (Cortesi et al., 2007). The pointing system allows MIPAS to observe atmospheric parameters in a maximum altitude range of $5-160 \mathrm{~km}$ with a vertical spacing of $1-8 \mathrm{~km}$ depending on the altitude and on the measurement mode (Fischer et al., 2008). Operational measurements at full spectral resolution $\left(0.025 \mathrm{~cm}^{-1}\right)$ were conducted from July 2002 to March 2004. However, anomalies affecting the interferometer slide mechanism led to the suspension of operations on 26 March 2004. Observations were resumed in January 2005 with a new operation mode, on a finer vertical grid and with reduced spectral resolution $\left(0.0625 \mathrm{~cm}^{-1}\right)$. The following analyses present the comparisons of the ACEFTS data product with three MIPAS datasets: the operational ESA processor (MIPAS full resolution mission), the ESA prototype processor used for validation purposes (reduced resolution observations) and the IMK-IAA scientific processor (full resolution observations). During the time period cor- responding to the full resolution observations, ACE-FTS acquired data from SS occultations only. Therefore, there are no ACE-FTS SR events in the comparisons with the ESA operational retrievals and the IMK-IAA retrievals.

\section{Comparison of ACE-FTS with the operational ESA retrievals}

The algorithm used for the ESA near-real-time Level 2 analysis is based on the Optimised Retrieval Model (ORM) scientific prototype (Raspollini et al., 2006; Ridolfi et al., 2000). Given the redundancy of measurements in MIPAS limbscanning sequences, vertical profiles do not need constraints such as a priori information. Complementary information, when available, can however be used to improve the quality of the retrieved parameters (Ridolfi et al., 2000). The retrieval uses a set of microwindows designed to obtain maximum information on the target species while minimizing the total error and the computing cost (Raspollini et al., 2006). 
The microwindow selection algorithm is described by Dudhia et al. (2002). The standard products of the ESA processor are the atmospheric pressure and temperature profiles along with the volume mixing ratio profiles of 6 "key species": $\mathrm{H}_{2} \mathrm{O}, \mathrm{O}_{3}, \mathrm{HNO}_{3}, \mathrm{CH}_{4}, \mathrm{~N}_{2} \mathrm{O}$ and $\mathrm{NO}_{2}$. These are provided at the tangent heights of the MIPAS measurements during the full resolution mission, i.e., from $68-6 \mathrm{~km}$ with a variable vertical spacing ranging from $3 \mathrm{~km}$ below $42 \mathrm{~km}$ to $8 \mathrm{~km}$ above $52 \mathrm{~km}$. A detailed validation analysis of the data acquired during the full resolution mission can be found in Cortesi et al. (2007). Briefly, the MIPAS profiles retrieved with the ESA operational processor (version 4.61 and 4.62) showed very good agreement with the correlative datasets in the middle and upper stratosphere, with relative differences within $\pm 10 \%$ in the altitude range between $\sim 20$ and $\sim 50 \mathrm{~km}$ (50-1 hPa). In the UT/LS, MIPAS profiles show a significant positive bias of +5 to $+25 \%$ with respect to the coincident observations (Cortesi et al., 2007).

Here, MIPAS operational ozone data version 4.62 (ESAv4.62) are compared with ACE-FTS. We found a total of 138 events at latitudes $70^{\circ}-80^{\circ} \mathrm{N}$, using coincidence criteria of $\pm 6 \mathrm{~h}$ and $300 \mathrm{~km}$. The time constraint was relaxed to $6 \mathrm{~h}$ (instead of the typical $2 \mathrm{~h}$ ) in order to increase the statistics of the comparison since it did not introduce notable biases in the atmospheric sampling. For MIPAS, only profiles associated with a successful pressure/temperature and target species retrievals have been considered. The results of the comparison are summarized in Fig. 17. Mean relative differences are within $\pm 10 \%$ between 11 and $41 \mathrm{~km}$, with a local maximum of about $+10 \%(+0.44 \mathrm{ppmv})$ at $30 \mathrm{~km}$. Between 35 and $48 \mathrm{~km}$, ACE-FTS reports increasingly larger ozone values, with a pronounced maximum around $48 \mathrm{~km}$ corresponding to mean relative differences of $+58 \%$ (about +1.4 ppmv). The amplitude of this peak is larger than the high altitude bias noted in other comparisons, but is limited to a narrower altitude range. The de-biased standard deviation of the mean relative differences is low $(<10 \%)$ between 17 and $25 \mathrm{~km}$ and increases above and below this range, but remains within $25 \%$ at all altitudes between 11 and $41 \mathrm{~km}$. As for most comparisons, the standard error of the mean is very small, showing that the observed biases are statistically significant.

Comparison of ACE-FTS with the reduced-resolution mission ESA data product

New measurement scenarios were adopted for the reduced resolution mission. These scenarios are characterized by a finer vertical limb scanning step of $1.5 \mathrm{~km}$ from $6-21 \mathrm{~km}$, $2 \mathrm{~km}$ from $21-31 \mathrm{~km}, 3 \mathrm{~km}$ from $31-46 \mathrm{~km}$ (i.e., equal to the instrument field-of-view) and $4 \mathrm{~km}$ above $46 \mathrm{~km}$. A detailed description of these measurement scenarios can be found in Ceccherini et al. (2006). Since the retrieval is performed at the tangent altitudes, the use of a limb scanning step smaller than the width of the instrument field-of-view

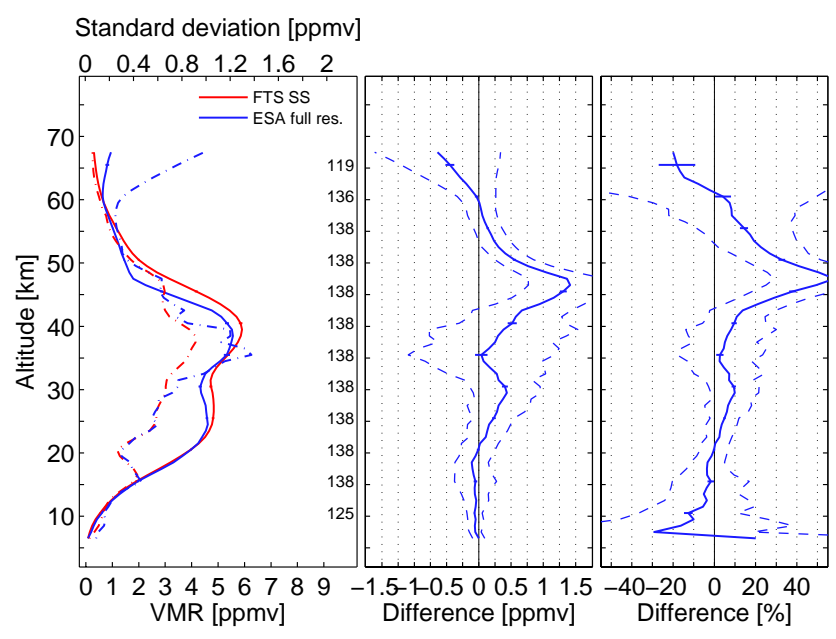

Fig. 17. Same as Fig. 7, but for the comparisons between ACEFTS and the MIPAS ozone product retrieved from the full resolution observations with the ESA operational processor v4.62.

introduces instabilities in the retrieval and requires a regularization to avoid oscillations in the retrieved profiles. For this reason, the ORM retrieval code was modified to implement a Tikhonov regularization scheme that is described in detail by Ceccherini et al. (2007). Furthermore, a new set of microwindows, optimised for the new measurement mode, was selected using the same algorithm as for the full resolution observations. In particular, a larger number of spectral points is considered, in order to compensate for the loss of information content caused by the reduced spectral resolution. Comparison of the results obtained for the full and reduced resolution measurements showed that the new algorithm yields improved spatial resolution (horizontal and vertical) and lower retrieval errors (Ceccherini et al., 2006). A first study of the quality of the MIPAS reduced resolution ozone profiles was reported by Ceccherini et al. (2008). In general, the quality of the ozone profile retrieved from reduced-resolution measurements is comparable or better than that obtained from the full-resolution dataset. The only significant change in MIPAS performance is found at altitudes around $40 \mathrm{~km}$, where a bias of approximately $3 \%$ is observed between full and reduced-resolution datasets.

For this comparison, we used $\pm 5^{\circ}$ and $\pm 10^{\circ}$ for the latitude and longitude criteria, respectively. Here also, the time criterion was relaxed to $\pm 6 \mathrm{~h}$ to increase the number of coincident pairs. A total of 160 coincidences was found. We used the MIPAS profiles retrieved with the ESA MIPAS Level 2 processor prototype (version ML2PP/5.0). These are a preliminary set of data that ESA generated for validation purposes. Figure 18 shows the results of the comparison. They are qualitatively consistent in the stratosphere with those from the full resolution observations. Mean relative differences are within $\pm 8 \%$ between 14 and $45 \mathrm{~km}$, with closest 


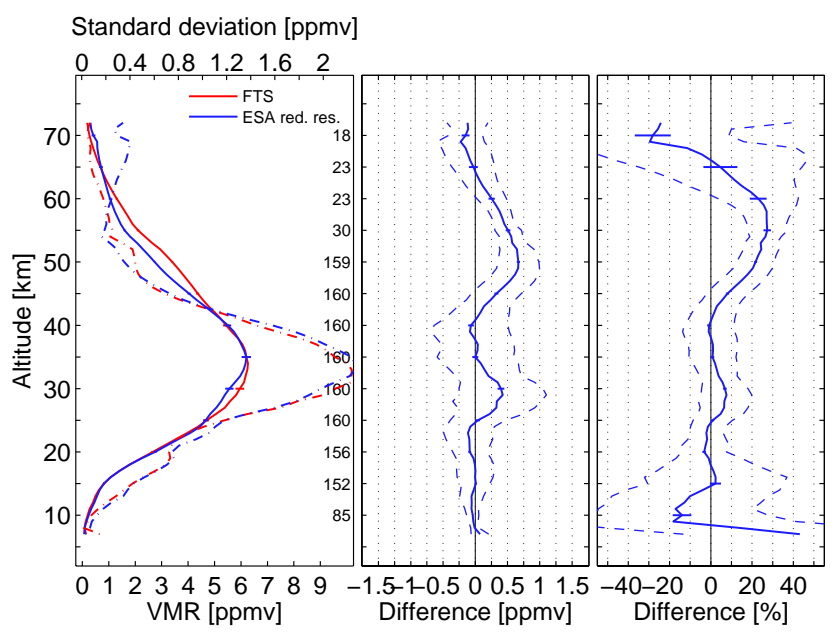

Fig. 18. Same as Fig. 7, but for the comparisons between ACE-FTS and the MIPAS ozone product retrieved from the reduced resolution observations with the ESA ML2PP/5.0 processor.

agreement around 20 and around $38 \mathrm{~km}( \pm 3 \%)$. Corresponding de-biased standard deviation values are within $12 \%$ in the range $20-58 \mathrm{~km}$ and increase subtantially above and below. At altitudes between 45 and $65 \mathrm{~km}$, the mean relative differences are larger, with a maximum of $+27 \%(55 \mathrm{~km})$. This is consistent with the comparisons with other satellite sensors.

\section{Comparison of ACE-FTS with the IMK-IAA scientific processor}

The IMK-IAA retrieval scheme (von Clarmann et al., 2003, and references therein) is a scientific processor complementary to ESA's near-real-time analysis. It is based on regularized inversion using a first-order Tikhonov-type smoothing constraint (von Clarmann et al., 2003) and optionally includes non-LTE calculations, implemented at the IAA, to analyse cases (specific molecular species and/or altitude levels) where the LTE assumption is not verified. Ozone retrievals use a set of 10 microwindows within the spectral ranges $740-800 \mathrm{~cm}^{-1}$ and $1060-1110 \mathrm{~cm}^{-1}$ where non-LTE emissions are mostly negligible (Glatthor et al., 2006). The retrieved profiles are provided on a vertical grid with finer spacing than the tangent height distances: $1 \mathrm{~km}$ up to $44 \mathrm{~km}$ and $2 \mathrm{~km}$ from 44 to $70 \mathrm{~km}$ (von Clarmann et al., 2003). For the analysis presented here, the current IMK-IAA ozone data product (V3O_O3_7) is used for the full spectral resolution observation period. This product was compared by Steck et al. (2007) with ground-based instruments, ozonesondes and observations from HALOE and POAM III. They found relative differences within $\pm 10 \%$ in the stratosphere, with a precision of $5-10 \%$ and an accuracy of $15-20 \%$. Below $18 \mathrm{~km}$, the precision was reduced to $20 \%$ or more (Steck et al., 2007).
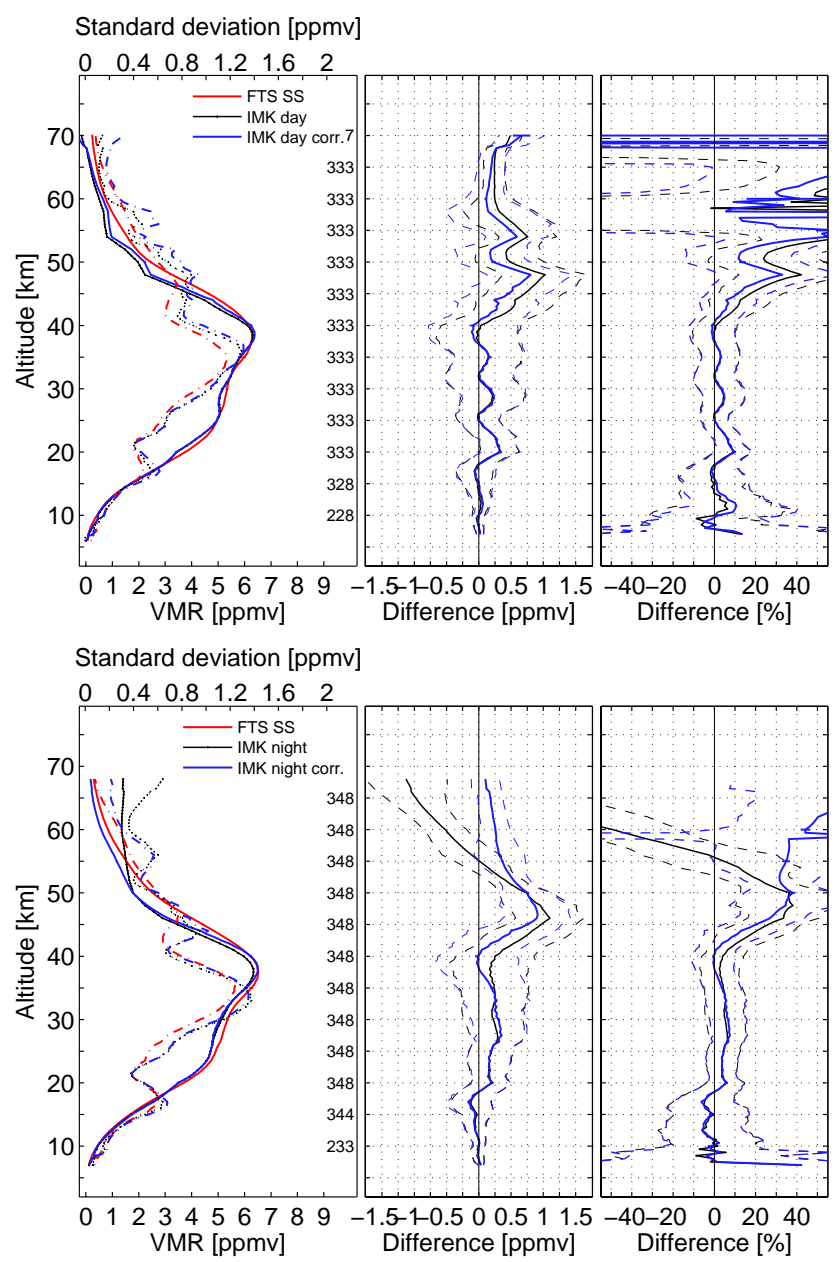

Fig. 19. Mean profiles and differences for the comparisons between ACE-FTS and the MIPAS ozone product retrieved from the full resolution observations with the IMK-IAA processor. Results are shown for MIPAS daytime (top panel) and nighttime (bottom panel) observations. In each panel: Left: Mean VMR profiles are shown for the ACE-FTS (red solid line), IMK-IAA original retrievals (black solid line) and IMK-IAA retrievals using the photochemical correction from KASIMA (blue solid line, see text). Middle: Mean absolute difference profiles (ACE-FTS-IMK-IAA) in ppmv for the IMK-IAA original retrievals (black) and the retrievals corrected with KASIMA (blue), with corresponding de-biased standard deviations (dashed line), and standard error (uncertainty) of the mean reported as error bars. Right: Mean relative differences in percent (solid line) shown as $2 \times($ ACE-FTS-IMK-IAA)/(ACEFTS+IMK-IAA), de-biased standard deviations of the mean relative differences (dashed line), and standard error (uncertainty) of the mean (error bars) for comparisons with the IMK-IAA original retrievals (black) and the retrievals corrected with KASIMA (blue).

Using criteria of $\pm 9 \mathrm{~h}$ and $800 \mathrm{~km}$, we found a total of 333 (348) coincidences between ACE-FTS and the daytime (nighttime) measurements from MIPAS. The results of the comparisons are shown in Fig. 19, for daytime (top panel) 
and nighttime (bottom panel) MIPAS profiles. To take into account diurnal variations in the ozone abundance, the retrieved MIPAS data were corrected using the KArlsruhe SImulation model of the Middle Atmosphere (KASIMA) chemistry and transport model (Kouker et al., 1999). Mean relative differences between ACE-FTS and the MIPAS data are within $\pm 8 \%$ from 12 to $43 \mathrm{~km}$ in both the KASIMAcorrected and uncorrected cases, with the ACE-FTS VMRs generally larger than those of MIPAS. The de-biased standard deviation of the mean relative differences is smaller than $15 \%$ in this range for both daytime and nighttime observations and smaller than $10 \%$ above $18 \mathrm{~km}$, with slightly better results for the nighttime MIPAS measurements (up to $8 \%$ ). When compared with the precision estimates of the MIPAS IMK-IAA product (previous paragraph), this seems to indicate, as mentioned previously, that the ACE-FTS random errors are small. This is also consistent with the results for the ESA retrievals from the full and reduced resolution data products. Above $40 \mathrm{~km}$, the KASIMA correction generally improves the comparison. Overall, the mean relative differences become larger with increasing altitude, with values of about $+40 \%(+0.9 \mathrm{ppmv})$ at $48 \mathrm{~km}$. For daytime MIPAS measurements, a sharp decrease of the mean absolute differences can be noted around $52 \mathrm{~km}$. The daytime mean relative differences at these altitudes are more affected by outliers but show a generally better agreement than the nighttime comparisons.

\subsubsection{Envisat/SCIAMACHY}

SCIAMACHY is a limb- and nadir-viewing imaging spectrometer, also capable of occultation measurements. It uses eight channels in the UV, visible and near-IR spectral range from 240 to $2380 \mathrm{~nm}$, with a moderate resolution of $0.2-$ $1.5 \mathrm{~nm}$ (Bovensmann et al., 1999). Number density profiles of several atmospheric species (such as $\mathrm{O}_{3}, \mathrm{NO}_{2}, \mathrm{BrO}$, $\mathrm{OClO}$ ), as well as polar stratospheric clouds and noctilucent clouds, are routinely retrieved from the limb measurements from the surface to $\sim 92 \mathrm{~km}$ with a vertical spacing of $3.3 \mathrm{~km}$ (e.g., Brinksma et al., 2006).

The retrievals of stratospheric ozone density profiles in the $15-40 \mathrm{~km}$ altitude range from SCIAMACHY limb scattering measurements, used in this study, are the scientific retrievals done at the Institute of Environmental Physics (IUP, Bremen, Germany). They use version 1.63 of the Stratozone retrieval code (von Savigny et al., 2005a). Stratozone employs limb radiance profiles at three discrete visible wavelengths $(525 \mathrm{~nm}, 600 \mathrm{~nm}, 675 \mathrm{~nm})$ and exploits the differential absorption signature of ozone between the center and the wings of the Chappuis absorption band. A nonlinear iterative Optimal Estimation scheme drives the radiative transfer model SCIARAYS (Kaiser and Burrows, 2003), which is used as the forward model.

As the SCIAMACHY limb tangent heights are affected by errors of up to $2.5 \mathrm{~km}$ (von Savigny et al., 2005b), in this study we used tangent height retrievals using the Tangent height Retrieval by UV-B Exploitation (TRUE) algorithm (Kaiser et al., 2004) version 1.7 to correct the tangent heights prior to the $\mathrm{O}_{3}$ profile retrieval. TRUE version 1.7 uses pressure and temperature data from the European Center for Medium-range Weather Forecast (ECMWF) for the location, date and time of each limb measurement. The ozone profile information required for the tangent height retrieval is taken from the dynamic ozone climatology of Lamsal et al. (2004), providing ozone profiles as a function of total ozone columns for five latitude regimes, in combination with total ozone column measurements from the Earth Probe - Total Ozone Mapping Spectrometer (EP-TOMS, http://toms.gsfc.nasa.gov/index_v8.html) for the location and date of each SCIAMACHY limb measurement. The tangent height offsets derived for tropical latitudes, where TRUE provides the most accurate results, are applied to all limb measurements in the corresponding orbit. The mean tangent height offset for 2004 is about $-1.5 \mathrm{~km}$. Previous SCIAMACHY IUP ozone profiles (version 1.6) have been validated extensively with lidars, ozonesondes, MWRs and SAGE II and SAGE III data (Brinksma et al., 2006). Results showed that the SCIAMACHY-IUP v1.62 data product is biased low between 16 and $40 \mathrm{~km}$, by a few percent (3$6 \%$ with a standard deviation of $\sim 10 \%$ ). In this analysis, we use version 1.63 of the IUP ozone number density profiles for SCIAMACHY. The difference between versions 1.62 and 1.63 is the improved pointing correction provided by TRUE version 1.7 algorithm.

The criteria chosen for the ACE-FTS and SCIAMACHY comparisons are a maximum difference of $\pm 6 \mathrm{~h}$ and a maximum distance of $500 \mathrm{~km}$. This gives a total of 734 coincidences between March and December of 2004, with more than $75 \%$ occurring in the Arctic polar region in the latitude range $60^{\circ}-82^{\circ} \mathrm{N}$, out of which $90 \%$ or more of the SCIAMACHY events are measured at high solar zenith angle $\left(70^{\circ}-85^{\circ}\right)$. The overall results are shown in Fig. 20. The vertical range was limited to $17-41 \mathrm{~km}$, since the retrieval below and above this range is dominated by the a priori and there is no information from the measurement. Over the full altitude range, the mean relative differences are within $\pm 4 \%$ (with de-biased standard deviations, within 8 to $16 \%$, consistent with previous validation results for SCIAMACHY IUP v1.62 data), except around $30 \mathrm{~km}$ where ACE-FTS reports larger ozone values than those of SCIAMACHY by up to $+15 \%$. This large bias around $30 \mathrm{~km}$ is noted in the highsolar zenith angle SCIAMACHY observations, mostly in the Arctic (564 events), but is not seen in other regions. It is still present in the most recent version of the SCIAMACHY ozone data product (v2.0, currently in development), but its amplitude is significantly reduced $(<10 \%)$ in comparisons with HALOE and SAGE II. The source of this bias is still unclear. 


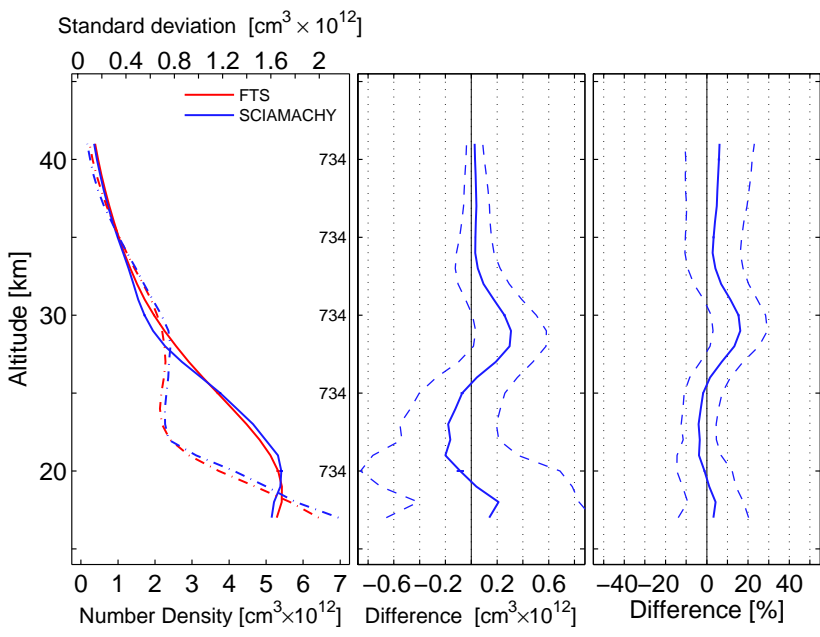

Fig. 20. Same as Fig. 7, but for the comparisons in number density between ACE-FTS and the SCIAMACHY IUP v1.63 ozone data product.

\subsection{Aura-MLS}

The Aura satellite (Schoeberl et al., 2006) was launched in July 2004 in a sun-synchronous, quasi-polar orbit, with an altitude of $\sim 700 \mathrm{~km}$, an inclination of $98^{\circ}$ and ascending node crossing at 13:45 (local time). MLS aboard Aura scans the Earth's limb to measure thermal emission at millimeter and submillimeter wavelengths, using seven radiometers designed to cover five broad spectral regions from $118 \mathrm{GHz}$ to $2.5 \mathrm{THz}$. The Aura-MLS instrument, calibration and performance for the different channels are described by Jarnot et al. (2006), Cofield and Stek (2006) and Pickett (2006). The orbit geometry provides global coverage from $82^{\circ} \mathrm{S}$ to $82^{\circ} \mathrm{N}$ each day. 240 vertical scans are performed during each orbit, allowing the retrieval of $\sim 3500$ profiles per day for 17 primary atmospheric parameters: pressure, temperature and cloud ice water content, as well as 14 trace constituents such as $\mathrm{O}_{3}$, $\mathrm{H}_{2} \mathrm{O}$ and $\mathrm{CO}$. An overview of the instrument and observation characteristics, main spectral lines and target species can be found in Waters et al. (2006).

The retrieval scheme is based on the Optimal Estimation Method (Rodgers, 2000). Taking advantage of the forwardlooking geometry of the instrument with respect to the spacecraft, the innovative approach of the Aura-MLS retrievals resides in the combination of $\sim 5-10$ subsequent scans to retrieve atmospheric parameters on a two-dimensional grid, in the vertical direction and along the line-of-sight. This retrieval approach is detailed by Livesey et al. (2006). The vertical retrieval is provided on a standard pressure grid with 6 pressure surfaces per decade change in stratospheric pressure, and 3 levels per decade for pressures smaller than $0.1 \mathrm{hPa}$. The corresponding vertical resolution is $3-5 \mathrm{~km}$. The ozone volume mixing ratio is retrieved from the observations of the radiometer centered at $240 \mathrm{GHz}$.
The Aura-MLS ozone version 1.5 dataset was compared with numerous correlative datasets (including SAGE II, HALOE, POAM III and the previous data version (v2.1) of ACE-FTS $\mathrm{O}_{3}$ ) in the early validation study of Froidevaux et al. (2006) and with Odin/SMR (Bordeaux version 222 processor) by Barret et al. (2006). An overall agreement of 5$10 \%$ was found throughout the stratosphere, with Aura-MLS biased high in the lower stratosphere but low in the upper stratosphere. Extensive validation of the Aura-MLS version 2.2 (hereinafter v2.2) ozone product, with a limited time coverage, showed better results than version 1.5 with respect to the correlative datasets, with an agreement of $5-8 \%$ in the stratosphere (Froidevaux et al., 2008; Boyd et al., 2007; Jiang et al., 2007). Estimated precision is about $5 \%$ or better between 100 and $3 \mathrm{hPa}$.

The comparisons presented here extend the analyses of Froidevaux et al. (2008) to the full Aura-MLS v2.2 dataset processed (as of May 2007) and include comparisons with ACE-MAESTRO. At the time of the analysis, coincidences were available on 465 dates, with very few in 2004 (19) and the remainder evenly distributed in the other years. A total of 3180 coincidences was found using the coincidence criteria: $\pm 2 \mathrm{~h}, \pm 5^{\circ}$ in latitude and $\pm 10^{\circ}$ in longitude. We used the recommended parameters for screening the Aura-MLS data: quality value $>0.4$, positive precision, even values of the status flag, and convergence $<1.8$ (Froidevaux et al., 2008). We also limited the vertical range of the comparisons to the altitudes $\sim 10-65 \mathrm{~km}$ as recommended for Aura-MLS and ACEMAESTRO. For the comparison, the Aura-MLS vertical profiles were interpolated in $\log$ (pressure) onto the ACE-FTS pressure levels and subsequently reported on the ACE-FTS or ACE-MAESTRO altitude grid.

The results of the comparisons for ACE-FTS are shown in Fig. 21. ACE-FTS reports consistently more ozone than Aura-MLS over the comparison range. Between $12 \mathrm{~km}$ and $43 \mathrm{~km}(\sim 2 \mathrm{hPa})$, the mean relative differences are within 0 to $+10 \%$ and often smaller than $+4 \%$. Above $43 \mathrm{~km}$ and below $\sim 60 \mathrm{~km}$, they are within +10 to $+25 \%$, with the maximum value found at $53 \mathrm{~km}(\sim 0.6 \mathrm{hPa})$. This is consistent with the findings of Froidevaux et al. (2008) and with the other comparisons presented in this paper. The de-biased standard deviation of the mean relative differences is within $25 \%$ in the full altitude range and smaller than $12 \%$ between 24 and $48 \mathrm{~km}$.

The results for ACE-MAESTRO are presented in Fig. 22, recalling what was found for SABER. The ACE-MAESTRO SR profiles show larger VMRs than Aura-MLS in the range $21-57 \mathrm{~km}$, with mean relative differences within +2 to $+15 \%$ ( $+6 \%$ on average), in closest agreement with the Aura-MLS data around $38 \mathrm{~km}(\sim+2 \%)$. Above and below this range, the SR retrievals report VMR values increasingly smaller than those of Aura-MLS, with mean relative differences down to about $-50 \%$ at the limits of the comparison range. In the case of the ACE-MAESTRO SS events, the mean relative differences increase with increasing altitude, with values 


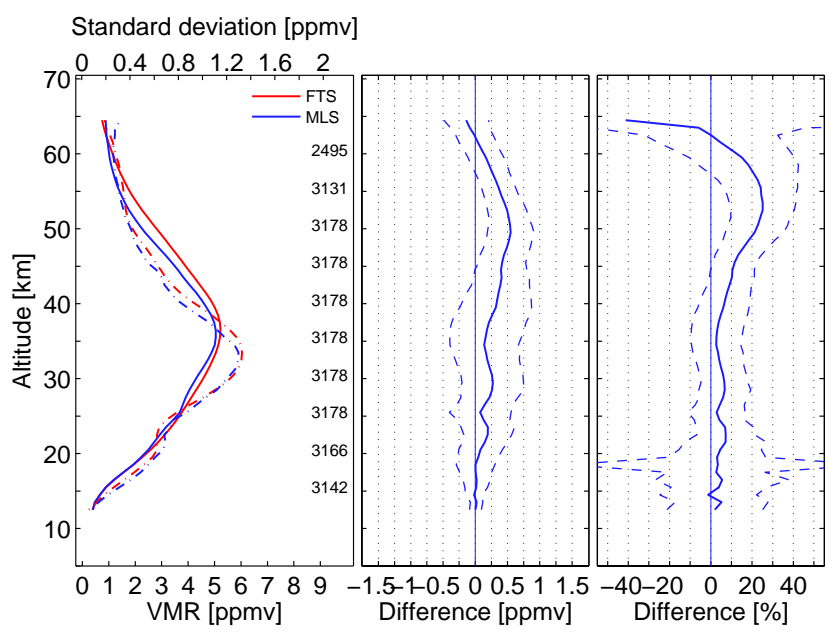

Fig. 21. Same as Fig. 7, but for the comparisons between ACE-FTS and Aura-MLS.

ranging from $-10 \%$ at $15 \mathrm{~km}(\sim 120 \mathrm{hPa})$ to a maximum of $+21 \%$ at $52 \mathrm{~km}(\sim 0.7 \mathrm{hPa})$, similar to that found for the ACE-FTS comparisons. For both SR and SS comparisons the de-biased standard deviation of the mean relative differences is within 10 to $25 \%$ between 19 and $\sim 45 \mathrm{~km}$, generally larger than what was found for ACE-FTS, suggesting again a poorer precision of the ACE-MAESTRO observations. Note that the standard deviation of the mean VMR profiles shows significant discrepancies for both SR and SS events.

\section{Comparisons with airborne, balloon-borne and ground-based instruments}

\subsection{Aircraft measurements from ASUR}

ASUR is a microwave receiver operating in a tunable frequency range between 604.3 and $662.3 \mathrm{GHz}$ (von Koenig et al., 2000). It measures atmospheric emission from various trace gas molecules including $\mathrm{O}_{3}, \mathrm{~N}_{2} \mathrm{O}, \mathrm{HNO}_{3}$ and $\mathrm{ClO}$. Stratospheric measurements performed with the AcoustoOptical Spectrometer (AOS) are used in this intercomparison exercise. The total bandwidth of the AOS is $1.5 \mathrm{GHz}$ and its resolution is $1.27 \mathrm{MHz}$. The heterodyne sensor is operated on board a high-flying research plane to avoid strong absorption signals from tropospheric water vapor. The instrument looks upwards at a stabilized constant zenith angle of $78^{\circ}$. Measured spectra are integrated during up to $80 \mathrm{~s}$, which leads to a horizontal resolution of about $18 \mathrm{~km}$ along the flight path. Vertical abundance profiles are retrieved on a $2 \mathrm{~km}$-spacing altitude grid using the Optimal Estimation Method (Rodgers, 2000). Vertical resolution of the ozone measurements is about $6-18 \mathrm{~km}$, and the vertical range is $16-$ $50 \mathrm{~km}$. The precision of a single measurement is $0.1 \mathrm{ppmv}$ ( 3 to $8 \%$ depending on the altitude) and the accuracy (includ-

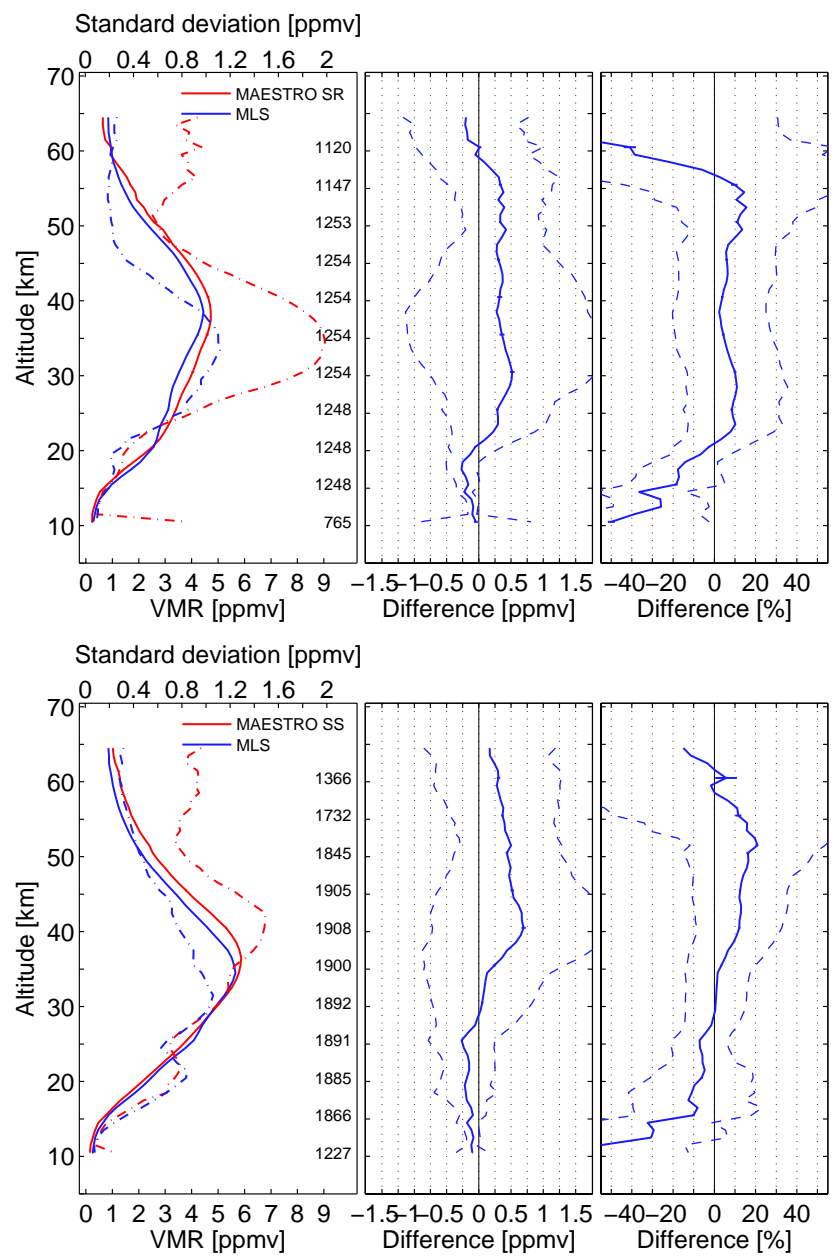

Fig. 22. Same as Fig. 1, but for the comparisons between ACE-MAESTRO and Aura-MLS. Top: comparison with ACEMAESTRO SR observations; bottom: comparison with ACEMAESTRO SS observations.

ing systematic uncertainties) is $15 \%$ or 0.3 ppmv, whichever is greater. Details about the measurement technique and retrieval theory can be found in Kuttippurath et al. (2007).

The ASUR ozone measurements used in this study were performed aboard the NASA DC-8 aircraft during the Polar Aura Validation Experiment (PAVE) (http://www.espo.nasa. gov/ave-polar/). These were compared with ACE-FTS and ACE-MAESTRO using coincidence criteria of $\pm 12 \mathrm{~h}$ and $1000 \mathrm{~km}$. This resulted in a total of 39 (37) coincident ASUR measurements with ACE-FTS (ACE-MAESTRO), from 5 flights out of Portsmouth (New Hampshire, USA) reaching northern high latitudes $\left(\sim 65^{\circ} \mathrm{N}\right)$ on 24,29 and 31 January and 2 and 7 February 2005. The corresponding ACE-FTS and ACE-MAESTRO occultations were obtained exclusively at sunrise. The ACE-FTS and ACE-MAESTRO VMR profiles were convolved with the ASUR averaging kernels to account for the lower vertical resolution of the ASUR profiles. 


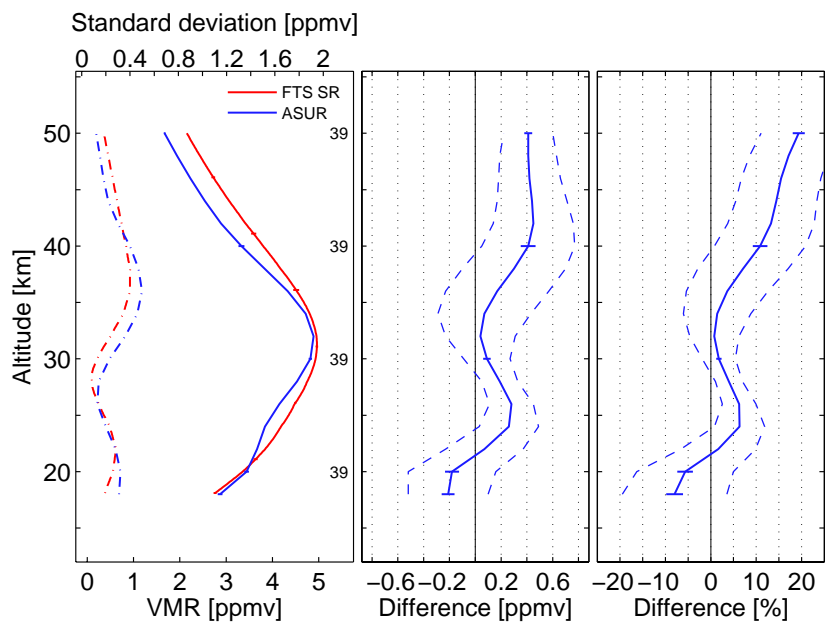

Fig. 23. Same as Fig. 1, but for the comparisons between ACE-FTS and ASUR. Mean relative differences are here expressed as (ACEFTS-ASUR)/ACE-FTS [\%]. All coincident ACE measurements were SR occultations.

Figure 23 shows the results from the comparison between ACE-FTS and ASUR. The mean relative differences are within $\pm 19 \%$ ( $0.45 \mathrm{ppmv})$ over the full altitude range and smaller than $\pm 8 \%$ between 18 and $38 \mathrm{~km}$, with consistently positive values above $22 \mathrm{~km}$. Below $22 \mathrm{~km}$, the ACE-FTS VMRs are slightly smaller than the ASUR values, down to $-8 \%(-0.2 \mathrm{ppmv})$. The de-biased standard deviation of the mean relative differences is smaller than $11 \%$ over the full altitude range ( $<7 \%$ in the range $22-32 \mathrm{~km}$ ). The agreement between the datasets is best around the peak in ozone VMR (mean relative difference of $0.8 \%$ at $32 \mathrm{~km}$ ).

The results from the comparison between ACEMAESTRO and ASUR are presented in Fig. 24. The mean relative differences are within $\pm 16 \%$ ( 0.33 ppmv) at all altitudes and within $\pm 3 \%$ from $22-38 \mathrm{~km}$, with a corresponding de-biased standard deviation of 6 to $13 \%$ $(<10 \%$ in the range $22-32 \mathrm{~km}$ ), again slightly larger than for ACE-FTS.

\subsection{Balloon-borne observations from FIRS-2}

The Far-InfraRed Spectrometer (FIRS)-2 is a remote-sensing FTIR spectrometer designed and built at the Smithsonian Astrophysical Observatory. It measures thermal emission from the atmosphere in the wavelength range $8-120 \mu \mathrm{m}(\sim 80$ $700 \mathrm{~cm}^{-1}$ ), with a spectral resolution of $0.004 \mathrm{~cm}^{-1}$ (Johnson et al., 1995). The balloon-borne observations are performed in the limb-sounding geometry. To analyse the data, first, the atmospheric pressure and temperature profiles are retrieved using the $15 \mu \mathrm{m}$ band of $\mathrm{CO}_{2}$. Then, vertical profiles of about 30 trace constituents are retrieved from the float altitude (typically $38 \mathrm{~km}$ ) down to the tropopause, using a nonlinear Levenberg-Marquardt least-squares algo-

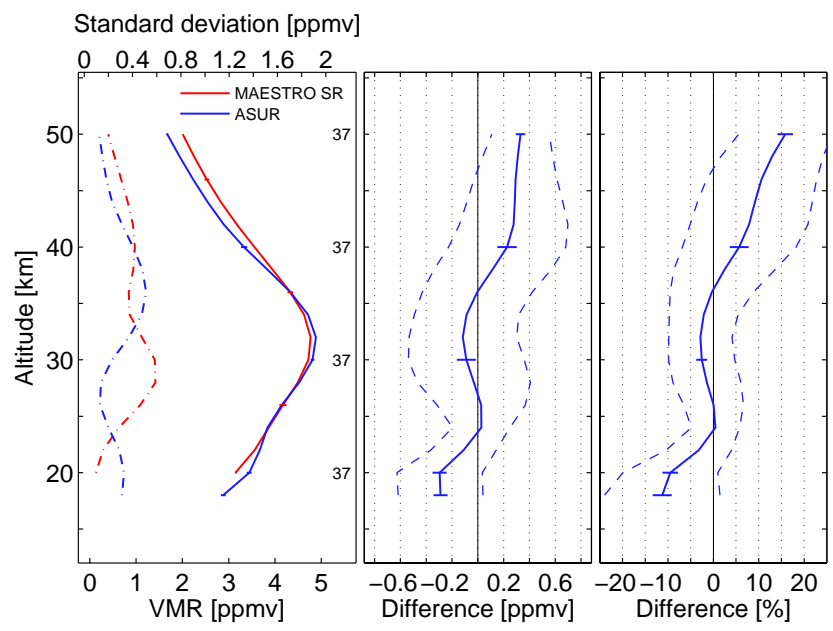

Fig. 24. Same as Fig. 1, but for the comparisons between ACEMAESTRO and ASUR. Mean relative differences are here expressed as (ACE-MAESTRO-ASUR)/ACE-MAESTRO [\%]. All coincident ACE measurements were SR occultations.

rithm (Johnson et al., 1995). Uncertainty estimates for FIRS2 contain random retrieval error from spectral noise and systematic components from errors in atmospheric temperature and pointing angle (Jucks et al., 2002; Johnson et al., 1995). In the case of the $\mathrm{O}_{3}$ profile used in this analysis, the total error is $10-20 \%$ below $20 \mathrm{~km}$ and $5-8 \%$ above. Balloon flights of FIRS-2 have been used to validate observations from the Improved Limb Atmospheric Spectrometer (ILAS) on board the Japanese Advanced Earth Observing Satellite (ADEOS) (e.g., Nakajima et al., 2002) as well as from the MLS, HALOE and the Cryogenic Limb Array Emission Spectometer (CLAES) instruments aboard UARS (Jucks et al., 2002, and references therein). Results from FIRS-2 were also compared more recently with Aura-MLS observations (Canty et al., 2006).

We compared a FIRS-2 observation acquired on 24 January $2007\left(\sim 68^{\circ} \mathrm{N}, \sim 22^{\circ} \mathrm{E}\right)$ with the ACE-FTS and ACE-MAESTRO profiles from the SR occultation sr18561 $\left(64.7^{\circ} \mathrm{N}, 15.0^{\circ} \mathrm{E}\right.$, distance: $\left.\sim 481 \mathrm{~km}\right)$ measured on $23 \mathrm{Jan}-$ uary 2007 at 08:25 UT (Fig. 25). Scaled (Dunkerton and Delisi, 1986; Manney et al., 1994) PV values for the times and locations of the measurements indicate that both ACE and FIRS-2 measured airmasses inside the polar vortex. Since the FIRS-2 data is reported on a $1 \mathrm{~km}$-spacing altitude grid, we simply interpolated the FIRS-2 profile onto the altitude grids of ACE-FTS $(1 \mathrm{~km})$ and ACE-MAESTRO $(0.5 \mathrm{~km})$. For this particular observation, the float altitude of the balloon carrying FIRS-2 was lower than usual, setting the upper limit of the vertical range of the comparison at $31 \mathrm{~km}$. The relative differences between the $\mathrm{O}_{3}$ profiles from ACE-FTS and FIRS-2 are within $\pm 15 \%$ over the vertical range $13-30 \mathrm{~km}$. ACE-FTS generally reports larger VMR 


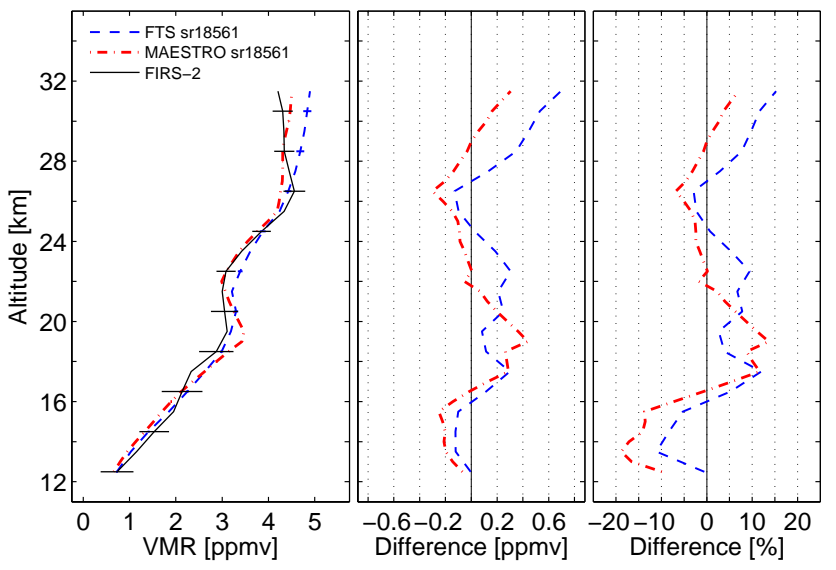

Fig. 25. Comparison of a profile from FIRS-2 on 24 January 2007 at 10:11 UT with profiles from ACE-FTS and ACE-MAESTRO SR occultation sr18561 obtained on 23 January 2007 at 08:25 UT. Left: Measured VMR profiles from FIRS-2 (solid black), ACE-FTS (dashed blue) and ACE-MAESTRO (dot-dashed red). Error bars show uncertainty estimate for FIRS-2 (see text). Middle: Absolute differences in ppmv for ACE-FTS-FIRS-2 (dashed blue) and ACE-MAESTRO-FIRS-2 (dot-dashed red). Right: Relative differences $2 \times(\mathrm{ACE}-\mathrm{FIRS}-2) /(\mathrm{ACE}+\mathrm{FIRS}-2)$ in percent shown for comparison with ACE-FTS (dashed blue) and ACE-MAESTRO (dotdashed red).

values than those of FIRS-2 above $16 \mathrm{~km}$, except around $26 \mathrm{~km}$. The comparisons with ACE-MAESTRO yield similar results, with relative differences within $\pm 15 \%$ at altitudes between 16 and $31 \mathrm{~km}$ but down to $-20 \%$ at lower altitudes.

\subsection{SAOZ-balloon measurements in the tropics}

The Système d'Analyse par Observation Zénitale (SAOZ) sonde is a light-weight UV-visible diode array spectrometer measuring the atmospheric absorption of sunlight during the ascent of the balloon and during a sunset occultation from float altitude (Pommereau and Piquard, 1994). Spectral analysis is performed using the Differential Optical Absorption Spectroscopy (DOAS) technique which uses least-squares fitting of the spectra with laboratory cross-sections. Ozone is measured in the Chappuis band (visible spectral range at $450-620 \mathrm{~nm}$ ) where the absorption cross-section is not sensitive to temperature. The profiles are retrieved in the altitude range $10-28 \mathrm{~km}$ with a vertical resolution of $1.4 \mathrm{~km}$, using the onion peeling method within $1 \mathrm{~km}$-thick atmospheric shells. Data contaminated by clouds are removed by looking at the atmospheric extinction at $615 \mathrm{~nm}$. For $\mathrm{O}_{3}$, the estimated precision is $1.5 \%$ at $20 \mathrm{~km}$, degrading to $5 \%$ at $17.5 \mathrm{~km}, 10 \%$ at $15 \mathrm{~km}$ and $23 \%$ at $10 \mathrm{~km}$. Accuracy is evaluated by adding a systematic error of $1.5 \%$ (uncertainty from the ozone absorption cross-sections) to the precision values. The SAOZ ozone profiles have been compared to a number of satellite and sonde observations and were found to be very

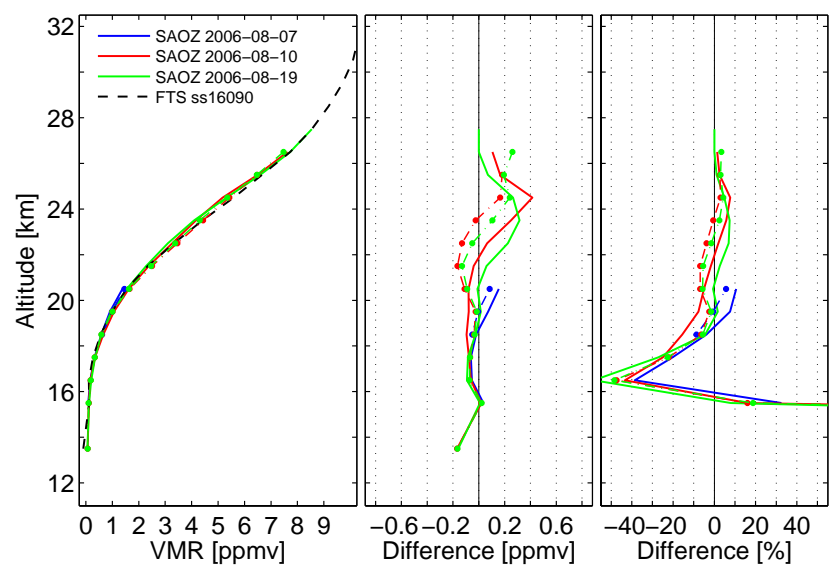

Fig. 26. Comparison of an ACE-FTS profile (ss16090, 8 August 2006 at 17:40 UT) with results from three spatially coincident SAOZ flights (7, 10 and 19 August 2006). Left: the ACEFTS profile is shown in dashed black. SAOZ profiles obtained during ascent (solid lines) and during SS occultation (dotted curves) on 7, 10, and 19 August 2006 are shown in blue, red and green, respectively. Middle: Absolute differences for ACE-FTS-SAOZ (in ppmv) are shown using the same colour scheme as left panel. Right: Relative differences (in percent) are given as $2 \times(\mathrm{ACE}-$ $\mathrm{SAOZ}) /(\mathrm{ACE}+\mathrm{SAOZ})$ using the same colour scheme as left and middle panels.

consistent with the most accurate data available (Lumpe et al., 2003; Haley et al., 2004; Borchi and Pommereau, 2007).

The three SAOZ flights used in this study were part of the African Monsoon Multidisciplinary Analysis (AMMA) balloon campaign (Redelsperger et al., 2006) undertaken within the framework of the Stratospheric-Climate Links with Emphasis on the Upper Troposphere and Lower Stratosphere (SCOUT-O3) European project (http://www.ozone-sec.ch. cam.ac.uk/scout_o3/). They occured in August 2006 in Niamey, Niger $\left(13.48^{\circ} \mathrm{N}, 2.16^{\circ} \mathrm{E}\right)$ during the wet season. The first flight $\left(\sim 13.8^{\circ} \mathrm{N}, \sim 0.8^{\circ} \mathrm{E}\right.$ on 7 August 2006) reached a float altitude of $22 \mathrm{~km}$, while the other two $\left(\sim 14.0^{\circ} \mathrm{N}\right.$, $\sim 0.0^{\circ} \mathrm{E}$ on 10 August 2006 and $\sim 13.9^{\circ} \mathrm{N}, \sim 0.0^{\circ} \mathrm{E}$ on 19 August 2006) reached $28 \mathrm{~km}$. The measurements (ascent and occultation) occured for all three flights around 18:00 UT. The six resulting profiles ( 3 for ascent and 3 occultation profiles at float altitude) are compared with the spatially coincident ACE profiles from SS occultation ss16090 (8 August 2006 at 17:40 UT). Since the vertical resolution of the SAOZ balloon instrument is comparable to that of the ACE instruments, the SAOZ profiles were simply interpolated onto the vertical grids of ACE-FTS $(1 \mathrm{~km})$ and ACE-MAESTRO $(0.5 \mathrm{~km})$.

The results for ACE-FTS are presented in Fig. 26. Relative differences are within $\pm 10 \%$ ( $<0.4 \mathrm{ppmv}$ ) above $19 \mathrm{~km}$ for all ascent (solid lines) and occultation (dotted lines) SAOZ profiles. Below $19 \mathrm{~km}$ the relative differences increase, with 


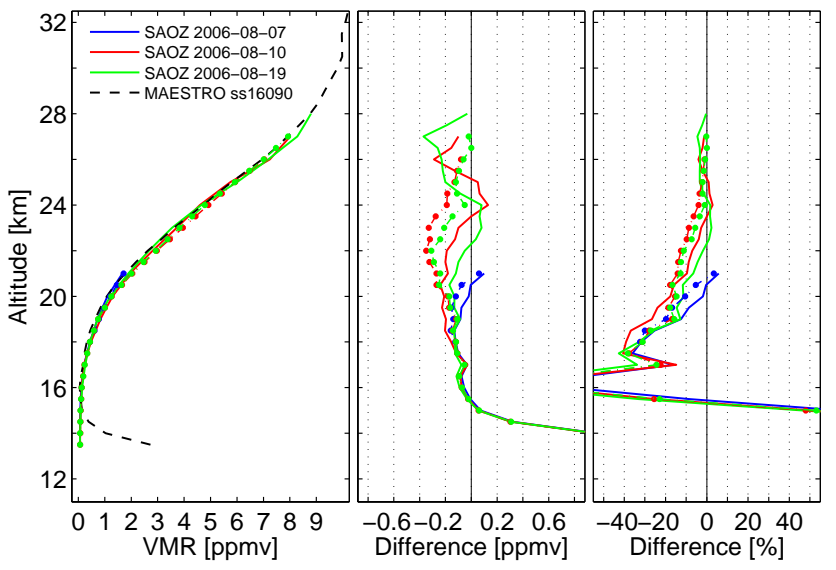

Fig. 27. Same as Fig. 26 but for ACE-MAESTRO and SAOZ.

maximum values between -40 and $-60 \%$ at $16 \mathrm{~km}$ for all SAOZ profiles. Figure 27 shows the comparison for ACEMAESTRO. The ACE-MAESTRO and the SAOZ profiles are in good agreement, with relative differences within -15 to $+5 \%$ above $19 \mathrm{~km}$. As was found for ACE-FTS, ACEMAESTRO reports significantly less ozone than SAOZ in the range $15-19 \mathrm{~km}$, with maximum relative differences larger than $-70 \%$. Below $16 \mathrm{~km}$, the ACE-MAESTRO VMRs are considerably larger than those of SAOZ. The large differences noted for ACE-FTS as well as for ACE-MAESTRO below $\sim 18 \mathrm{~km}$ may be explained by the fact that the SAOZ measurements used in this study were deliberately performed in the vicinity of high altitude (up to $18 \mathrm{~km}$ ) convective clouds. Because the effects of these clouds can be highly localized, it is possible that the ozone field at the lowest altitudes measured by SAOZ and ACE could be quite different.

\subsection{Balloon-borne SPIRALE observations}

The SPectroscopie Infra-Rouge d'Absorption par Lasers Embarqués (SPIRALE) instrument is operated from a balloon-borne gondola by the Laboratoire de Physique et Chimie de l'Environnement (LPCE, Orléans, France) and is routinely used at all latitudes, in particular as part of European validation campaigns for the Odin and Envisat missions. The six tunable diode laser absorption spectrometer (TDLAS) has been previously described in detail (Moreau et al., 2005). In brief, it can perform simultaneous in situ measurements of about ten chemical species over the vertical range $10-35 \mathrm{~km}$. The high frequency sampling $(\sim 1 \mathrm{~Hz})$ yields a vertical resolution of a few meters, depending on the ascent rate of the balloon. The diode lasers emit at midIR wavelengths (3-8 $\mu \mathrm{m})$ and the beams are injected into a multipass Heriott cell, located under the gondola and largely exposed to ambient air. The cell ( $3.5 \mathrm{~m}$ long) is deployed during ascent when the pressure is lower than $300 \mathrm{hPa}$. The multiple reflections obtained between the two cell mirrors

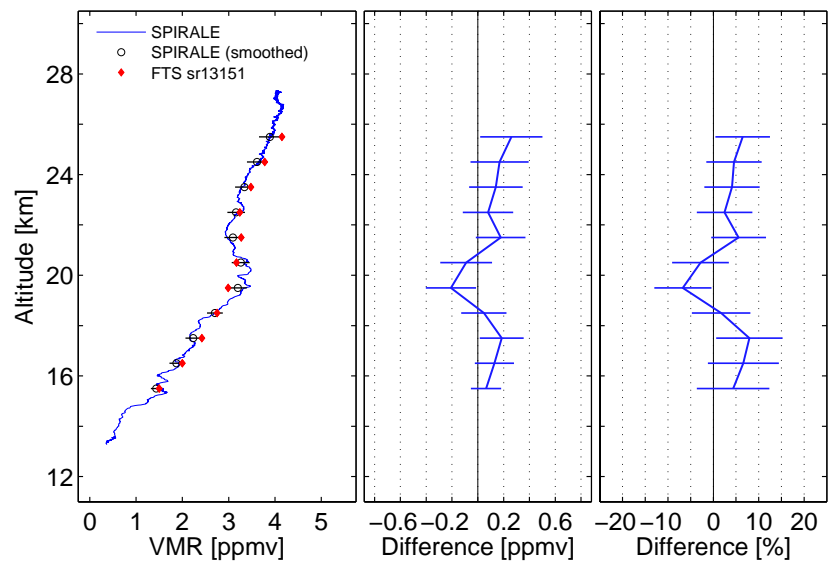

Fig. 28. SPIRALE profile measured on 20 January 2007 compared with ACE-FTS profile obtained from SR occultation sr13151 on 21 January 2007 at 08:00 UT. Left: VMR profiles from ACE-FTS (red diamonds) and SPIRALE (solid blue line) are shown along with the smoothed SPIRALE profile (black circles, see text). Uncertainties in the SPIRALE profiles are reported as error bars. Middle: Absolute differences in ppmv, expressed as (ACE-FTS-SPIRALE(smoothed)), with combined random errors given as error bars. Right: Relative differences in percent given as $2 \times($ ACE-FTS-SPIRALE(smoothed))/(ACEFTS+SPIRALE(smoothed)), with combined random errors given as error bars.

give a total optical path of $430.78 \mathrm{~m}$. Species concentrations are retrieved from direct IR absorption, by fitting experimental spectra with spectra calculated using the HITRAN 2004 database (Rothman et al., 2005). Specifically, the rovibrational lines at 2086.0191 and $2086.4294 \mathrm{~cm}^{-1}$ were used for the SPIRALE $\mathrm{O}_{3}$ retrievals. Simultaneous measurements of pressure and temperature onboard the gondola allow the number densities to be converted to VMRs. Estimates of the uncertainties in the SPIRALE measurements were detailed by Moreau et al. (2005). Total root-sum-square uncertainties are about $6 \%$ above $18 \mathrm{~km}(<80 \mathrm{hPa})$ and $8 \%$ below ( $>80 \mathrm{hPa})$.

For this study, we compared a SPIRALE profile (obtained during ascent) from 20 January 2006 (17:34-19:47 UT) with the coincident ACE-FTS and ACE-MAESTRO profiles from the SR occultation sr13151. The SPIRALE $\mathrm{O}_{3}$ vertical range was $10.8-27.3 \mathrm{~km}$. The balloon position remained rather constant around a mean location of $67.6 \pm 0.2^{\circ} \mathrm{N}$ and $21.6 \pm 0.2^{\circ} \mathrm{E}$. The ACE occultation occurred $13 \mathrm{~h}$ later (on 21 January 2006 at 08:00 UT) and was located at $64.28^{\circ} \mathrm{N}-$ $21.56^{\circ} \mathrm{E}$ at a distance of $413 \mathrm{~km}$ from the SPIRALE mean position. Potential vorticity (PV) maps were calculated with the Modélisation Isentrope du transport Méso-échelle de l'Ozone Stratosphérique par Advection (MIMOSA) contour advection model (Hauchecorne et al., 2002). They confirmed that SPIRALE and ACE sounded similar air masses in the 


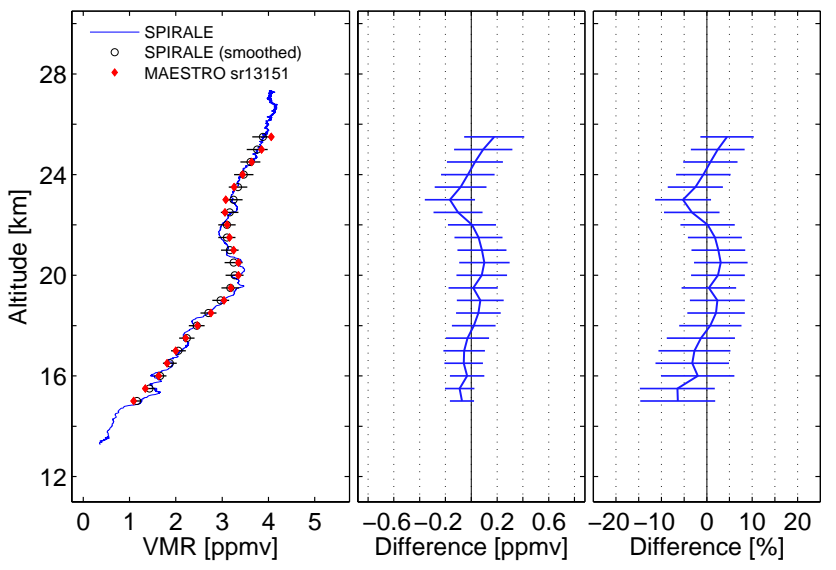

Fig. 29. Same as Fig. 28, but for comparison of ACE-MAESTRO and SPIRALE coincident profiles.

well established polar vortex at this time, for the whole range of altitudes, with PV differences of less than $10 \%$.

Since the vertical resolution for SPIRALE is of the order of meters, we smoothed the SPIRALE data using triangular or Gaussian convolution functions as described in Sect. 4. The ACE-FTS (Fig. 28) and ACE-MAESTRO (Fig. 29) $\mathrm{O}_{3}$ profiles are in good agreement with the SPIRALE profile between 15 and $25 \mathrm{~km}$, where the relative differences remain within the error bars of the comparison.

\subsection{Ozonesonde measurements}

Ozonesondes are balloon-borne instruments launched (typically) weekly from various stations around the globe. They perform in situ measurements of pressure, temperature, humidity and $\mathrm{O}_{3}$ abundances from the surface to the balloon's burst altitude (typically $\sim 35 \mathrm{~km}$ ) with a resolution of 100 $150 \mathrm{~m}$. There are three types of ozonesondes currently in operation: the Electrochemical Concentration Cell (ECC) (Komhyr et al., 1995), Brewer-Mast (BM) (Brewer and Milford, 1960) and Carbon-Iodine (CI) (Kobayashi and Toyama, 1966) ozonesondes. The accuracy of ozonesonde observations is generally estimated to be 5\% (e.g., SPARC, 1998) but in fact depends on numerous parameters (for instance, for ECC ozonesondes, the concentration of the sensing solution or the manufacturer influence the accuracy). Depending on the type of ozonesonde and the altitude, typical values for the precision and accuracy are $\sim 3-8 \%$ and $\sim 5-15 \%$, respectively, up to $30 \mathrm{~km}$ (see Smit et al., 2007, and references therein).

For the statistical comparison of ACE-FTS and ACEMAESTRO with ozonesonde observations, we used measurements from the World Ozone and Ultraviolet Data Center (WOUDC), the Southern Hemisphere ADditional OZonesonde (SHADOZ) archive and the 2004 INTEX Ozonesonde Network Study (IONS) campaign (see Table 2

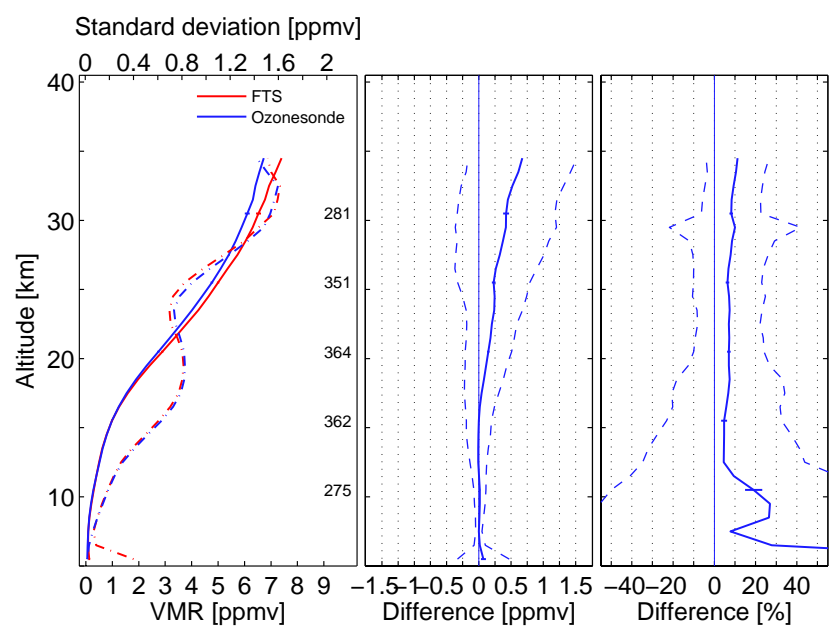

Fig. 30. Results of statistical comparisons of ACE-FTS and ozonesonde profiles. Left: Mean VMR profiles from ACE-FTS (solid red) and ozonesondes (solid blue) are shown along with the $1-\sigma$ standard deviation of the mean (dot-dashed lines). The standard error (uncertainty) of the mean is reported as error bars on the VMR profiles. The number of coincident pairs is given every $5 \mathrm{~km}$. Middle: Mean absolute differences (ACE-FTS-ozonesonde) in ppmv (solid line), with corresponding de-biased standard deviations (dashed line) and standard error (uncertainty) of the mean shown as error bars every $5 \mathrm{~km}$. Right: Mean relative differences in percent (solid line) shown as (ACE-FTS-ozonesonde)/(ozonesonde), debiased standard deviations of the mean relative differences (dashed line), and standard error (uncertainty) of the mean (error bars).

for URLs and references). We defined coincidence criteria of $\pm 24 \mathrm{~h}$ and $800 \mathrm{~km}$. Table 2 lists the stations for which coincidences were found. Because of their high vertical resolution, the ozonesonde data were smoothed using the convolution functions described in Sect. 4. When several ACEFTS or ACE-MAESTRO profiles were coincident with the same ozonesonde measurement, they were averaged and the resulting mean profile was compared with the ozonesonde data (Randall et al., 2003). From the initial total of 547 coincidences, we compared 376 profiles.

Figure 30 shows the results for the comparison with ACEFTS. There is good agreement with the ozonesonde observations in the altitude range $11-35 \mathrm{~km}$. In this range, ACEFTS reports systematically larger VMRs than the ozonesondes, with mean relative differences within -1 to $+10 \%$ and corresponding de-biased standard deviations within 12 to $15 \%$ (17 to $30 \%$ ) above (below) $20 \mathrm{~km}$. Note that ACE-FTS and the ozonesondes sample airmasses with similar variability, as demonstrated by the standard deviations of the mean VMR profiles. Below $11 \mathrm{~km}$, the variability of the measured profiles is high (de-biased standard deviation of the mean relative differences of $40 \%$ and larger) and the mean relative differences increase significantly. Above $35 \mathrm{~km}$, the 
Table 2. List of the ozonesonde stations which provided data for the analyses, including location (column 2) and operating agency (column 3 ). The type of sensor used by each station is indicated in column 5. The source of the data used for these studies is indicated in column 6 . In column 1, normal font indicates the stations included only in the statistical comparisons (Sect. 6.5); bold font shows the stations used in the studies presented in Sects. 6.5 and 6.6; italicized font applies to stations used in the detailed NDACC study described in Sect. 6.6.

\begin{tabular}{|c|c|c|c|c|c|}
\hline Station & Coordinates & Agency & GAW ID & Type & Source \\
\hline Alert & $82.5^{\circ} \mathrm{N}, 62.3^{\circ} \mathrm{W}$ & MSC & CAN & ECC & WOUDC/MSC $^{\mathrm{a}}$ \\
\hline Eureka & $80.1^{\circ} \mathrm{N}, 86.4^{\circ} \mathrm{W}$ & MSC & CAN & ECC & WOUDC/MSC ${ }^{\mathrm{a}}$ \\
\hline Ny Ålesund & $78.9^{\circ} \mathrm{N}, 11.9^{\circ} \mathrm{E}$ & AWI & NOR & ECC & WOUDC/AWI ${ }^{\mathrm{a}}$ \\
\hline Thule & $76.5^{\circ} \mathrm{N}, 68.7^{\circ} \mathrm{W}$ & DMI & GRL & $\mathrm{ECC}$ & $\mathrm{DMI}^{\mathrm{a}}$ \\
\hline Resolute & $74.7^{\circ} \mathrm{N}, 95.0^{\circ} \mathrm{W}$ & MSC & CAN & ECC & WOUDC/MSC $^{\mathrm{a}}$ \\
\hline Summit & $72.60^{\circ} \mathrm{N}, 38.50^{\circ} \mathrm{W}$ & NOAA-CMDL & GRL & ECC & NDACC \\
\hline Scoresbysund & $70.5^{\circ} \mathrm{N}, 22.0^{\circ} \mathrm{W}$ & DMI & DNK & ECC & $\mathrm{DMI}^{\mathrm{a}}$ \\
\hline Sodankylä & $67.37^{\circ} \mathrm{N}, 26.67^{\circ} \mathrm{E}$ & FMI & FIN & ECC & NDACC \\
\hline Keflavik & $63.97^{\circ} \mathrm{N}, 22.60^{\circ} \mathrm{E}$ & INTA & ISL & ECC & NDACC \\
\hline Orlandet & $63.42^{\circ} \mathrm{N}, 9.24^{\circ} \mathrm{E}$ & NILU & NOR & ECC & NDACC \\
\hline Jokioinen & $60.82^{\circ} \mathrm{N}, 23.48^{\circ} \mathrm{E}$ & FMI & FIN & ECC & NDACC \\
\hline Churchill & $58.8^{\circ} \mathrm{N}, 94.7^{\circ} \mathrm{W}$ & MSC & CAN & ECC & NDACC \\
\hline Edmonton & $53.6^{\circ} \mathrm{N}, 114.1^{\circ} \mathrm{W}$ & MSC & CAN & ECC & WOUDC/MSC ${ }^{\mathrm{a}}$ \\
\hline Goose Bay & $53.3^{\circ} \mathrm{N}, 60.4^{\circ} \mathrm{E}$ & MSC & CAN & ECC & WOUDC/MSC $^{\mathrm{a}}$ \\
\hline Legionowo & $52.4^{\circ} \mathrm{N}, 21.0^{\circ} \mathrm{E}$ & PIMWM & POL & ECC & WOUDC \\
\hline Lindenberg & $52.2^{\circ} \mathrm{N}, 14.1^{\circ} \mathrm{E}$ & DWD & DEU & ECC & WOUDC \\
\hline Vanscoy & $52.1^{\circ} \mathrm{N}, 107.2^{\circ} \mathrm{W}$ & MSC & CAN & ECC & WOUDC \\
\hline Debilt & $52.1^{\circ} \mathrm{N}, 5.1^{\circ} \mathrm{E}$ & KNMI & NLD & ECC & WOUDC \\
\hline Uccle & $50.8^{\circ} \mathrm{N}, 4.4^{\circ} \mathrm{E}$ & RMI & BEL & ECC & WOUDC \\
\hline Bratts Lake (Regina) & $50.2^{\circ} \mathrm{N}, 104.7^{\circ} \mathrm{W}$ & MSC & CAN & ECC & $\mathrm{IONS}^{\mathrm{b}}$ \\
\hline Prague & $50.0^{\circ} \mathrm{N}, 14.5^{\circ} \mathrm{E}$ & CHMI & CZE & ECC & WOUDC \\
\hline Kelowna & $49.9^{\circ} \mathrm{N}, 119.4^{\circ} \mathrm{W}$ & MSC & CAN & ECC & IONS $S^{b}$ \\
\hline Hohenpeißenberg & $47.8^{\circ} \mathrm{N}, 11.0^{\circ} \mathrm{E}$ & DWD & DEU & B.-M. & WOUDC \\
\hline Payerne & $46.5^{\circ} \mathrm{N}, 6.6^{\circ} \mathrm{E}$ & MeteoSwiss & CHE & $\mathrm{ECC}$ & WOUDC \\
\hline Egbert & $44.2^{\circ} \mathrm{N}, 79.8^{\circ} \mathrm{W}$ & MSC & CAN & $\mathrm{ECC}$ & $\mathrm{IONS}^{\mathrm{b}} /$ WOUDC \\
\hline Sable Island & $44.0^{\circ} \mathrm{N}, 60.0^{\circ} \mathrm{W}$ & MSC & CAN & ECC & $\mathrm{IONS}^{\mathrm{b}}$ \\
\hline Haute-Provence & $43.94^{\circ} \mathrm{N}, 5.71^{\circ} \mathrm{E}$ & CNRS & FRA & ECC & NDACC \\
\hline Yarmouth & $43.9^{\circ} \mathrm{N}, 66.1^{\circ} \mathrm{W}$ & MSC & CAN & $\mathrm{ECC}$ & IONS $^{\mathrm{b}}$ \\
\hline Sapporo & $43.1^{\circ} \mathrm{N}, 141.3^{\circ} \mathrm{E}$ & JMA & JPN & C.-I. & WOUDC \\
\hline Madrid & $40.8^{\circ} \mathrm{N}, 12.2^{\circ} \mathrm{W}$ & INME & ESP & ECC & WOUDC \\
\hline Boulder & $40.03^{\circ} \mathrm{N}, 105.25^{\circ} \mathrm{W}$ & NOAA-CMDL & USA & ECC & $\mathrm{IONS}^{\mathrm{b}} / \mathrm{NDACC}$ \\
\hline Trinidad Head & $40.5^{\circ} \mathrm{N}, 3.7^{\circ} \mathrm{W}$ & NOAA-CMDL & USA & $\mathrm{ECC}$ & $\mathrm{IONS}^{\mathrm{b}}$ \\
\hline Wallops Island & $37.9^{\circ} \mathrm{N}, 75.5^{\circ} \mathrm{W}$ & NASA-WFF & USA & ECC & $\mathrm{IONS}^{\mathrm{b}}$ \\
\hline Tateno (Tsukuba) & $36.1^{\circ} \mathrm{N}, 140.1^{\circ} \mathrm{E}$ & JMA & JPN & C.-I. & WOUDC \\
\hline Isfahan & $32.5^{\circ} \mathrm{N}, 51.4^{\circ} \mathrm{E}$ & MDI & IRN & ECC & WOUDC \\
\hline Honk Kong Obs. & $22.3^{\circ} \mathrm{N}, 114.2^{\circ} \mathrm{E}$ & HKO & HKG & ECC & WOUDC \\
\hline Paramaribo & $5.8^{\circ} \mathrm{N}, 55.2^{\circ} \mathrm{W}$ & KNMI & SUR & ECC & SHADOZ \\
\hline Nairobi & $1.3^{\circ} \mathrm{S}, 36.8^{\circ} \mathrm{E}$ & MeteoSwiss & KEN & ECC & SHADOZ $^{\mathrm{c}}$ \\
\hline Malindi & $3^{\circ} \mathrm{S}, 40.2^{\circ} \mathrm{E}$ & CRPSM & KEN & ECC & SHADOZ $^{\mathrm{c}}$ \\
\hline Maxaranguape (Natal) & $5.4^{\circ} \mathrm{S}, 35.4^{\circ} \mathrm{W}$ & INPE & BRA & ECC & SHADOZ $^{\mathrm{c}}$ \\
\hline American Samoa & $14.3^{\circ} \mathrm{S}, 170.6^{\circ} \mathrm{W}$ & NOAA-CMDL & ASM & ECC & SHADOZ $^{\mathrm{c}}$ \\
\hline Irene & $25.9^{\circ} \mathrm{S}, 28.2^{\circ} \mathrm{E}$ & SAWS & ZAF & ECC & $\mathrm{SHADOZ}^{\mathrm{c}}$ \\
\hline Lauder & $45.0^{\circ} \mathrm{S}, 169.7^{\circ} \mathrm{E}$ & NIWA & NZL & ECC & WOUDC/NIWA $^{\mathrm{a}}$ \\
\hline Marambio & $64.2^{\circ} \mathrm{S}, 56.7^{\circ} \mathrm{W}$ & FMI & ATA & ECC & WOUDC \\
\hline Dumont d'Urville & $66.67^{\circ} \mathrm{S}, 140.01^{\circ} \mathrm{E}$ & CNRS & ATA & ECC & NDACC \\
\hline Davis & $68.6^{\circ} \mathrm{S}, 78.0^{\circ} \mathrm{E}$ & $\mathrm{ABM}$ & ATA & ECC & WOUDC/AAD ${ }^{\mathrm{a}}$ \\
\hline Syowa & $69^{\circ} \mathrm{S}, 39.6^{\circ} \mathrm{E}$ & JMA & JPN & C.-I. & WOUDC \\
\hline Neumayer & $70.7^{\circ} \mathrm{S}, 8.3^{\circ} \mathrm{W}$ & AWI & ATA & ECC & WOUDC/AWI $^{\mathrm{a}}$ \\
\hline McMurdo & $77.85^{\circ} \mathrm{S}, 166.67^{\circ} \mathrm{E}$ & UWYO & ATA & ECC & NDACC \\
\hline Belgrano & $77.87^{\circ} \mathrm{S}, 34.63^{\circ} \mathrm{W}$ & INTA & ATA & ECC & NDACC \\
\hline
\end{tabular}

a Data obtained from the WOUDC database (http://www.woudc.org/). In the case of missing data (e.g., in 2006), the corresponding results were provided directly by the station P.I.

b Summer 2004 sounding was part of the IONS protocol optimized for Aura validation (Thompson et al., 2007b,c); data available at http: //croc.gsfc.nasa.gov/intex/ions.html.

c Data acquired from the SHADOZ archive (http://croc.gsfc.nasa.gov/shadoz/; Thompson et al., 2003a,b, 2007a). 


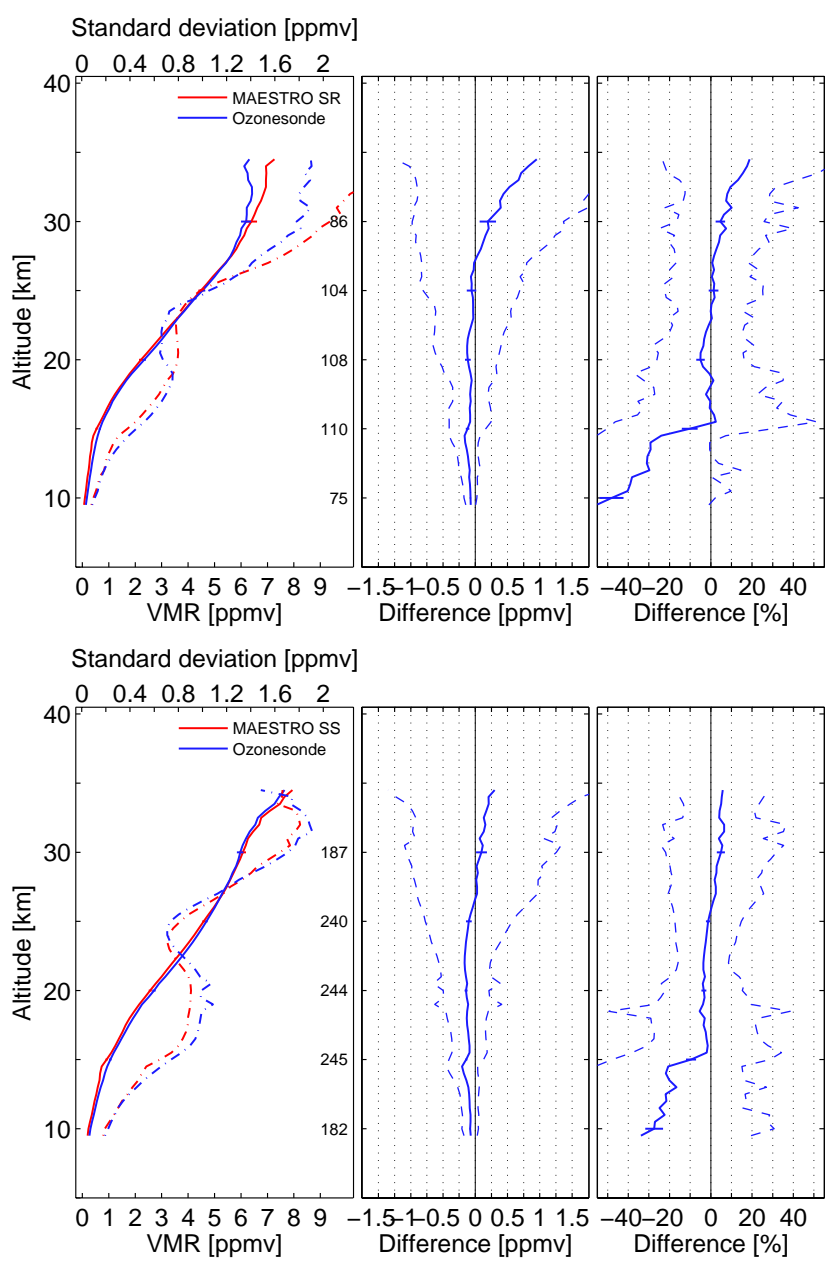

Fig. 31. Same as Fig. 30, but for statistical comparisons between ACE-MAESTRO and ozonesondes. Top (bottom) panel shows comparisons for ACE-MAESTRO SR (SS) occultations.

number of coincident events drops sharply and the statistical significance of the results is limited, therefore these results are not shown.

Comparison results for ACE-MAESTRO are shown in Fig. 31 for the SR (top panel) and SS (bottom panel) events. Overall, the mean relative differences are within $\pm 5 \%$ from $16-30 \mathrm{~km}$, increasing above and below this altitude range, with corresponding de-biased standard deviation within 12 to $30 \%$ and 15 to $40 \%$ for the SR and for the SS comparisons, respectively. Using a rather limited sample, Kar et al. (2007) had earlier shown a small bias (of about $+5 \%$ ) between the ACE-MAESTRO SR and SS retrievals in the altitude range $20-30 \mathrm{~km}$, when compared with the ozonesondes, with larger mean relative differences for the ACE-MAESTRO SR events. This bias is not seen for this larger sample of coincidences. The mean relative differences are larger below $15 \mathrm{~km}$ and reach $-20 \%(\mathrm{SS})$ and $-40 \%(\mathrm{SR})$ at the lowest altitudes, with ACE-MAESTRO reporting consistently lower
Table 3. Name, location and operating agency for the lidar stations which provided data for the detailed NDACC analyses (Sect. 6.6).

\begin{tabular}{lcc}
\hline Station & Coordinates & Agency \\
\hline Eureka & $80.05^{\circ} \mathrm{N}, 86.42^{\circ} \mathrm{W}$ & MSC \\
Ny-Ålesund & $78.91^{\circ} \mathrm{N}, 11.88^{\circ} \mathrm{E}$ & AWI \\
Andoya & $69.28^{\circ} \mathrm{N}, 16.02^{\circ} \mathrm{E}$ & NILU \\
Hohenpeißenberg & $47.8^{\circ} \mathrm{N}, 11.02^{\circ} \mathrm{E}$ & DWD \\
Haute-Provence & $43.94^{\circ} \mathrm{N}, 5.71^{\circ} \mathrm{E}$ & CNRS \\
\hline
\end{tabular}

VMRs than the ozonesondes, while the de-biased standard deviation at these altitudes exceeds $35 \%$.

The bias and de-biased standard deviation values found here are compatible with the second study including ozonesonde data (following section) for both ACE instruments.

\subsection{NDACC ozonesonde and lidar measurements}

Detailed comparisons were performed for individual sites with two types of ozone profiling instruments, ozonesondes and lidars. These are operated within the framework of the Network for the Detection of Atmospheric Composition Change (NDACC, formerly the Network for the Detection of Stratospheric Change or NDSC), a major component of the World Meteorological Organization's Global Atmosphere Watch program (WMO-GAW). The ozonesonde measurements have been described in the previous section. DIfferential Absorption Lidar (DIAL) systems provide the vertical distribution of night-time ozone number density at altitudes between $\sim 10 \mathrm{~km}$ and $\sim 45 \mathrm{~km}$, with a vertical resolution of $300 \mathrm{~m}$ to $3 \mathrm{~km}$, depending on the altitude. Typical values for lidar accuracies are 3-7\% between 15 and $40 \mathrm{~km}$. At $40 \mathrm{~km}$ and above, due to the rapid decrease in signal-tonoise ratio, the errors increase and a significant bias of up to 10\% may appear (Godin et al., 1999; Keckhut et al., 2004).

Coincidence criteria of $\pm 12 \mathrm{~h}$ and $500 \mathrm{~km}$ were used to select available data from a total of 31 ozonesonde stations (Table 2) and 5 lidar stations (Table 3). Figure 32 shows the time and latitude coverage of all coincidences stored in the database used for this study. However, to ensure a minimum statistical significance of the comparison results at all stations, only those for which at least three coincidences were found with the ACE instruments were included in the analyses. Therefore, stations visible in Fig. 32 but for which there were less than three coincident observations are not listed in Tables 2 and 3.

The analyses were conducted in three steps. First, the individual coincident events were examined to check the quality of the retrieved profiles. Then, time series for the ACE and the ground-based measurements and their relative differences were analyzed. This allowed time periods to be identified 


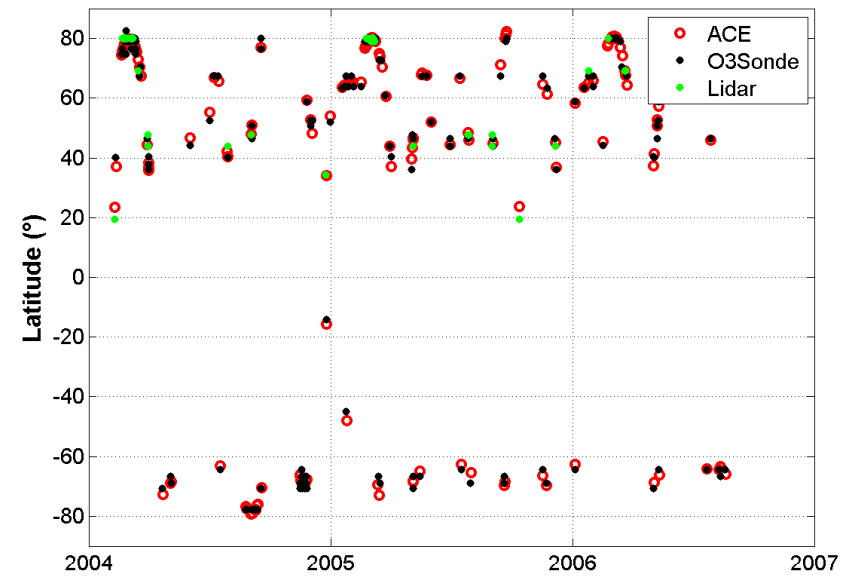

Fig. 32. Time and latitude coverage of the collocations between ACE and the NDACC ground-based ozone instruments for coincidence criteria of $\pm 12 \mathrm{~h}$ and $500 \mathrm{~km}$. Note, not all collocations noted here were used in the calculations (see text).

in which homogeneous results, and hence meaningful statistics, could be obtained. Finally, the vertical structure of the differences was investigated within these homogeneous time periods, by grouping the stations where similar results were found. The second and third steps will be described below. The integration methodology applied in smoothing the high-resolution ozonesonde and lidar profiles is described in Sect. 4.

In the detailed analysis of the time series, mean relative differences between the ACE-FTS profiles and the groundbased data were within $\pm 10 \%$, in the altitude ranges 10 $30 \mathrm{~km}$ for the ozonesondes and $15-42 \mathrm{~km}$ for the lidars. For ACE-MAESTRO, the mean relative differences with ozonesondes were mostly negative, with values of about $-10 \%$ in the altitude range $15-30 \mathrm{~km}$ and down to $-16 \%$ below. When compared to lidars, ACE-MAESTRO also reported lower ozone VMRs (mean relative difference of about $-7 \%$ ) in the range $15-37 \mathrm{~km}$, whilst larger negative values (down to $-18 \%$ ) were found below $15 \mathrm{~km}$, and positive mean relative differences $(\sim+8 \%)$ were found in the range $37-$ $41 \mathrm{~km}$. This analysis showed that the temporal variations of the ozone layer are well captured by ACE-FTS and ACEMAESTRO, but that the limited temporal sampling does not allow finer-scale variations to be revealed. Within the stratosphere, no important structure or seasonal variation was identified in the time series which allowed us to derive meaningful statistics for the ACE-FTS and ACE-MAESTRO ozone data products by combining the three years of the comparison period.

We also investigated the height-resolved statistical differences over the full comparison time period for each station. An example of these relative difference profiles is shown in Fig. 33 for the coincidences between ACE-FTS

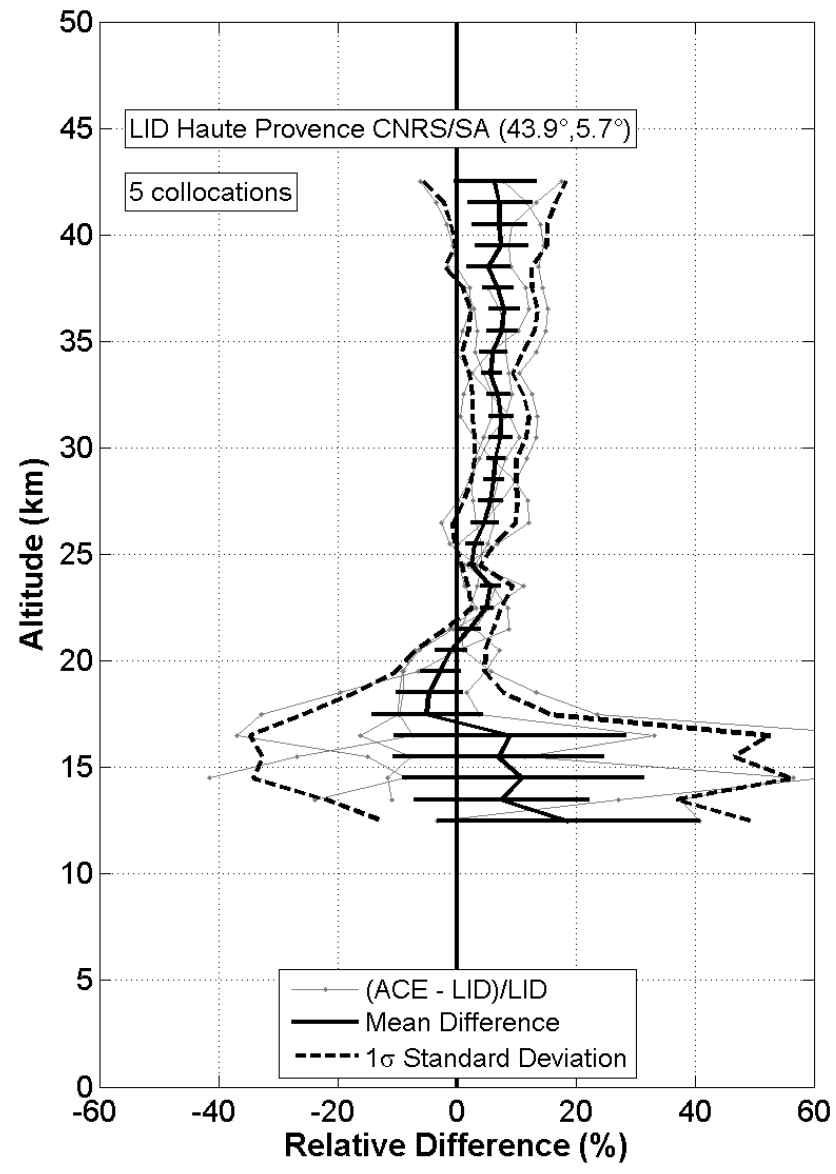

Fig. 33. Relative differences for each pair of coincident ACEFTS and Haute-Provence lidar measurements plotted versus altitude (grey lines). Corresponding mean (solid black line) and 1- $\sigma$ de-biased standard deviation (dashed line). The standard error - or uncertainty - of the mean is shown as horizontal error bars on the mean relative difference profile.

and lidar measurements at the Haute-Provence station. Figure 34 shows a similar example for ACE-MAESTRO and the ozonesonde data obtained at Eureka. The overall comparison results are summarized as zonally averaged (within $5^{\circ}$ bins) distributions shown in Figs. 35 and 36 for ACEFTS and ACE-MAESTRO, respectively. Figure 35 shows the mean relative differences between ACE-FTS and NDACC ozonesondes (top panel) and lidars (bottom panel), while the results for ACE-MAESTRO are summarized in Fig. 36. Figures 35 and 36 also illustrate the good consistency of the ACE data with respect to latitude, since there is no systematic meridional bias in the mean relative differences.

For the ACE-FTS and ozonesonde comparisons, the mean relative differences were within $\pm 7 \%$ in the range $10-35 \mathrm{~km}$ and larger below this range. For the comparisons with lidars, the mean relative differences were within $\pm 10 \%$ in the range $10-45 \mathrm{~km}$. These values can be accounted for by 
known contributions to the systematic errors of the comparison, which indicates that ACE-FTS systematic errors are small. For the comparisons of ACE-MAESTRO retrievals with ozonesondes and lidar observations, the mean relative differences were globally negative, with an average value of about $-7 \%$ above $15 \mathrm{~km}$. Below this altitude, ACEMAESTRO reported significantly less ozone than either of the ground-based instruments, with mean relative difference values within -20 to $-40 \%$. The negative biases observed for ACE-MAESTRO cannot be accounted for by the contributions from known sources, but are indicative of a systematic underestimation of the ozone VMR by the instrument.

The de-biased standard deviations of the mean relative differences, for both ACE-FTS and ACE-MAESTRO, were lower than $10 \%$ in the stratosphere but much larger in the troposphere. This can be explained by the atmospheric variability and the different horizontal smoothing by the occultation and ground-based measurements, which means that the contribution from the ACE retrievals to the combined of random errors of the comparison is small. The different horizontal smoothing of the ozone field is an important contribution to the random error budget of the comparisons, since it can contribute to about $10 \%$ of the standard deviation of the differences in the middle and upper stratosphere and more at lower altitudes (Cortesi et al., 2007).

\subsection{Eureka DIAL measurements}

A DIAL instrument has been in operation at the Arctic Stratospheric Ozone (AStrO) Observatory/Polar Environmental Atmospheric Research Laboratory (PEARL) in Eureka $\left(80.05^{\circ} \mathrm{N}, 86.42^{\circ} \mathrm{W}\right)$ since 1993 . In February-March 2004, 2005 and 2006, it measured temperature and ozone profiles as part of the Canadian Arctic ACE Validation Campaigns (Kerzenmacher et al., 2005; Walker et al., 2005; Sung et al., 2007; Manney et al., 2008; Fraser et al., 2008; Fu et al., 2008; Sung et al., 2009). The measurements use radiation from a $\mathrm{XeCl}$ excimer laser at two wavelengths, one with a strong absorption signature of $\mathrm{O}_{3}$ (the "on" wavelength, $308 \mathrm{~nm}$ for the Eureka lidar) and one with little absorption (the "off" wavelength, hydrogen Raman-shifted to $353 \mathrm{~nm}$ at Eureka) (Donovan et al., 1995). A detailed description of the system is given by Carswell et al. (1991). The Eureka DIAL is operated exclusively at night and provides vertical profiles of ozone from the tropopause level to $\sim 45 \mathrm{~km}$ with a vertical resolution of $300 \mathrm{~m}$ and an estimated accuracy for ozone of 1-2\% (e.g., Bird et al., 1997).

Data from the Eureka DIAL measurements obtained during the 2004 Canadian Arctic ACE Validation Campaigns were used for validation of the previous release of the ACEFTS and ACE-MAESTRO data (Kerzenmacher et al., 2005). Comparisons of the DIAL temperature profiles with ACE observations can also be found in companion papers (e.g., Manney et al., 2008; Sica et al., 2008). We present the comparisons of DIAL $\mathrm{O}_{3}$ with ACE-FTS and ACE-MAESTRO.

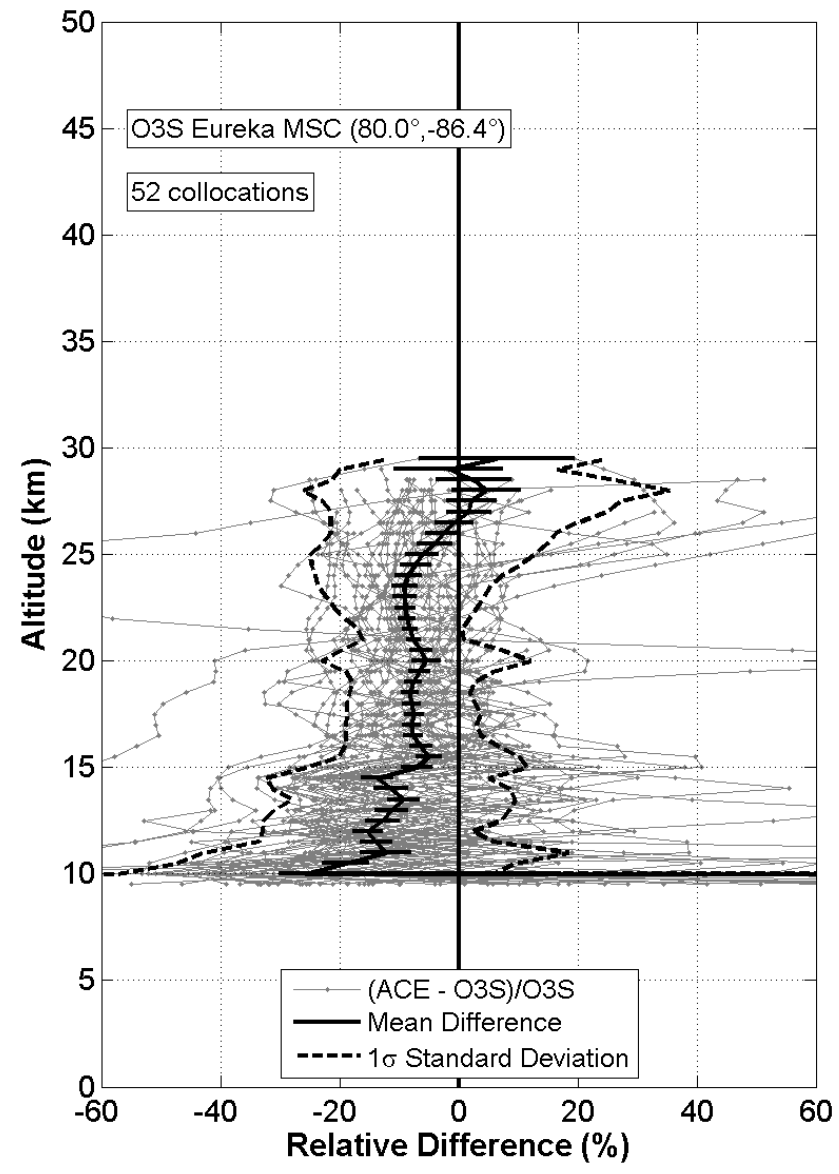

Fig. 34. Same as Fig. 33 but for comparison between ACEMAESTRO and ozonesonde measurements at Eureka.

We used coincidence criteria of $\pm 12 \mathrm{~h}$ and $500 \mathrm{~km}$, yielding 10 (8) coincidences for ACE-FTS (ACE-MAESTRO) for the 2004-2006 winters.

The results are presented in Fig. 37 for ACE-FTS and Fig. 38 for ACE-MAESTRO. The mean relative differences between the lidar measurements and the ACE-FTS profiles are within -10 to $+3 \%$ (on average $-7 \%$ and down to -0.8 ppmv) between 15 and $34 \mathrm{~km}$. The corresponding debiased standard deviation is within $10 \%$ between 21 and $31 \mathrm{~km}$ and increases above and below this range. At the lowermost altitudes, the mean relative differences are larger (down to $-27 \%$ ). Above $35 \mathrm{~km}$, the lidar profiles appear very noisy and the low statistics prevent us from drawing meaningful conclusions.

The shape of the difference profile for the comparison with ACE-MAESTRO is quite similar, but ACE-MAESTRO shows a larger negative bias with respect to the Eureka DIAL observations. Mean relative difference values range from -20 to $+7 \%$ (on average $-13 \%$ ) in the range $12-38 \mathrm{~km}$. The de-biased standard deviation of the mean relative differences is within $10 \%$ between 19 and $30 \mathrm{~km}$ and increases above 

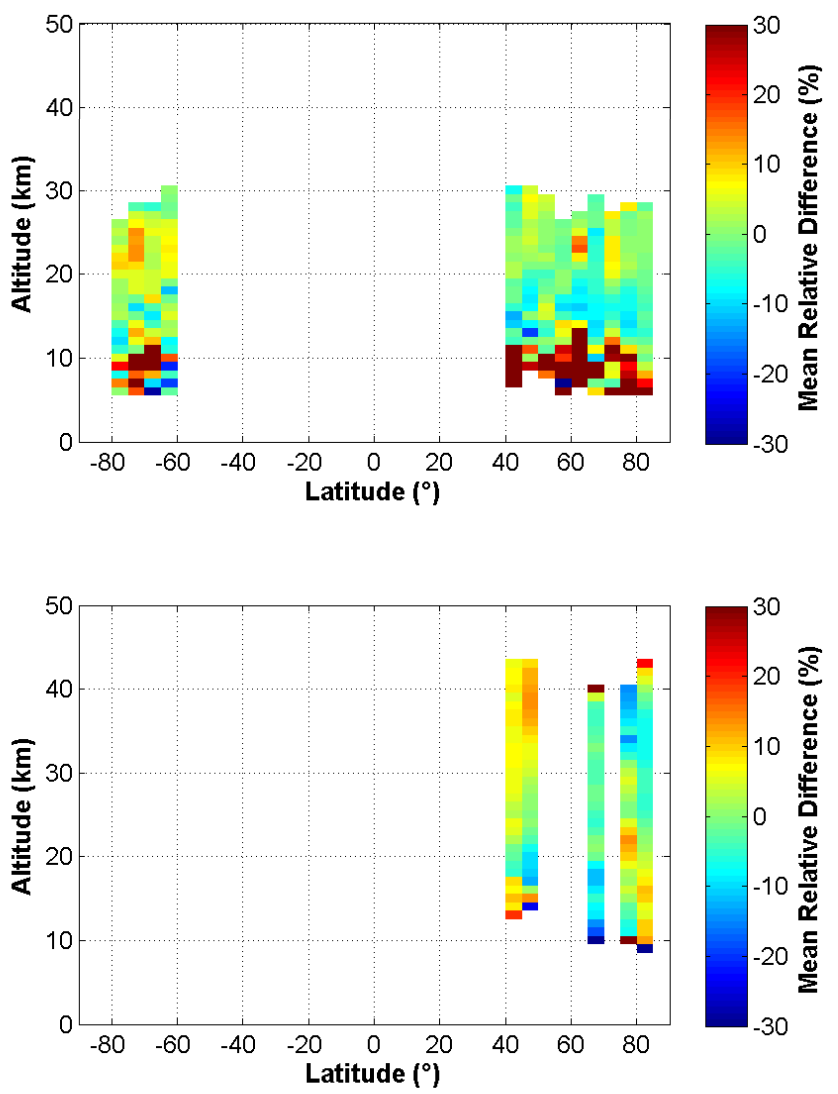

Fig. 35. Mean relative differences for comparisons between ACEFTS and ozonesonde data, plotted versus altitude and latitude (top); same information as above for comparisons with lidar data (bottom). Uncertainties are discussed in the text.

and below this range. This result is comparable to the values found for ACE-FTS. The maximum mean absolute difference is $-1.1 \mathrm{ppmv}$ at $28 \mathrm{~km}$. These results are qualitatively comparable with those described in Sect. 6.6 for other lidars but show an unusual (especially for ACE-FTS) low bias of the ACE instruments with respect to the Eureka DIAL.

\subsection{Ground-based FTIR observations}

In this section, we compare partial columns derived from the ACE-FTS and ACE-MAESTRO observations with groundbased measurements obtained by FTIR spectrometers, at ten NDACC stations (Table 4). Although the coarse vertical resolution of FTIR measurements limits their use for profile comparisons, they provide regular observations at different locations under clear-sky conditions and offer possibilities that complement the ozonesonde and lidar measurements for evaluating the temporal variations of the ACE dataset.

The FTIR instruments involved in the comparisons use microwindows in the range $780-3060 \mathrm{~cm}^{-1}$ and have spectral resolutions ranging from 0.001 to $0.012 \mathrm{~cm}^{-1}$. They pro-
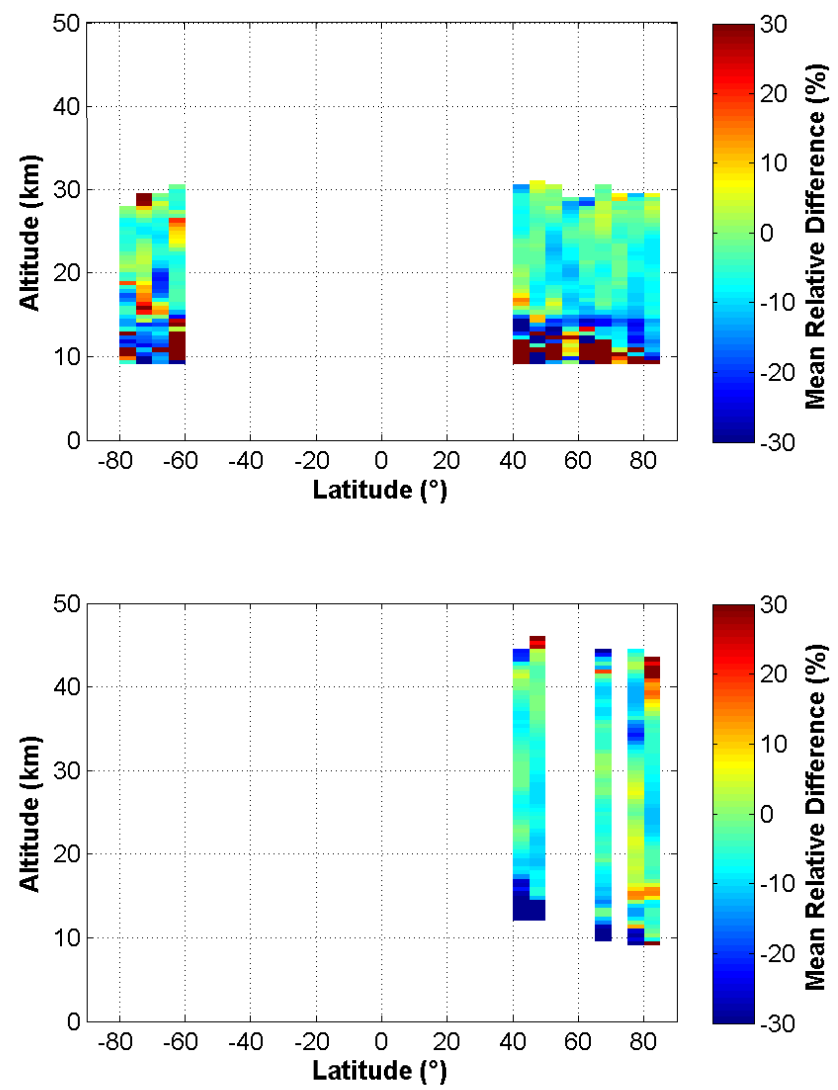

Fig. 36. Same as Fig. 35 but for differences between ACEMAESTRO and ozonesonde (top) and lidar (bottom) data.

vide information on numerous species including $\mathrm{O}_{3}$ from the lower troposphere to the middle and upper stratosphere. Two different retrieval codes are used (depending on the station): SFIT2 (Pougatchev and Rinsland, 1995; Pougatchev et al., 1995; Rinsland et al., 1998) and PROFITT92 (Hase, 2000). They were compared by Hase et al. (2004), who found that these algorithms are in excellent agreement (generally better than $1 \%$ ) for both VMR retrievals and total column calculations. Both processing codes are based on the Optimal Estimation Method (Rodgers, 2000), thus providing averaging kernels which are useful for determining the information content and for smoothing higher vertical resolution measurements such as those from ACE-FTS and ACEMAESTRO.

In this study, we used the coincidence criteria listed in Table 4. Because of the limited number of coincidences at some stations, the time period for the comparison exercise was extended to the end of 2006. The ACE-FTS and ACEMAESTRO profiles were interpolated on the FTIR retrieval grid for each station and extended below the lowest retrieved altitude using the FTIR a priori VMR values. The resulting composite profile was smoothed using the FTIR averaging kernels and a priori profile, as described in Sect. 4. Partial 
Table 4. List of the FTIR stations which provided data for the analyses (Sect. 6.8). The latitude and longitude of the station are provided, together with the altitude above sea level in meters ( $\mathrm{m}$ a.s.1.) (columns 3-4). The coincidence criteria used in this study are indicated for each station (column 5). References describing the stations, measurements and analyses are given in column 6.

\begin{tabular}{llcccl}
\hline Station & Location & Coordinates & Alt. [m a.s.l.] & Coincidence Criteria & Reference \\
\hline Thule & Greenland & $76.5^{\circ} \mathrm{N}, 68.7^{\circ} \mathrm{W}$ & 225 & $\pm 24 \mathrm{~h}, 1000 \mathrm{~km}$ & Goldman et al. (1999) \\
Kiruna & Sweden & $67.8^{\circ} \mathrm{N}, 20.4^{\circ} \mathrm{E}$ & 420 & $\pm 12 \mathrm{~h}, 500 \mathrm{~km}$ & Blumenstock et al. (2006) \\
Poker Flat & Alaska & $65.1^{\circ} \mathrm{N}, 147.4^{\circ} \mathrm{W}$ & 610 & $\pm 24 \mathrm{~h}, 1000 \mathrm{~km}$ & Kasai et al. (2005) \\
Harestua & Norway & $60.2^{\circ} \mathrm{N}, 10.8^{\circ} \mathrm{E}$ & 600 & $\pm 24 \mathrm{~h}, 1000 \mathrm{~km}$ & Paton-Walsh et al. (1997) \\
Zugspitze & German Alps & $47.4^{\circ} \mathrm{N}, 11^{\circ} \mathrm{E}$ & 2962 & $\pm 24 \mathrm{~h}, 1000 \mathrm{~km}$ & Sussmann and Borsdorff (2007) \\
Jungfraujoch & Swiss Alps & $46.5^{\circ} \mathrm{N}, 8.0^{\circ} \mathrm{E}$ & 3580 & $\pm 48 \mathrm{~h}, 1000 \mathrm{~km}$ & Zander et al. (2008) \\
Toronto & Canada & $43.7^{\circ} \mathrm{N}, 79.4^{\circ} \mathrm{W}$ & 174 & $\pm 48 \mathrm{~h}, 1000 \mathrm{~km}$ & Wiacek et al. (2007) \\
Izaña & Canary Islands & $28.3^{\circ} \mathrm{N}, 16.5^{\circ} \mathrm{W}$ & 2367 & $\pm 24 \mathrm{~h}, 1000 \mathrm{~km}$ & Schneider et al. (2008a,b) \\
La Réunion & Indian Ocean & $20.9^{\circ} \mathrm{S}, 55.5^{\circ} \mathrm{E}$ & 50 & $\pm 24 \mathrm{~h}, \pm 10^{\circ}$ lat., $\pm 15^{\circ}$ lon. & Senten et al. (2008) \\
Wollongong & Australia & $34.5^{\circ} \mathrm{S}, 150.9^{\circ} \mathrm{E}$ & 30 & $\pm 24 \mathrm{~h}, 1000 \mathrm{~km}$ & Griffith et al. (1998) \\
\hline
\end{tabular}

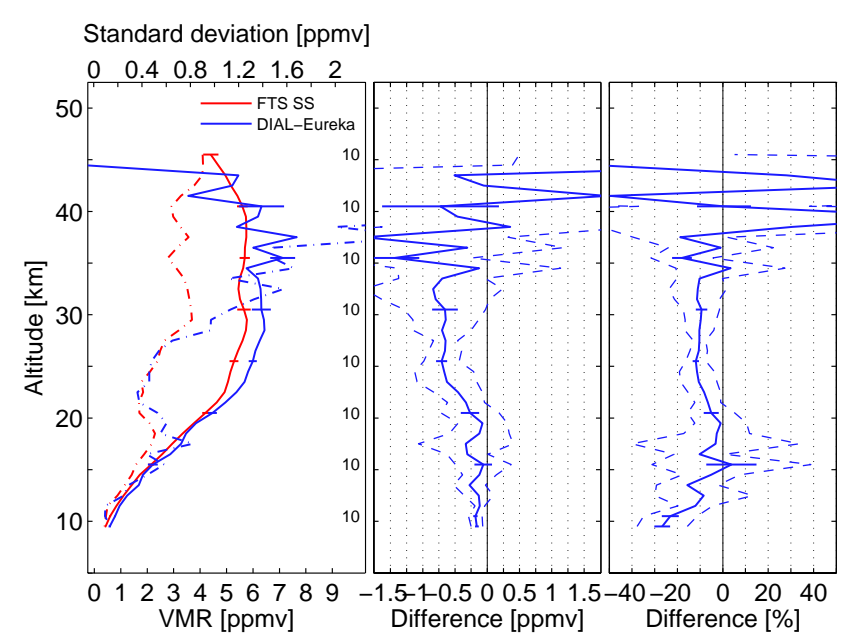

Fig. 37. Same as Fig. 1, but for the comparisons between ACE-FTS and the Eureka DIAL. All coincident ACE measurements were SS occultations.

columns were calculated for a specific altitude range for each station. To calculate the ACE-FTS and ACE-MAESTRO partial columns, we used the atmospheric density derived from the ACE-FTS measurements. For the FTIR instruments, we calculated a density profile from the pressure and temperature profiles used in their retrievals.

The lower limit of the partial column range was given by the ACE-FTS or ACE-MAESTRO lowest measured altitude, while the upper limit was determined from the sensitivity of the FTIR measurements. We used an approach similar to that of Vigouroux et al. (2007): the sensitivity (also called measurement response) at one altitude is given by the area under the corresponding averaging kernel. The useful range for the FTIR is defined as the altitudes where the FTIR sensitivity

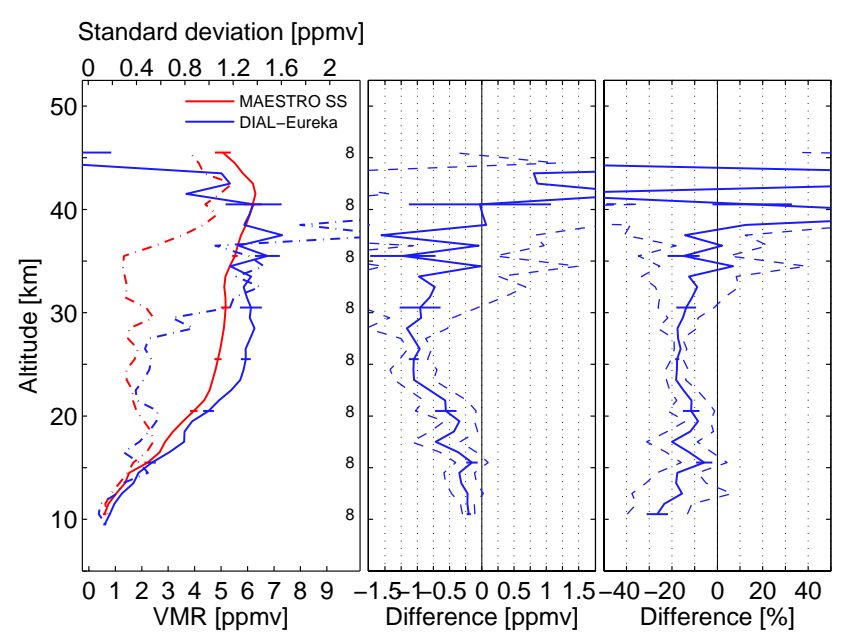

Fig. 38. Same as Fig. 1, but for the comparisons between ACEMAESTRO and the Eureka DIAL. All coincident ACE measurements were SS occultations.

is greater than 0.5 (i.e., where the information comes primarily from the measurement). The resulting vertical ranges vary from station to station and for ACE-FTS and ACEMAESTRO, with lower limits of $10-18 \mathrm{~km}$ and upper limits of $38-47 \mathrm{~km}$. For the partial columns, this yields a number of degrees of freedom for signal (DOFS, defined as the trace of the averaging kernel matrix over the altitude range of the partial column) ranging from $\sim 1.7$ for Toronto to $\sim 3.9$ for Izaña.

In Figs. 39 (for ACE-FTS) and 40 (for ACE-MAESTRO), we present time series of the partial columns and relative differences for the comparisons with each FTIR instrument. In some cases, the comparison period is limited to several days of measurements in 2004 (Poker Flat and La Réunion). The 

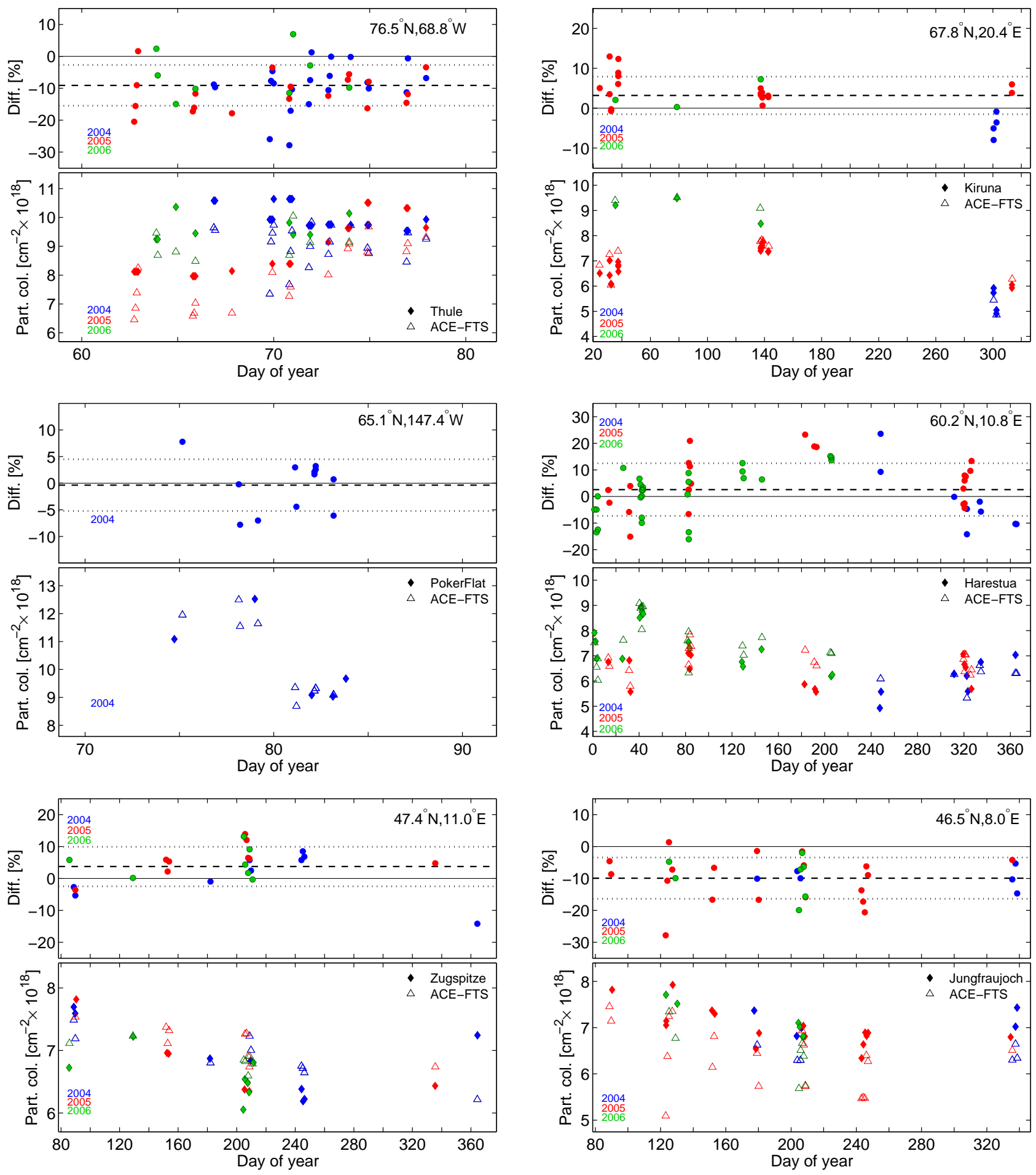

Fig. 39. Time series of ozone partial column comparisons for ACE-FTS with each ground-based FTIR instrument listed in Table 4. For each station, the bottom panel shows the partial column values for ACE-FTS (open triangles) and for the correlative FTIR measurements (filled diamonds). The top panel gives the relative differences between the partial column values for ACE-FTS and for the FTIR instruments. Latitude and longitude of the ground-based station are indicated in the upper right-hand corner. The horizontal black lines show the mean relative differences (dashed, thick), the associated de-biased standard deviations (dotted) and the 0\% line (solid, thin). The comparison results are colour-coded according to the year of the observation: blue for 2004, red for 2005 and green for 2006. Note that the x- and y-axis scales used for each station are different. 

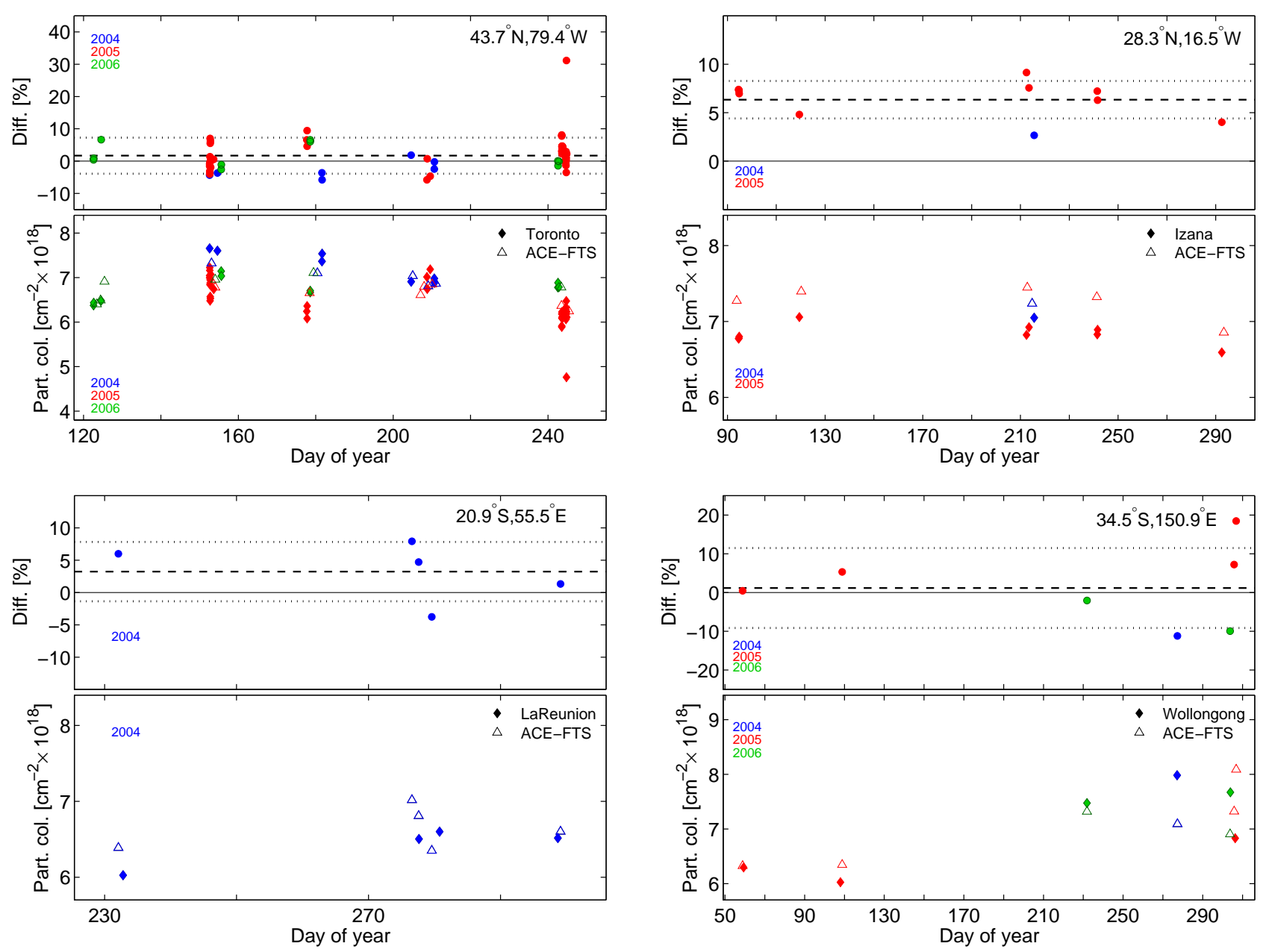

Fig. 39. Continued.

partial columns derived from the ACE-FTS profiles are in acceptable agreement $( \pm 20 \%)$ with the FTIR values, with mean relative differences within -10 to $+7 \%$ and corresponding de-biased standard deviation ranging from $\sim 2 \%$ for Izaña to about $10 \%$ for Jungfraujoch and Wollongong. The results are slightly better for ACE-MAESTRO, with mean relative differences within -9 to $+2 \%$. For ACEMAESTRO, the de-biased standard deviation of the mean relative differences is about 6\% except for Harestua $(\sim 10 \%)$ as well as Wollongong and Thule (16\%). Furthermore, the scatterplots presented in Fig. 41 for ACE-FTS and in Fig. 42 for ACE-MAESTRO show very good correlation between the $\mathrm{O}_{3}$ partial columns for the ACE instruments and the ground-based FTIR spectrometers, with correlation coefficients of 0.88 for ACE-FTS and 0.84 for ACE-MAESTRO. When comparing the results for the northern high latitude stations, a larger scatter in the mean relative differences (especially for ACE-MAESTRO) can be noted for Thule than for Kiruna. This is most likely due to the coincidence cri- teria which were broader for Thule than for Kiruna (Table 4). Additional tests were done with a stricter distance criterion $(500 \mathrm{~km})$ for comparison with Thule and showed significantly less scatter. However, it did not modify the mean agreement between the ACE data and the ground-based measurements. The results of the analysis for ACE-FTS and ACE-MAESTRO are presented in Table 5, showing the altitude range used for the calculations, the DOFS values, and the mean relative differences and associated de-biased standard deviations for each ground-based station. The latter are useful for quantitative evaluation of the results, even though the statistical relevance can be limited by the low number of coincidences for some stations. Since we have calculated (and described) the de-biased standard deviations of the mean relative differences, the values given above and in Table 5 represent an estimate or an upper limit to the combined precision of the FTIR and ACE instruments. 

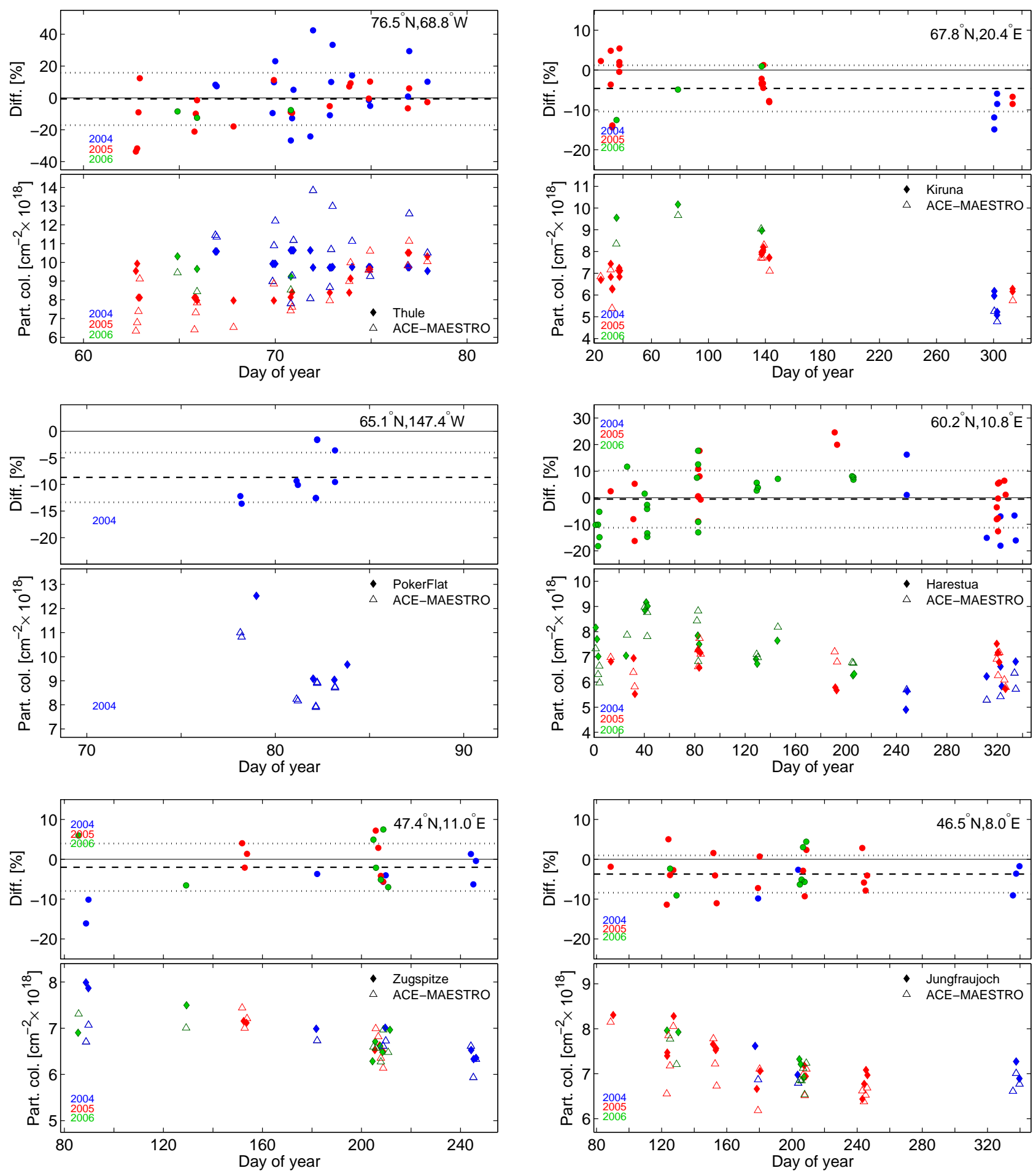

Fig. 40. Same as Fig. 39 but for ACE-MAESTRO comparisons. 

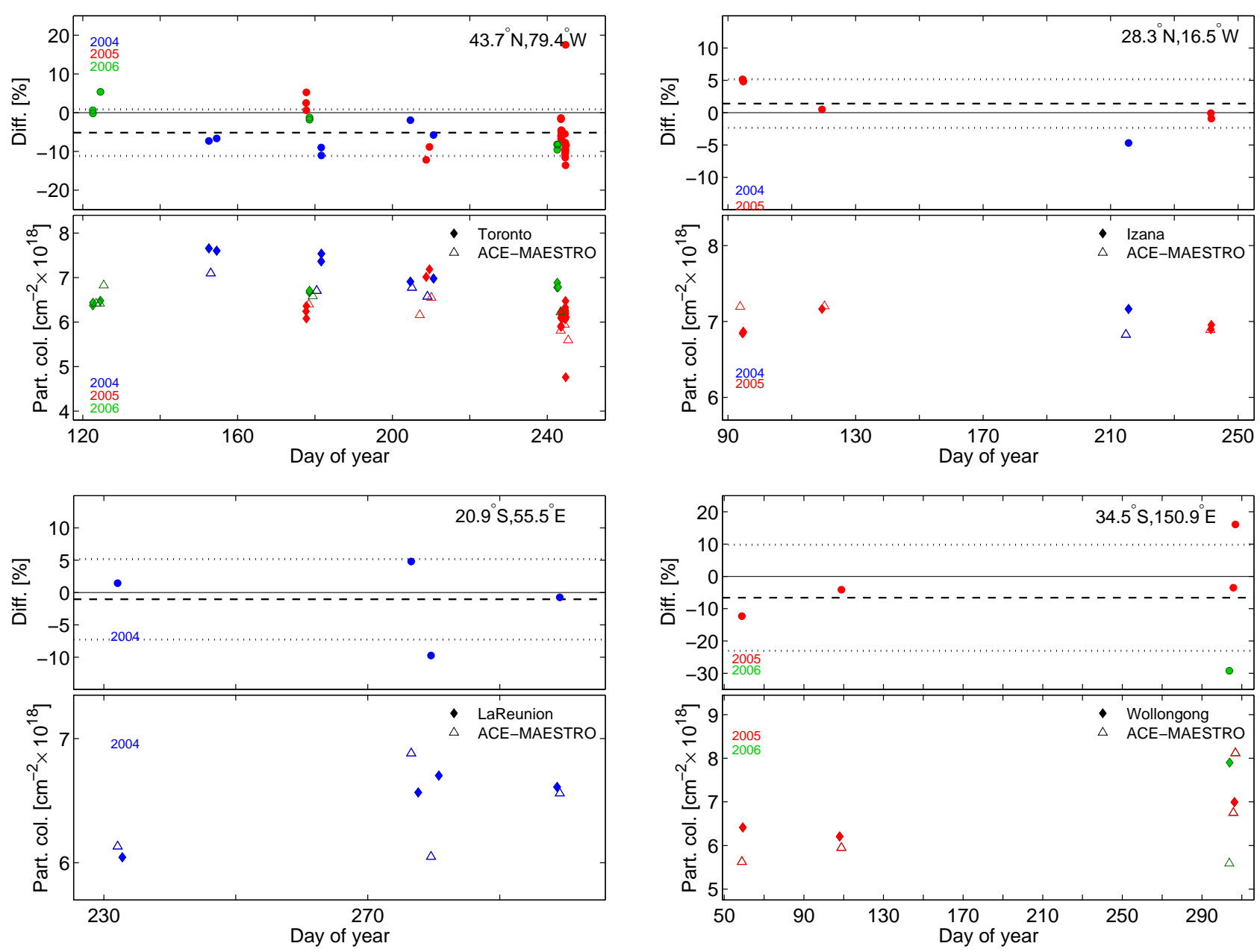

Fig. 40. Continued.

6.9 Comparison with ground-based microwave radiometer measurements

Stratospheric and mesospheric profiles from the MWRs at the Lauder, New Zealand and Mauna Loa, Hawaii NDACC sites have been compared with ACE-FTS and ACEMAESTRO measurements. These have also been used to perform non-coincident comparisons with other satelliteborne and ground-based instruments, in a manner previously employed by Boyd et al. (2007). This method allows comparison of datasets that would otherwise have limited or no coincident or collocated measurements. Here we compare a set of historical and current satellite-borne datasets as well as ground-based lidar measurements with the MWR measurements and, by using the MWRs as transfer standards, determine the agreement between the ACE instruments and a consensus of these other instruments.

The MWR instruments (Parrish et al., 1992; Parrish, 1994) observe atmospheric thermal emission of ozone at
$110.836 \mathrm{GHz}$ and the pressure-broadened line shape is analyzed to obtain the altitude distribution of ozone using the Optimal Estimation Method of Rodgers (2000). The observations are made $24 \mathrm{~h}$ a day and routinely averaged over 4$6 \mathrm{~h}$ to provide up to four VMR profiles per day. The lower altitude limit for the profiles is about $20 \mathrm{~km}$ based on the influence of the a priori on the retrieval, and the quality of the measurement averaging kernels. The upper altitude limit is between $64 \mathrm{~km}$ for daytime measurements and about $72 \mathrm{~km}$ during night, due to the increased mesospheric ozone signal. The expected precision is $4-5 \%$ between 20 and $57 \mathrm{~km}$, and $7 \%$ at about $64 \mathrm{~km}$. The expected accuracy (i.e., combined random and systematic error) is $6-9 \%$ between 20 and $57 \mathrm{~km}$ and $11 \%$ at about $64 \mathrm{~km}$. The vertical resolution of the MWR profiles is $6-10 \mathrm{~km}$ between 20 and $50 \mathrm{~km}$ and about $13 \mathrm{~km}$ at $64 \mathrm{~km}$. A detailed description of the error analysis approach used for this work is included in the work of Connor et al. (1995). 


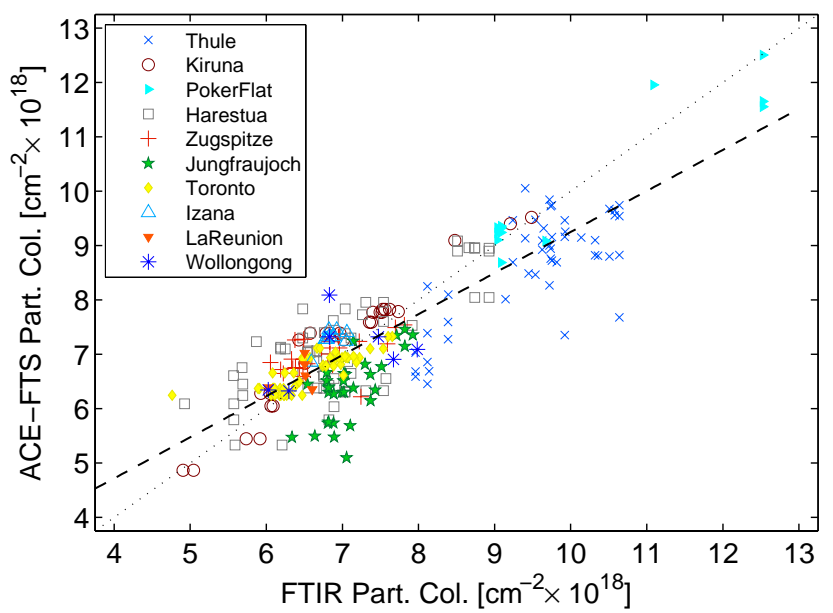

Fig. 41. Scatter plot of the ACE-FTS and ground-based FTIR partial columns of ozone shown in Fig. 39. The correlation value is 0.877 . The least-squares linear fit of the data is also shown (dashed black).

In the ACE-MWR comparisons, broad coincidence criteria of $\pm 24 \mathrm{~h}, \pm 6^{\circ}$ latitude and $\pm 12^{\circ}$ longitude were used to increase the number of coincidences available. In the event that there was more than one ACE measurement fitting this criterion, the one closest in time to the MWR measurement is chosen. To avoid the effects of the significant diurnal variations in ozone amounts in the upper stratosphere and mesosphere, comparisons are restricted to below $52 \mathrm{~km}$. To account for the different vertical resolutions of the instruments each ACE measurement is convolved with the averaging kernels of the MWR measurement as described by Connor et al. (1995), using Eq. (2) (Sect. 4). The profiles used here are interpolated onto an altitude grid with $2 \mathrm{~km}$ vertical spacing. The differences in the VMR profiles are determined with respect to the correlative dataset ((ACE-MWR)/MWR).

The mean relative differences between the ACE and MWR measurements, as well as the corresponding mean ozone VMR profiles, are presented in Fig. 43. Despite the small number of comparison pairs at Mauna Loa (less than 15), the difference profiles at both sites are generally similar. Below $44 \mathrm{~km}$, the mean relative differences between the ACE instruments and the MWRs are within $\pm 10 \%$, and often better than $\pm 5 \%$, except for the ACE-MAESTRO - MWR mean relative differences at Lauder from $32-36 \mathrm{~km}$, which are between +10 and $+15 \%$. Above $42 \mathrm{~km}$, the ACE instruments have a positive bias, compared with the MWR, with mean relative differences within +3 to $+25 \%$ and larger for ACEFTS than for ACE-MAESTRO by 5-8\%. Apart from a region between about 28 and $38 \mathrm{~km}$ at Lauder, ACE-FTS ozone retrievals yield larger VMRs than ACE-MAESTRO, though the differences are always within the indicated error bars.

A noticeable feature in the plots is the oscillation in the profile around the VMR peak at $34 \mathrm{~km}$. This feature is

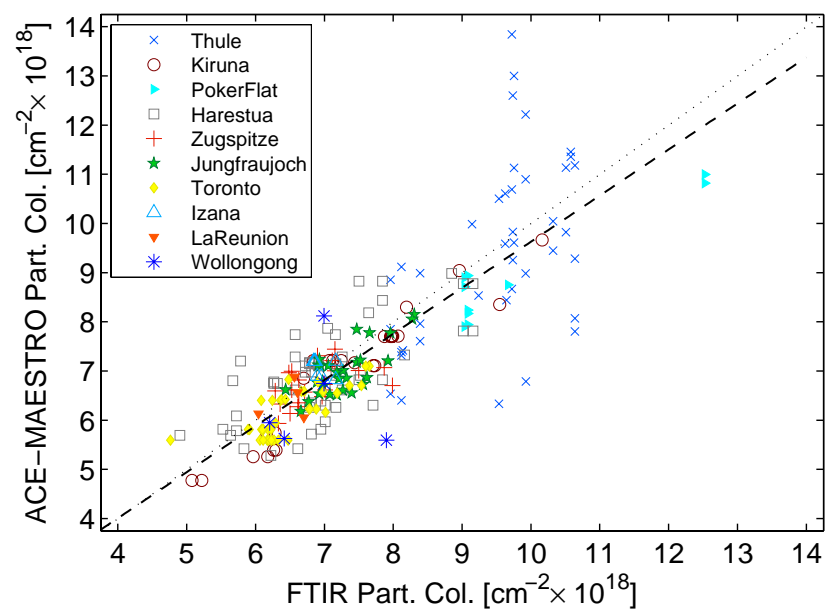

Fig. 42. Same as Fig. 41 but for ACE-MAESTRO. The correlation value is 0.841 .

also seen in comparisons between MWR measurements and those made with other instruments, as shown in Fig. 44, and can therefore be attributed to the MWR. Ground-based microwave measurements tend to produce retrievals with a small oscillatory component. The origin of this oscillation is discussed in Boyd et al. (2007) and Connor et al. (1995). These are effects of systematic spectral measurement errors that propagate through the process of averaging multiple spectra and can produce artifacts in difference profiles such as those seen in the figure.

To extend our validation comparisons, the MWR measurements were used as a transfer standard. The method compares data from the SAGE II, HALOE, Aura-MLS, GOMOS, and MIPAS satellite-borne instruments, as well as groundbased lidars, with the MWRs at Mauna Loa and Lauder. The difference profiles from these comparisons are then averaged to obtain a consensus difference profile. Also included in the averaging are MWR-MWR "zero-line" profiles so that the MWRs, themselves, are included in the consensus. These are then subtracted from the ACE-FTS - MWR and ACE-MAESTRO - MWR difference profiles from Fig. 43, to obtain profiles which show the agreement between the ACE instruments and the consensus of the other instruments. Instrument comparisons with the MWRs were made using criteria similar to those used for the ACE-MWR comparisons discussed above, except the geolocation window for the satellite-borne measurements extends to $\pm 5.0^{\circ}$ latitude and $\pm 10.0^{\circ}$ longitude of the two sites. All the instruments have relatively high vertical resolutions compared to the MWRs and have been convolved using the MWR averaging kernels for the comparison.

All available measurements made by the satellite- and ground-based instruments, in the three year period from 2004 through to the end of 2006 , were used to determine the 
Table 5. Results of the comparisons between ACE-FTS, ACE-MAESTRO and the ground-based FTIRs. The microwindow(s) used in the FTIR retrievals are listed in column 2. For each ACE/FTIR instrument pair, the number of comparison pairs, the vertical range used to calculate the partial columns, the corresponding degrees of freedom (DOFS) and the mean difference and 1- $\sigma$ standard deviation of the mean are indicated. The retrieval code (with version number) and spectroscopic database used by each station are given in the footnotes.

\begin{tabular}{|c|c|c|c|c|c|c|c|c|c|}
\hline \multirow{2}{*}{$\begin{array}{l}\text { FTIR } \\
\text { Station }^{\mathrm{a}}\end{array}$} & \multirow{2}{*}{$\begin{array}{c}\text { Microwindows } \mathrm{b}, \mathrm{c} \\
{\left[\mathrm{cm}^{-1}\right]}\end{array}$} & \multicolumn{4}{|c|}{ ACE-FTS } & \multicolumn{4}{|c|}{ ACE-MAESTRO } \\
\hline & & $\begin{array}{l}\text { \# of } \\
\text { pairs }\end{array}$ & $\begin{array}{l}\text { Range } \\
{[\mathrm{km}]}\end{array}$ & $\begin{array}{l}\text { DOFS } \\
\text { FTIR }\end{array}$ & $\begin{array}{l}\text { Mean diff. } \\
\pm \text { Std. Dev. }\end{array}$ & $\begin{array}{l}\text { \# of } \\
\text { pairs }\end{array}$ & $\begin{array}{l}\text { Range } \\
{[\mathrm{km}]}\end{array}$ & $\begin{array}{l}\text { DOFS } \\
\text { FTIR }\end{array}$ & $\begin{array}{l}\text { Mean diff. } \\
\pm \text { Std. Dev. }\end{array}$ \\
\hline Thule & $1130.0-1133.00$ & 48 & $12.2-41.1$ & 2.8 & $-9.1 \pm 6.4$ & 41 & $12.2-41.1$ & 2.8 & $-0.7 \pm 16.4$ \\
\hline Kiruna & $\begin{array}{c}782.56-782.86 \\
788.85-789.37 \\
993.30-993.80 \\
1000.00-1005.00^{d}\end{array}$ & 27 & $14.3-46.7$ & 3.3 & $3.2 \pm 4.7$ & 27 & $13.2-46.7$ & 3.4 & $-4.6 \pm 5.8$ \\
\hline Poker Flat & $3051.29-3051.90$ & 12 & $10-38$ & 3.1 & $-0.4 \pm 4.9$ & 10 & $11-38$ & 3.0 & $-8.7 \pm 4.7$ \\
\hline Harestua & $1000.00-1005.00^{\mathrm{d}}$ & 60 & $15.5-46.9$ & 2.7 & $2.6 \pm 9.9$ & 52 & $14.7-46.9$ & 2.9 & $-0.5 \pm 10.8$ \\
\hline Zugspitze & $1000.00-1005.00^{d}$ & 25 & $15.4-36.3$ & 1.8 & $3.7 \pm 6.2$ & 22 & $14.7-36.3$ & 2.0 & $-2.0 \pm 6.0$ \\
\hline Jungfraujoch & $1000.00-1005.00^{\mathrm{d}}$ & 32 & $15.4-42.4$ & $\sim 2.5$ & $-9.9 \pm 6.5$ & 29 & $14.2-42.4$ & $\sim 2.5$ & $-3.7 \pm 4.7$ \\
\hline Toronto & $3045.10-3045.35$ & 54 & $17.8-40.9$ & 1.7 & $1.7 \pm 5.6$ & 39 & $16.3-40.9$ & 1.8 & $-5.2 \pm 6.0$ \\
\hline Izaña & $\begin{array}{c}782.56-782.86 \\
788.85-789.37 \\
993.30-993.80 \\
1000.00-1005.00^{d}\end{array}$ & 10 & $14.3-46.7$ & 3.9 & $6.3 \pm 1.9$ & 7 & $14.3-46.7$ & 3.9 & $1.4 \pm 3.8$ \\
\hline La Réunion & $1000.00-1005.00^{\mathrm{d}}$ & 4 & $16.6-44.9$ & 3.0 & $3.2 \pm 4.6$ & 4 & $15.4-44.9$ & 3.1 & $-1.1 \pm 6.2$ \\
\hline Wollongong & $\begin{array}{l}1002.58-1003.50 \\
1003.90-1004.40 \\
1004.58-1005.00\end{array}$ & 7 & $14-42$ & 2.8 & $1.2 \pm 10.3$ & 5 & $12-42$ & 3.1 & $-6.6 \pm 16.4$ \\
\hline
\end{tabular}

a Retrieval codes: PROFITT92 is used in Kiruna and Izaña. The other stations use SFIT2: Thule (v3.92b), Toronto, La Réunion and Wollongong (v3.92), Jungfraujoch (v3.91), Zugspitze (v3.90), Harestua (v3.81) and Poker Flat (v3.7).

b Spectroscopic linelist: HITRAN 2001 for Kiruna and Izaña. All other stations use HITRAN 2004.

c When multiple microwindows are listed for a station, they are fitted simultaneously during the retrieval process.

$\mathrm{d}$ The 1000.00-1005.00 $\mathrm{cm}^{-1}$ microwindow was selected following the studies of Barret et al. (2002, 2003), for use within the European project UFTIR: "Time series of Upper Free Troposphere observations from a European ground-based FTIR network" (http://www.nilu.no/ uftir/).

difference profiles. Table 6 summarizes the datasets used in this study, including the processing version number, the number of collocated pairs used in determining the difference profiles presented here and the gaps in the datasets. Results from the comparisons between the various instruments and the MWRs are presented in Fig. 44 for Mauna Loa (panel a) and for Lauder (panel b).

The resulting (ACE-consensus) difference profiles are again generally similar at both sites. Below $40 \mathrm{~km}$, ACEFTS shows a consistent positive bias, relative to the consensus, with mean relative differences within +2 to $+7 \%$ at Mauna Loa and +4 to $+8 \%$ at Lauder. ACE-MAESTRO also shows generally positive mean relative differences within +1 to $+9 \%$, in this altitude region, at Lauder. At Mauna Loa, the ACE-MAESTRO mean relative differences with the consensus are within $\pm 5 \%$ up to $40 \mathrm{~km}$, starting as a small negative bias but then tending positive. Above $40 \mathrm{~km}$, both ACE instruments have an increasing positive bias, with mean relative differences between ACE-FTS and the consensus of up to $+24 \%$ and, for ACE-MAESTRO, of up to $+19 \%$. Diurnal variation in ozone amounts becomes a factor above about $45 \mathrm{~km}$, with rapid changes in ozone occurring around sunrise and sunset. The solar occultation SAGE II instrument has a small positive bias above this height, compared to the other consensus instruments, but still measures less ozone than the ACE instruments, suggesting other systematic errors are contributing to the higher positive bias in the ACE instruments. While HALOE is also a solar occultation instrument, the HALOE retrieval incorporates a photochemical model intended to account for diurnal variation of ozone along the instrument's line of sight at sunrise and sunset.

\section{Summary - discussion}

Here we summarize and discuss the VMR profile and partial column comparison results described in the previous sections. The mean relative differences from the vertical profile comparisons are presented in Figs. 45 and 46 for ACE-FTS 
Mauna Loa ACE-MWR

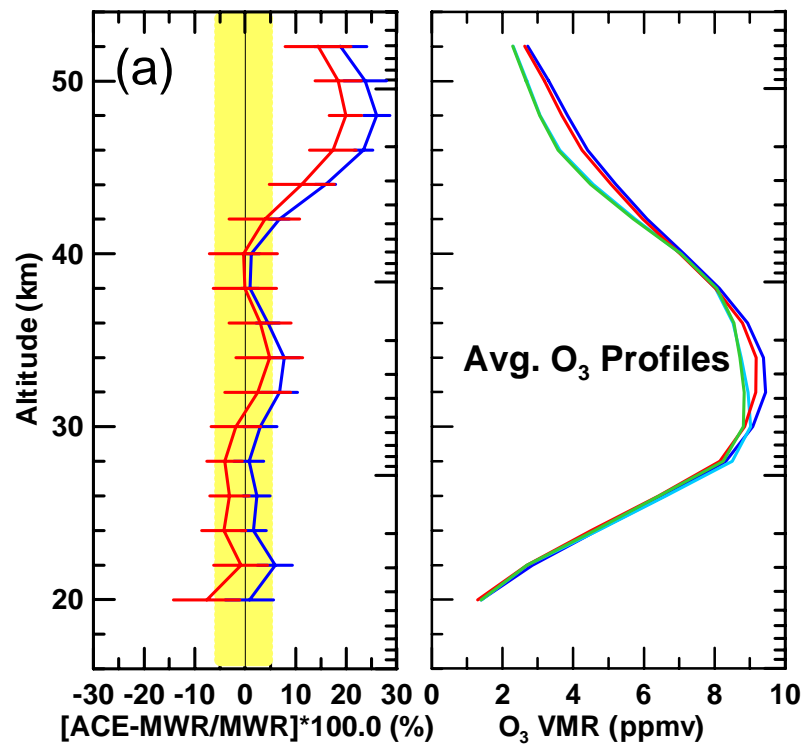

\section{Lauder ACE-MWR}

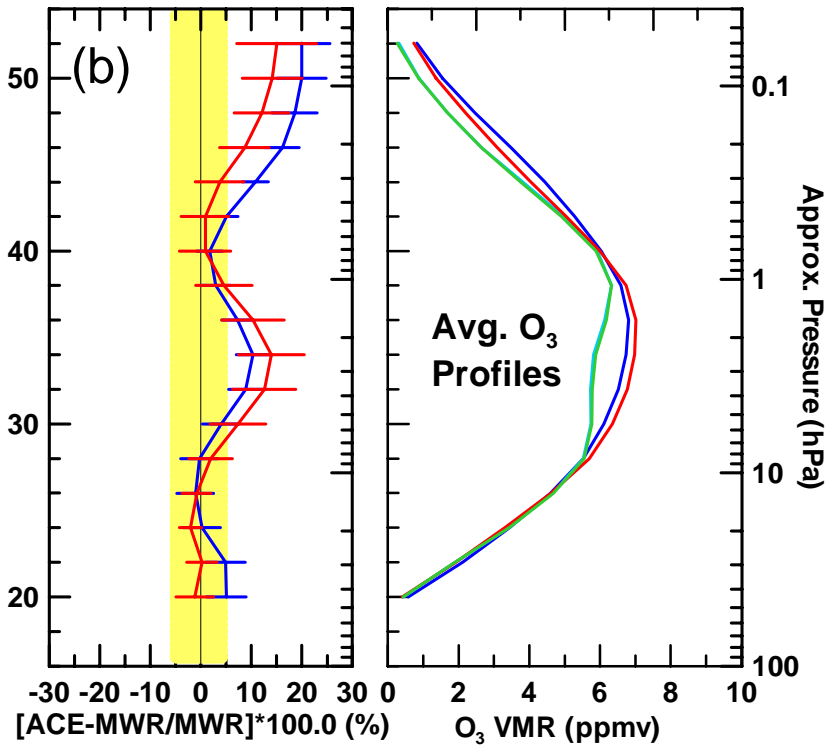

Fig. 43. Mean profiles and mean relative differences for the comparison of ACE-FTS and ACE-MAESTRO with the ground-based MWRs at Mauna Loa (a) and Lauder (b). For each site: Left: Mean relative differences ((ACE-FTS-MWR)/MWR) in percent shown for comparison with ACE-FTS (blue) and ACE-MAESTRO (red). Error bars indicate twice the standard error (uncertainty) of the mean. Right: Mean VMR profiles from ACE-FTS (blue), ACE-MAESTRO (red) and the MWR mean profiles paired with ACE-FTS (green) and with ACE-MAESTRO (cyan). Approximate pressures corresponding to the altitudes are reported on the right-hand side.
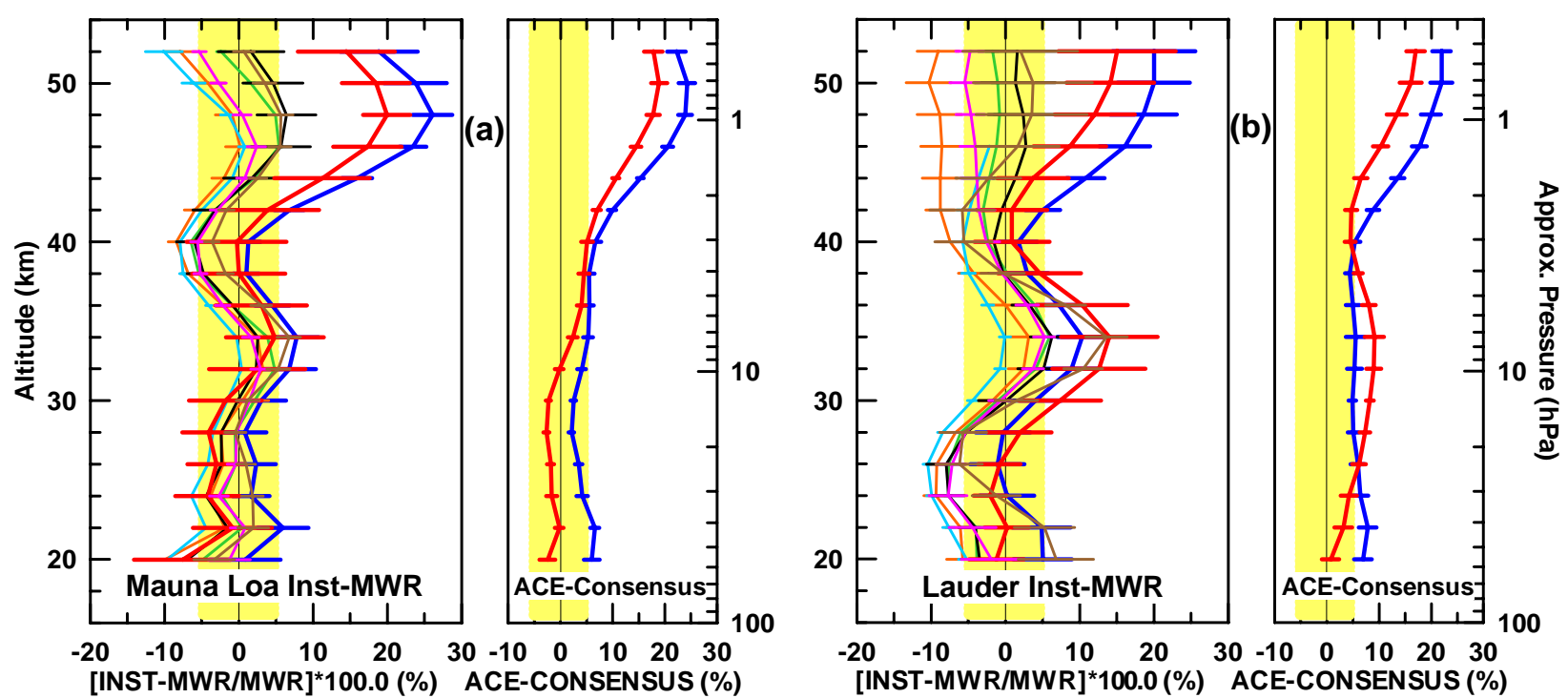

Fig. 44. Mean relative differences for the comparison of the instruments listed in Table 6 with the ground-based MWRs and for the comparison of ACE-FTS and ACE-MAESTRO with the consensus profile at Mauna Loa (a) and Lauder (b). For each site: Left: Mean relative differences ((Instrument-MWR)/MWR) in percent shown for comparison with ACE-FTS (blue), ACE-MAESTRO (red), SAGE II (black), HALOE (orange), Aura-MLS (green), GOMOS (magenta), MIPAS (brown) and Lidar (light blue). Error bars indicate twice the standard error (uncertainty) of the mean. Right: Mean relative differences ((ACE-Consensus)/Consensus) in percent obtained by subtracting the average of the non-ACE difference profiles (left panel) from the ACE-MWR difference profiles. Mean relative differences and $2 \times$ the standard error (uncertainty) of the mean (error bars) are shown for ACE-FTS (blue) and ACE-MAESTRO (red). 
and ACE-MAESTRO, respectively. In these plots, the vertical range has been limited to $60 \mathrm{~km}$ except for the comparisons with the Eureka DIAL, where the plotting limit was set to $38 \mathrm{~km}$ because of the large oscillations noted above this altitude. Only statistical comparisons are included in these summary plots, hence the comparisons with individual FIRS2, SAOZ and SPIRALE measurements are not included. The corresponding results are given in Table 7 .

\subsection{ACE-FTS}

Figure 45 shows the mean relative differences of all statistical comparisons of VMR profiles for ACE-FTS. As can be seen, the results are highly consistent in the stratosphere between $\sim 16 \mathrm{~km}$ and $44 \mathrm{~km}$ for nearly all comparison datasets. In this vertical range, ACE-FTS reports on average $+4 \%$ more ozone than the comparison instruments, with a spread of the mean relative differences on the order of $\pm 5 \%$. In this altitude range, two outliers for which much larger mean relative differences were found can be noted. In one case the mean relative differences are larger and positive, while in the other case the mean relative difference values are larger but negative. The former profile is the result of the comparison with Odin/SMR, for which the ACE-FTS VMR is consistently larger than that of SMR in the stratosphere (with mean relative differences within +3 to $+20 \%$ ), and the latter was obtained when comparing ACE-FTS with the Eureka DIAL, which shows negative mean relative differences of about $-7 \%$. The low bias of SMR ozone was noted in the validation study of Jones et al. (2007). The reason for the significant negative differences between ACE-FTS and the Eureka DIAL is still unclear. Furthermore, the individual comparisons with the balloon-borne instruments (not included in Fig. 45) show a similar agreement (with relative differences within $\pm 10 \%$ ). Additionally, the (ACE-FTSconsensus) mean relative difference profile (shown in Fig. 44 but not included in Fig. 45) obtained in the MWR study is an example of what can be obtained by combining the correlative observations from different instruments (Sect. 6.9). This shows results similar to what can be seen in Fig. 45, with a small positive bias of ACE-FTS with respect to the consensus at altitudes below $40 \mathrm{~km}$, where the mean relative differences are within +2 to $+8 \%$ at Mauna Loa and Lauder.

Below $16 \mathrm{~km}$, the relative differences are more scattered. This can be explained by both geophysical and instrumental factors. The lower stratosphere is an atmospheric region with intrinsically large variability in the ozone VMR (as expressed by the large increase of the standard deviation of the mean VMR profiles at these altitudes), where the observations can encounter clouds or where the sensitivity of satellite sensors can decrease. Therefore, the methology used here is not optimal for quality assessment of the ACE-FTS measurements at the lowest levels of the comparison. For detailed validation in the upper troposphere/lower stratosphere using alternative methods, the reader is referred to Hegglin et al. (2008).
Table 6. List of instruments used in comparisons with the MWRs at Mauna Loa and Lauder. The retrieval version number (column 2) and number of coincident pairs for Mauna Loa (column 3) and Lauder (column 4) are listed. All available measurements from 2004-end of 2006 were used with the exceptions noted below. Note, the MWR located at Lauder had a receiver failure at the end of 2003, with regular measurements commencing again in May 2004.

\begin{tabular}{lccc}
\hline Instrument & Version & \multicolumn{2}{c}{ No. of pairs } \\
& & Mauna Loa & Lauder \\
\hline ACE-FTS & 2.2 Update & 14 & 29 \\
ACE-MAESTRO & 1.2 & $11-12^{\mathrm{f}}$ & $26-29 \mathrm{~g}$ \\
SAGE II $^{\mathrm{a}}$ & 6.20 & $19-20^{\mathrm{f}}$ & 29 \\
HALOE $^{\mathrm{b}}$ & 19 & 32 & 43 \\
Aura-MLS $^{\mathrm{c}}$ & 2.2 & $780-781^{\mathrm{f}}$ & 514 \\
GOMOS $^{\mathrm{d}}$ & $6.0 \mathrm{f}$ & $56-87^{\mathrm{f}}$ & $52-64^{\mathrm{f}}$ \\
MIPAS $^{\mathrm{e}}$ & $4.62 / 4.65$ & $53-76^{\mathrm{f}}$ & 11 \\
Lidar (Mauna Loa) & 5.0 & $79-405^{\mathrm{g}}$ & - \\
Lidar (Lauder) & 7.0 & - & $82-142^{\mathrm{g}}$ \\
\hline
\end{tabular}

a Measurements ended in August 2005.

b Measurements ended in November 2005.

c Measurements began in September 2004.

d Instrument offline from January-August 2005 due to an instrument anomaly.

e Full resolution measurements from January-March 2004 (version 4.62) and reduced resolution measurements from AugustSeptember 2004 (version 4.65) used in comparison.

${ }^{\mathrm{f}}$ First number is the number of coincident measurements used at the bottom of the comparison vertical range; second number is the maximum number of coincident pairs.

$\mathrm{g}$ First number is the number of coincident measurements used at the top of the comparison vertical range; second number is the maximum number of coincident pairs.

The persistent high bias of ACE-FTS in the mesosphere $(45-60 \mathrm{~km})$, noted frequently in previous sections, is clearly seen in Fig. 45. The mean relative differences are generally of about $+20 \%$ at an altitude of about $55 \mathrm{~km}$. Similar high VMR values were already noted in the initial validation for version 1.0 of the ACE-FTS data product (e.g., Walker et al., 2005; McHugh et al., 2005). The natural diurnal cycle of ozone in the mesosphere may be a factor in explaining the discrepancies, since the nighttime VMR values can be as much as 30 to $60 \%$ higher than the daytime values in the range 48-60 km (Schneider et al., 2005). However, these large differences are observed for comparisons with different instruments operating from different platforms, in different spectral ranges and with different viewing geometries. Therefore, it is unlikely that this difference at altitudes between $\sim 45$ and $60 \mathrm{~km}$ arises solely due to the ozone diurnal cycle.

In addition, the comparison of partial columns derived from the ACE-FTS and ground-based FTIR measurements provide an alternate test of the overall quality of the 


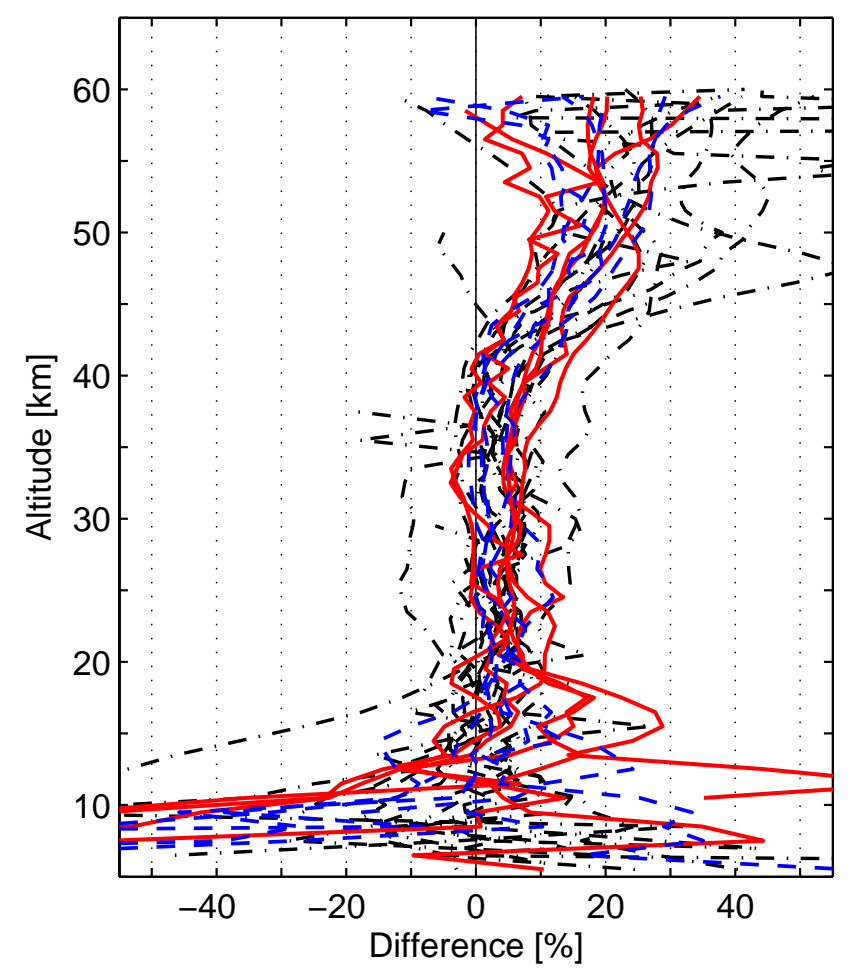

Fig. 45. Summary plot of the mean relative difference profiles for all statistical comparisons with ACE-FTS. Results are shown for ACE-FTS SR (solid red line) and SS (dashed blue line) when analyses were made separately. Mean relative difference profiles when no SR/SS separation was made are shown in black dot-dashed lines.

ACE-FTS retrievals in the stratosphere. The partial column mean relative differences are within $\pm 10 \%$ and generally positive, except for Thule $(-9.1 \%)$ and Jungfraujoch $(-9.9 \%)$, with de-biased standard deviation of the mean relative differences ranging from $\sim 2 \%$ for Izaña to $10 \%$ for Jungfraujoch and Wollongong. There is a good global correlation $(\sim 0.88)$ between the values derived from the ACEFTS measurements and those calculated for the FTIR observations.

For all statistical comparisons, we calculated the uncertainty of the mean (standard error) whose values are very small over the altitude range $16-44 \mathrm{~km}$ for most comparisons, and larger but still small at mesopheric altitudes. This indicates that the biases characterized in this work are statistically significant, since they are very rarely within the standard error bars of the comparison. Furthermore, we reported the de-biased standard deviation of the mean relative differences, which remains within 5 to $15 \%$ between 16 and $44 \mathrm{~km}$ and increases very rapidly below and above this altitude range. A large part of the de-biased standard deviation of the mean relative differences can be accounted for by the stated uncertainties of the correlative measurements. This seems to show that the contribution of the ACE-FTS re-

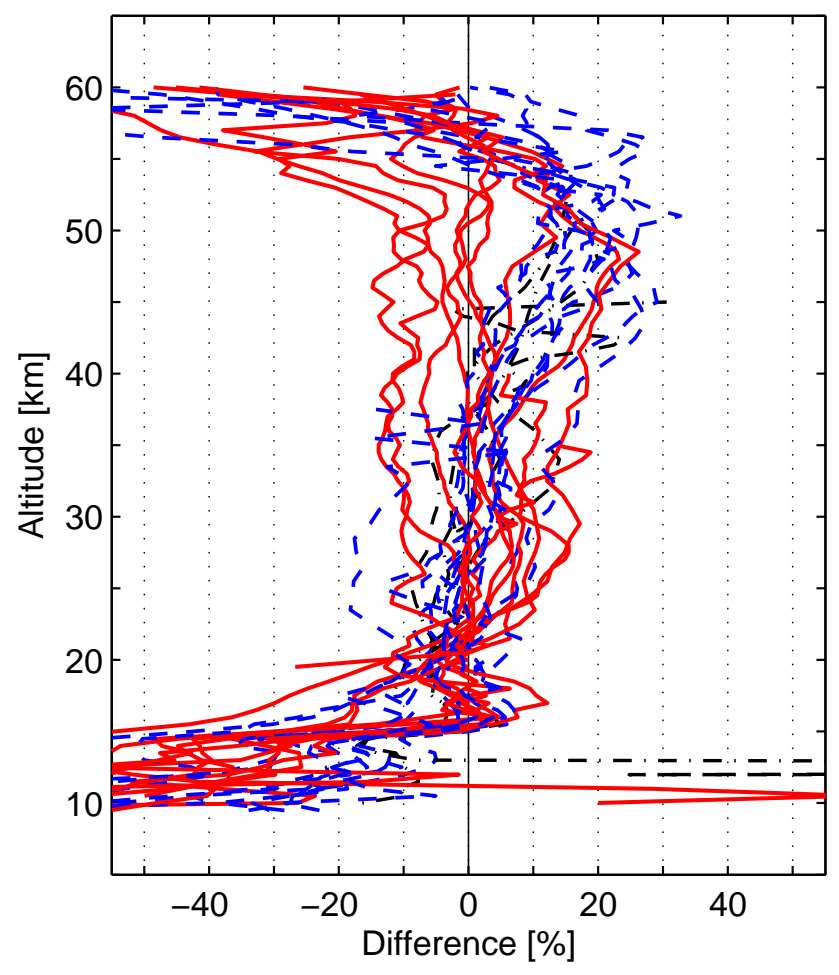

Fig. 46. Summary plot of the mean relative difference profiles for all statistical comparisons with ACE-MAESTRO. Results are separated between ACE-MAESTRO SR (solid red line) and SS (dashed blue line) occultations. The detailed NDACC study results are for the combined SR/SS results and are shown using the black dotdashed lines.

trievals to the combined random errors of the comparisons is small and well estimated by the statistical fitting errors.

Several tests were performed with the ACE-FTS retrieval scheme to evaluate potential sources for systematic biases. The next processing version of the ACE-FTS software features an improved instrumental line shape (ILS) for the instrument. The ILS used for ACE-FTS version 2.2 processing gave an apparent $3-5 \%$ high bias in retrievals above $\sim 40 \mathrm{~km}$ for $\mathrm{N}_{2}$ and $\mathrm{HCl}$ (and presumably other molecules as well). There is also an improvement in the retrieval process for pressure and temperature developed for the next version of the ACE-FTS analysis software. Neither the new ILS nor the improvements in the pressure/temperature processing eliminate the systematic high bias in ACE-FTS $\mathrm{O}_{3}$ retrievals between 45 and $60 \mathrm{~km}$. A more promising explanation for the high bias may be spectroscopy for the microwindows employed in the retrievals. An alternative set of microwindows was tested for this altitude region that appears to yield improved agreement with other datasets, but this issue remains under investigation.

Finally, no systematic difference has been found between the ACE-FTS SR and SS profiles for all comparisons. There 
is very good consistency between the comparisons for ACEFTS SR and SS occultations, as seen in Fig. 45.

\subsection{ACE-MAESTRO}

The current analyses have extended the results of Kar et al. (2007) to a broader range of correlative datasets. Figure 46 shows the mean relative differences of all statistical comparisons. These are separated into ACE-MAESTRO SR and ACE-MAESTRO SS events. For completeness, we have included the results of Kar et al. (2007) for POAM III and SAGE III in this plot.

The most obvious result is the bias between the MAESTRO SR and SS observations, at all altitudes between $\sim 35$ and $55 \mathrm{~km}$. The amplitude of this bias varies with altitude and with the comparison instrument. Below $35 \mathrm{~km}$, the results are essentially comparable for both SR and SS, although the SR comparisons show generally positive and larger mean relative differences than the SS results in the range $25-35 \mathrm{~km}$. Above $\sim 35 \mathrm{~km}$ and up to $\sim 55 \mathrm{~km}$, the ACE-MAESTRO SR observations are systematically lower than the SS results for the same correlative dataset, and yield more scattered mean relative differences. The SR/SS bias is largest for POAM III and SAGE III around $50 \mathrm{~km}$. For these instruments, the discrepancy can reach 25-30\%, with mean relative differences of $-10 \%$ for the ACE-MAESTRO SR occultations and $+20 \%$ for the ACE-MAESTRO SS occultations. It should be noted that the ACE-MAESTRO measurements are known to have a variable timing error of up to one second with respect to the ACE-FTS measurements. Since the ACE-MAESTRO retrievals use the tangent heights retrieved for ACE-FTS, this can lead to an offset of a few kilometers in the ACE-MAESTRO tangent heights, resulting in VMR profiles that can be significantly lower or higher than those retrieved from ACE-FTS or the comparison instrument (Manney et al., 2007). This issue is under investigation and has not been resolved yet. In particular, the v1.2 ACE-MAESTRO data used in the present study have not been corrected for this timing error. While this affects both SR and SS profiles, the effect is more pronounced for the SR profiles. This might explain the fact that, in general, the de-biased standard deviations of the mean relative differences for the comparisons involving the ACE-MAESTRO SR profiles are significantly larger than those obtained using the ACE-MAESTRO SS profiles. Part of the large spread in the SR differences seen in Fig. 46 might also be attributed to this.

For most instruments apart from POAM III and SAGE III, the comparisons with ACE-MAESTRO SR measurements show mean relative differences generally within $\pm 5 \%$ but with an average close to $0 \%$ over the altitude range 20 $55 \mathrm{~km}$. However, the spread of the results is about $\pm 10 \%$ around the average difference, larger than for ACE-FTS. In contrast, the ACE-MAESTRO SS results are more consistent. They show good agreement between 18 and $40 \mathrm{~km}$, here also with an average difference close to $0 \%$, and mean relative differences starting negative $(-5 \%$ at $18 \mathrm{~km})$ but becoming increasingly positive with increasing altitude $(+5 \%$ at $40 \mathrm{~km})$. As was found for ACE-FTS, the largest discrepancies in the altitude range $\sim 18-40 \mathrm{~km}$ are seen in the comparisons with Odin/SMR ( +2 to $+17 \%$ ) and with the Eureka DIAL (about $-13 \%$ ). It is interesting to note that the SR/SS bias is not apparent in the comparisons with SMR. Consistent results were found using the MWR instruments as a transfer standard (Sect. 6.9), for which no separation of SR/SS was made. The mean relative differences below $40 \mathrm{~km}$ for (ACEMAESTRO - consensus) are within +1 to $+9 \%$ at Lauder and within $\pm 5 \%$ at Mauna Loa.

In the upper stratosphere/lower mesosphere altitude range, the ACE-MAESTRO SS occultations show significantly more ozone than the comparison instrument, typically by up to $+20 \%$. This is comparable to the high altitude positive bias already noted for ACE-FTS in the mesosphere. Potential explanation for this similarity between the ACEFTS and the ACE-MAESTRO SS results may reside in the fact that the pressure and temperature profiles used in the ACE-MAESTRO retrievals are the profiles calculated from the ACE-FTS observations. This is also under investigation.

Below $\sim 18 \mathrm{~km}$ and above $\sim 55 \mathrm{~km}$, the mean relative differences increase in magnitude and reach large negative values both for SR and SS observations. Above $55 \mathrm{~km}$, the low signal-to-noise ratio in the $\mathrm{O}_{3}$ Chappuis band affects the retrievals and may be responsible for the larger negative differences noted at these altitudes.

Finally, comparisons of partial columns with the groundbased FTIR instruments show good agreement in the range used for calculations, with mean relative differences within $\pm 9 \%$ but generally around $\pm 2 \%$ and corresponding debiased standard deviations of 6 to $16 \%$. The correlation coefficient (0.84) is slightly lower than that found for the ACEFTS comparisons.

As was found for ACE-FTS, the standard errors are very small for most statistical comparisons of VMR profiles, showing that the biases found in this study are statistically significant. The de-biased standard deviation of the mean relative differences is within $\sim 10$ to $20 \%$ at most altitudes between 18 and $40 \mathrm{~km}$ and increases rapidly above and below this range. Unlike for ACE-FTS, the spectral fitting errors cannot account for the full contribution of ACE-MAESTRO retrievals to the de-biased standard deviation of the mean relative differences. Therefore, other sources will need to be taken into account in the ACE-MAESTRO random error budget.

\section{Conclusions}

We have completed a comprehensive bias determination study for the ozone profiles retrieved from measurements by the Atmospheric Chemistry Experiment satellite-borne 
Table 7. Summary of results for the ACE-FTS and ACE-MAESTRO profile comparisons with correlative measurements. For cases when the SR and SS comparisons were performed separately or when only one type of occultation was used, the mean relative differences are labeled this way. SR/SS is used when the comparison was not separated by occultation type. Columns 2-5: for ACE-FTS, number of comparison pairs, continuous altitude range in which the mean relative differences are globally within $\pm 10 \%$, mean value (column 4 ) and maximum/minimum values (column 5) in this range. Columns 6-9: same information for ACE-MAESTRO.

\begin{tabular}{|c|c|c|c|c|c|c|c|c|}
\hline \multirow[t]{3}{*}{ Instrument } & \multicolumn{4}{|c|}{ ACE-FTS } & \multicolumn{4}{|c|}{ ACE-MAESTRO } \\
\hline & \multirow{2}{*}{$\begin{array}{l}\text { Number } \\
\text { of events }\end{array}$} & \multirow{2}{*}{$\begin{array}{c}\text { Range } \\
{[\mathrm{km}]}\end{array}$} & \multicolumn{2}{|c|}{ Difference [\%] } & \multirow{2}{*}{$\begin{array}{l}\text { Number } \\
\text { of events }\end{array}$} & \multirow{2}{*}{$\begin{array}{c}\text { Range } \\
{[\mathrm{km}]}\end{array}$} & \multicolumn{2}{|c|}{ Difference [\%] } \\
\hline & & & Mean & Range & & & Mean & Range \\
\hline SAGE II & $30(\mathrm{SS})$ & $11-46$ & +4.7 & +0.6 to +13.7 & $30(\mathrm{SS})$ & $15-48$ & +0.3 & -5.1 to +9.9 \\
\hline \multirow[t]{2}{*}{ HALOE } & $8(\mathrm{SR})$ & $19-40$ & +8.0 & +4.9 to +13.5 & $8(\mathrm{SR})$ & $15-39$ & +5.1 & -6.6 to +15.5 \\
\hline & $41(\mathrm{SS})$ & $16-40$ & +7.1 & +3.4 to +11.9 & $40(\mathrm{SS})$ & $12-40$ & +3.0 & -10.6 to +9.2 \\
\hline \multirow[t]{2}{*}{ SAGE III ${ }^{\mathrm{a}}$} & 37 (SR) & $11-50$ & +3.5 & -12.2 to +18.2 & $12(\mathrm{SR})$ & $15-48$ & -5.0 & -13.5 to +12.2 \\
\hline & $611(\mathrm{SS})$ & $10-45$ & +1.9 & -2.5 to +9.2 & $695(\mathrm{SS})$ & $15-41$ & +0.7 & -7.1 to +9.3 \\
\hline \multirow[t]{2}{*}{ OSIRIS (York) } & $913(\mathrm{SR} / \mathrm{SS})$ & $10-40$ & +6.9 & -5.3 to +10.6 & $439(\mathrm{SR})$ & $15-40$ & +5.3 & -9.9 to +12.0 \\
\hline & - & - & - & - & $548(\mathrm{SS})$ & $15-40$ & +3.0 & -2.0 to +9.9 \\
\hline OSIRIS (SaskMART) & $1219(\mathrm{SR} / \mathrm{SS})$ & $9-48$ & +4.5 & -5.6 to +8.8 & $489(\mathrm{SR})$ & $18-54$ & +1.8 & -2.1 to +6.7 \\
\hline SABER & - & - & - & - & 3383 (SS) & $19-44$ & +1.5 & -9.5 to +9.5 \\
\hline GOMOS & $1240(\mathrm{SR} / \mathrm{SS})$ & $12-40$ & +3.4 & -9.1 to +9.0 & - & - & - & - \\
\hline MIPAS (ESA f.r.) & $138(\mathrm{SS})$ & $11-41$ & +2.7 & -5.5 to +9.9 & - & - & - & - \\
\hline MIPAS (ESA r.r.) & $160(\mathrm{SR} / \mathrm{SS})$ & $14-45$ & +1.8 & -3.8 to +8.1 & - & - & - & - \\
\hline MIPAS (IMK-IAA, day) & $348(\mathrm{SS})$ & $8-45$ & +3.0 & -4.8 to +10.7 & - & - & - & - \\
\hline MIPAS (IMK-IAA, night) & $333(\mathrm{SS})$ & $9-43$ & +2.1 & -6.3 to +8.4 & - & - & - & - \\
\hline SCIAMACHY & $734(\mathrm{SR} / \mathrm{SS})$ & $17-41^{\mathrm{c}}$ & +4.2 & -4.0 to +16.2 & - & - & - & - \\
\hline \multirow[t]{2}{*}{ Aura-MLS } & $3178(\mathrm{SR} / \mathrm{SS})$ & $12-43$ & +4.7 & -1.3 to +9.1 & $1254(\mathrm{SR})$ & $19-48$ & +5.9 & -6.6 to +10.9 \\
\hline & - & - & - & - & $1910(\mathrm{SS})$ & $19-39$ & -1.1 & -9.6 to +9.1 \\
\hline ASUR & 39 (SR) & $18-38$ & +1.8 & -8.0 to +7.1 & 37 (SR) & $20-44$ & +0.3 & -9.5 to +9.2 \\
\hline Ozonesondes ${ }^{\mathrm{d}}$ & $376(\mathrm{SR} / \mathrm{SS})$ & $11-35$ & +5.0 & -1.0 to +9.7 & $151(\mathrm{SR})$ & $17-33$ & +1.6 & -5.0 to +10.1 \\
\hline
\end{tabular}

a For comparisons of ACE-MAESTRO with POAM III and SAGE III, results are taken from Kar et al. (2007).

b Comparisons with SMR: altitude range with differences of +10 to $+20 \%$ for ACE-FTS ( +5 to $+20 \%$ for ACE-MAESTRO); Comparisons of ACE-MAESTRO with the Eureka lidar: range with abs(differences) lower than $20 \%$.

${ }^{c}$ Range restricted to the levels recommended for the SCIAMACHY limb-scattering measurements.

${ }^{\mathrm{d}}$ Results from the statistical analyses presented in Sect. 6.5.

${ }^{\mathrm{e}}$ Results from the detailed NDACC study of Sect. 6.6.

instruments, namely the ACE-FTS version 2.2 Ozone Update and the ACE-MAESTRO version 1.2 data products. These datasets have been compared with VMR profiles from 11 satellite-borne instruments as well as ozonesondes and aircraft, balloon-borne and ground-based observations, over a time period of 1.5-3 years. Moreover, partial columns derived from the ACE measurements were compared with ground-based FTIR instruments. In these analyses, efforts were made to use consistent coincidence criteria, comparison methodology and data filtering (including selection of events with simultaneous observations from ACE-FTS, ACE-MAESTRO and the comparison instrument) in order to 
better assess the overall quality of the ACE-FTS and ACEMAESTRO $\mathrm{O}_{3}$ data products. The overall results of the intercomparisons are summarized in Table 5 (partial column comparisons with ground-based FTIR instruments) and Table 7 (profile comparisons).

The analyses show generally good agreement and very good consistency between ACE-FTS, ACE-MAESTRO and the correlative instruments in the stratosphere. Biases were identified over particular altitude domains in both datasets. The main findings for the ACE-FTS version 2.2 Ozone Update product are that there is very good agreement with the correlative measurements in the stratosphere, with a slight positive bias with mean relative differences of about $5 \%$ between 15 and $45 \mathrm{~km}$ and a larger, well-characterized, systematic bias above $42-45 \mathrm{~km}$. The analyses are remarkably consistent for the range of data products used in the comparisons, with a few exceptions which are generally accounted for by known biases of the comparison instrument. The debiased standard deviation of the mean relative differences can be used to evaluate the ACE-FTS and comparison instrument combined precision. It shows that the statistical fitting errors appear to be an acceptable precision estimate for the ACE-FTS retrievals. This implies that the ACE-FTS measurements have good precision, comparable to, or lower than that of the correlative instruments. Complete precision validation will be undertaken for the next version of the ACEFTS ozone data product.

For the ACE-MAESTRO version 1.2 data product obtained from the VIS spectrometer, there is a noticeable bias between observations performed at sunrise and at sunset. Agreement for the SS measurements is generally better (with mean relative differences of $+4 \%$ on average) in the range 20-40 km than that found for the SR events (with mean relative differences close to zero but showing a large scatter of $\pm 15 \%$ ), but there is a high bias above $\sim 45 \mathrm{~km}$ similar to the one noted for ACE-FTS. The SS difference profiles more closely resemble the results found for the ACE-FTS analyses. For ACE-MAESTRO, preliminary analysis of the de-biased standard deviations of the mean relative differences indicate that ACE-MAESTRO has poorer precision than ACE-FTS. The spectral fitting errors currently reported are not enough to account for the ACE-MAESTRO contribution to the random error budget of the comparison. Possible additional sources of random error are being investigated and should be included in the error budget of the ACE-MAESTRO ozone data product.

For both ACE-FTS and ACE-MAESTRO, comparisons of partial columns with ground-based FTIR instruments confirm the overall results and show comparable agreement with all stations.

Tests with a preliminary version of the next generation ACE-FTS retrievals (version 3.0) have shown that the slight positive stratospheric bias has been removed and that the large mesospheric differences have been decreased but are still present. Possible sources for these biases are being in- vestigated at the time of writing. Additional work is ongoing to resolve the differences between the SR and SS retrievals for ACE-MAESTRO. A complete characterization of the random and systematic errors for both instruments will be undertaken during development of the next versions of the ACE ozone products. The ACE-FTS and ACE-MAESTRO ozone measurements analyzed in this work will be a valuable dataset to continue the long-standing record of occultation measurements from space and will play a role in monitoring stratospheric ozone recovery.

Acknowledgements. Funding for the ACE mission was provided primarily by the Canadian Space Agency (CSA) and the Natural Sciences and Engineering Research Council (NSERC) of Canada. The Canadian Arctic ACE Validation Campaign project has been supported by CSA, Environment Canada (EC), NSERC, the Northern Scientific Training Program and the Centre for Global Change Science at the University of Toronto. Logistical and on-site technical support for the 2006 campaign was provided by the Canadian Network for the Detection of Atmospheric Change (CANDAC). CANDAC and PEARL are funded by the Canadian Foundation for Climate and Atmospheric Sciences (CFCAS), NSERC, the Canadian Foundation for Innovation (CFI), the Ontario Innovation Trust, the Ontario Ministry of Research and Innovation, and the Nova Scotia Research and Innovation Trust.

The comparisons with the solar occultation instruments conducted at the Laboratory for Atmospheric and Space Physics (LASP) by C. Randall were supported by the National Aeronautics and Space Administration (NASA) under the grant No. NNG04GF39G. We gratefully acknowledge L. Harvey for processing the ACE data into a suitable format for those comparisons.

The authors thank the SABER and HALOE Science and Data Processing Teams for providing the ozone profiles used in this work and for helpful discussions and comments on the manuscript.

Odin is a Swedish-led satellite project funded jointly by the Swedish National Space Board (SNSB), the CSA, the Centre National d'Études Spatiales (CNES) in France and the National Technology Agency of Finland (Tekes). The OSIRIS ozone retrievals were supported by CSA and NSERC.

SCIAMACHY is jointly funded by Germany, the Netherlands, and Belgium. The analysis of SCIAMACHY measurements was supported in part by the German Ministry of Education and Research (BMBF), the German Aerospace Center (DLR) and the University of Bremen. This validation work for the ozone comparisons between ACE and SCIAMACHY was funded in part by ESA under the SciLoV project, and by BMBF under the project DLR 50EE0502.

The SAOZ flights in Niger were carried out in the framework of the SCOUT-O3/AMMA campaign supported by the European Commission, CNES and CNRS-LEFE.

The SPIRALE balloon measurements could only be performed thanks to the technical team (L. Pomathiod, B. Gaubicher, G. Jannet). The flight was funded by ESA and CNES for the Envisat validation project. The CNES balloon launching team is greatly acknowledged for successful operations. A. Hauchecorne is acknowledged for making available the MIMOSA advection model and thanks are extended to F. Coquelet for useful help in the PV calculations and ACE data formatting. 
The correlative data from ozonesondes and ground-based lidars and FTIRs used in this publication were obtained as part of the WMO-GAW programme, including the NDACC (http://www.ndacc.org) and the WOUDC (http://www.woudc.org). This programme relies on the contribution of ground-based stations which are nationally funded and supported. The Belgian contributions to the present effort were partly supported by the ProDEx projects ACE, CINAMON and Envisat Database. We are grateful to the following institutes, and thank their co-workers who contributed to generating lidar data: AWI (Ny-Ålesund station, PI R. Neuber and O. Schrems), NILU (ALOMAR, Andoya station, PI G. H. Hansen) and DWD (Hohenpeißenberg station, PI H. Claude).

The European ground-based FTIR stations have been supported partly by the EU project UFTIR (http://www.nilu.no/uftir). Thanks are extended to the "International Foundation High Altitude Research Stations Jungfraujoch and Gornergrat" (HFSJG, Bern, Switzerland) for hosting the Liège FTIR laboratory and for providing accommodation for the observers at the Jungfraujoch site.

Work at the Toronto Atmospheric Observatory was supported by NSERC, CSA, CFCAS, ABB Bomem, the Ontario Research and Development Challenge Fund, the Premier's Excellence Research Award and the University of Toronto.

Thanks to B. Bojkov of the Aura Validation Data Center (AVDC) and the Aura-MLS Data Distribution Team for access to the Aura-MLS dataset (see http://avdc.gsfc.nasa.gov). Work at the Jet Propulsion Laboratory (JPL), California Institute of Technology (CalTech), is carried out under a contract with NASA. Work at the University of Massachusetts is supported by NASA under award No. NNG05GN46G.

Edited by: A. Richter

\section{References}

Barret, B., De Mazière, M., and Demoulin, P.: Retrieval and characterization of ozone profiles from solar infrared spectra at the Jungfraujoch, J. Geophys. Res., 107, 4788-4803, doi:10.1029/2001JD001298, 2002.

Barret, B., De Mazière, M., and Demoulin, P.: Correction to "Retrieval and characterization of ozone profiles from solar infrared spectra at the Jungfraujoch", J. Geophys. Res., 108(D12), 4372, doi:10.1029/2003JD003809, 2003.

Barret, B., Ricaud, P., Santee, M. L., Attié, J.-L., Urban, J., Le Flochmoën, E., Berthet, G., Murtagh, D., Eriksson, P., Jones, A., de La Noë, J., Dupuy, E., Froidevaux, L., Livesey, N. J., Waters, J. W., and Filipiak, M. J.: Intercomparison of trace gases profiles from the Odin/SMR and Aura/MLS limb sounders, J. Geophys. Res., 111, D21302, doi:10.1029/2006JD007305, 2006.

Bernath, P. F., McElroy, C. T., Abrams, M. C., Boone, C. D., Butler, M., Camy-Peyret, C., Carleer, M., Clerbaux, C., Coheur, P.F., Colin, R., DeCola, P., De Mazière, M., Drummond, J. R., Dufour, D., Evans, W. F. J., Fast, H., Fussen, D., Gilbert, K., Jennings, D. E., Llewellyn, E. J., Lowe, R. P., Mahieu, E., McConnell, J. C., McHugh, M., McLeod, S. D., Michaud, R., Midwinter, C., Nassar, R., Nichitiu, F., Nowlan, C., Rinsland, C. P., Rochon, Y. J., Rowlands, N., Semeniuk, K., Simon, P., Skelton, R., Sloan, J. J., Soucy, M.-A., Strong, K., Tremblay, P., Turnbull, D., Walker, K. A., Walkty, I., Wardle, D. A., Wehrle, V.,
Zander, R., and Zou, J.: Atmospheric Chemistry Experiment (ACE): Mission overview, Geophys. Res. Lett., 32, L15S01, doi:10.1029/2005GL022386, 2005.

Bhatt, P. P., Remsberg, E. E., Gordley, L. L., McInerney, J. M., Brackett, V. G., and Russell III, J. M.: An evaluation of the quality of Halogen Occultation Experiment ozone profiles in the lower atmosphere, J. Geophys. Res., 104(D8), 9261-9276, doi:10.1029/1999JD900058, 1999.

Bird, J. C., Pal, S. R., Carswell, A. I., Donovan, D. P., Manney, G. L., Harris, J. M., and Uchino, O.: Observations of ozone structures in the Arctic polar vortex, J. Geophys. Res., 102(D9), 10785-10800, doi:10.1029/96JD03787, 1997.

Blumenstock, T., Kopp, G., Hase, F., Hochschild, G., Mikuteit, S., Raffalski, U., and Ruhnke, R.: Observation of unusual chlorine activation by ground-based infrared and microwave spectroscopy in the late Arctic winter 2000/01, Atmos. Chem. Phys., 6, 897905, 2006, http://www.atmos-chem-phys.net/6/897/2006/.

Boone, C. D., Nassar, R., Walker, K. A., Rochon, Y., McLeod, S. D., Rinsland, C. P., and Bernath, P. F.: Retrievals for the Atmospheric Chemistry Experiment Fourier-transform spectrometer, Appl. Optics, 44(33), 7218-7231, 2005.

Borchi, F., Pommereau, J.-P., Garnier, A., and Pinharanda, M.: Evaluation of SHADOZ sondes, HALOE and SAGE II ozone profiles at the tropics from SAOZ UV-Vis remote measurements onboard long duration balloons, Atmos. Chem. Phys., 5, 13811397, 2005, http://www.atmos-chem-phys.net/5/1381/2005/.

Borchi, F. and Pommereau, J.-P.: Evaluation of ozonesondes, HALOE, SAGE II and III, Odin- OSIRIS and -SMR, and ENVISAT-GOMOS, -SCIAMACHY and -MIPAS ozone profiles in the tropics from SAOZ long duration balloon measurements in 2003 and 2004, Atmos. Chem. Phys., 7, 2671-2690, 2007, http://www.atmos-chem-phys.net/7/2671/2007/.

Bourassa, A. E., Degenstein, D. A., and Llewellyn, E. J.: SASKTRAN: A Spherical Geometry Radiative Transfer Code for Measurements of Limb Scattered Sunlight, J. Quant. Spectrosc. Radiat. Trans., 109(1), 52-73, 2008.

Bovensmann, H., Burrows, J. P., Buchwitz, M., Frerick, J., Noël, S., Rozanov, V. V., Chance, K. V., and Goede, A. P. H.: SCIAMACHY: Mission objectives and measurement modes, J. Atmos. Sci., 56(2), 127-150, 1999.

Boyd, I. S., Parrish, A. D., Froidevaux, L., von Clarmann, T., Kyrölä, E., Russell III, J. M., and Zawodny, J. M.: Groundbased microwave ozone radiometer measurements compared with Aura-MLS v2.2 and other instruments at two NDACC sites, J. Geophys. Res., 112, D24S33, doi:10.1029/2007JD008720, 2007.

Bracher, A., Bovensmann, H., Bramstedt, K., Burrows, J. P., von Clarmann, T., Eichmann, K.-U., Fischer, H., Funke, B., GilLópez, S., Glatthor, N., Grabowski, U., Höpfner, M., Kaufmann, M., Kellmann, S., Kiefer, M., Koukouli, M. E., A. Lindenb, López-Puertas, M., Mengistu Tsidu, G., Milz, M., Noel, S., Rohen, G., Rozanov, A., Rozanov, V. V., von Savigny, C., Sinnhuber, M., Skupin, J., Steck, T., Stiller, G. P., Wang, D.-Y., Weber, M., and Wuttke, M. W.: Cross comparisons of $\mathrm{O}_{3}$ and $\mathrm{NO}_{2}$ measured by the atmospheric ENVISAT instruments GOMOS, MIPAS, and SCIAMACHY, Adv. Space Res., 36(5), 855-867, 2005.

Brewer, A. and Milford, J.: The Oxford Kew ozone sonde, Proc. Roy. Soc. London, Ser. A, 256, 470-495, 1960. 
Brinksma, E. J., Bracher, A., Lolkema, D. E., Segers, A. J., Boyd, I. S., Bramstedt, K., Claude, H., Godin-Beekmann, S., Hansen, G., Kopp, G., Leblanc, T., McDermid, I. S., Meijer, Y. J., Nakane, H., Parrish, A., von Savigny, C., Stebel, K., Swart, D. P. J., Taha, G., and Piters, A. J. M.: Geophysical validation of SCIAMACHY Limb Ozone Profiles, Atmos. Chem. Phys., 6, 197209, 2006, http://www.atmos-chem-phys.net/6/197/2006/.

Brohede, S., Jones, A., and Jégou, F.: Internal consistency in the Odin stratospheric ozone products, Can. J. Phys., 85, 1275-1285, 2007.

Brühl, C., Drayson, S. R., Russell, J. M. III, Crutzen, P. J., McInerney, J. M., Purcell, P. N., Claude, H., Gernandt, H., McGee, T. J., McDermid, I. S., and Gunson, M. R.: Halogen Occultation Experiment ozone channel validation, J. Geophys. Res., 101(D6), 10217-10240, doi:10.1029/95JD020310, 1996.

Canty, T., Pickett, H. M., Salawitch, R. J., Jucks, K. W., Traub, W. A., and Waters, J. W.: Stratospheric and mesospheric $\mathrm{HO}_{\mathrm{x}}$ : results from Aura-MLS and FIRS-2, Geophys. Res. Lett., 33, L12802, doi:10.1029/2006GL025964, 2006.

Carswell, A. I., Pal, S. R., Steinbrecht, W., Whiteway, J. A., Ulitsky, A., and Wang, T. Y.: Lidar measurements of the middle atmosphere, Can. J. Phys., 69, 1076-1086, 1991.

Ceccherini, S., Belotti, C., Carli, B., Raspollini, P., and Ridolfi, M.: MIPAS new measurement scenario: enhanced vertical resolution and regularization, in Proceedings of "Atmospheric Science Conference" SP-628, ESA-ESRIN Frascati, Italy, 8-12 May 2006.

Ceccherini, S., Belotti, C., Carli, B., Raspollini, P., and Ridolfi, M.: Technical Note: Regularization performances with the error consistency method in the case of retrieved atmospheric profiles, Atmos. Chem. Phys., 7, 1435-1440, 2007,

http://www.atmos-chem-phys.net/7/1435/2007/.

Ceccherini, S., Cortesi, U., Verronen, P. T., and Kyrölä, E.: Technical Note: Continuity of MIPAS-ENVISAT operational ozone data quality from full- to reduced-spectral-resolution operation mode, Atmos. Chem. Phys., 8, 2201-2212, 2008, http://www.atmos-chem-phys.net/8/2201/2008/.

Chabrillat, S. and Fonteyn, D.: Modeling long-term changes of mesospheric temperature and chemistry, Adv. Space Res., 32(9), 1689-1700, 2003.

Chu, W. P., McCormick, M. P., Lenoble, J., Brogniez, C., and Pruvost, P.: SAGE II inversion algorithm, J. Geophys. Res., 94(D6), 8339-8351, doi:10.1029/89JD00113, 1989.

Cofield, R. E. and Stek, P. C.: Design and field-of-view calibration of 114-660 GHz optics of the Earth Observing System Microwave Limb Sounder, IEEE Trans. Geosci. Remote Sens., 44(5), 1166-1181, doi:10.1109/TGRS.2006.873234, 2006.

Connor, B. J., Parrish, A., Tsou, J.-J., and McCormick, M. P.: Error analysis for the ground-based microwave ozone measurements during STOIC, J. Geophys. Res., 100(D5), 9283-9292, doi:10.1029/94JD00413, 1995.

Cortesi, U., Lambert, J. C., De Clercq, C., Bianchini, G., Blumenstock, T., Bracher, A., Castelli, E., Catoire, V., Chance, K. V., De Mazière, M., Demoulin, P., Godin-Beekmann, S., Jones, N., Jucks, K., Keim, C., Kerzenmacher, T., Kuellmann, H., Kuttippurath, J., Iarlori, M., Liu, G. Y., Liu, Y., McDermid, I. S., Meijer, Y. J., Mencaraglia, F., Mikuteit, S., Oelhaf, H., Piccolo, C., Pirre, M., Raspollini, P., Ravegnani, F., Reburn, W. J., Redaelli, G., Remedios, J. J., Sembhi, H., Smale, D., Steck, T., Taddei, A., Varotsos, C., Vigouroux, C., Waterfall, A., Wetzel, G., and
Wood, S.: Geophysical validation of MIPAS-ENVISAT operational ozone data, Atmos. Chem. Phys., 7, 4807-4867, 2007, http://www.atmos-chem-phys.net/7/4807/2007/.

Degenstein, D. A., Bourassa, A. E., Roth, C. Z., and Llewellyn, E. J.: Limb scatter ozone retrieval from 10 to $60 \mathrm{~km}$ using a Multiplicative Algebraic Reconstruction Technique, Atmos. Chem. Phys. Discuss., 8, 11853-11877, 2008,

http://www.atmos-chem-phys-discuss.net/8/11853/2008/.

Donovan, D. P., Bird, J. C., Whiteway, J. A., Duck, T. J., Pal, S. R., and Carswell, A. I.: Lidar observations of stratospheric ozone and aerosol above the Canadian high arctic during the 1994-95 winter, Geophys. Res. Lett., 22(24), 3489-3492, 1995.

Dudhia, A., Jay, V. L., and Rodgers, C. D.: Microwindow selection for high-spectral-resolution sounders, Appl. Optics, 41, 36653673, 2002.

Dunkerton, T. J. and Delisi, D. P.: Evolution of potential vorticity in the winter stratosphere of January-February 1979, J. Geophys. Res., 91, 1199-1208, 1986.

Fischer, H., Birk, M., Blom, C., Carli, B., Carlotti, M., von Clarmann, T., Delbouille, L., Dudhia, A., Ehhalt, D., Endemann, M., Flaud, J. M., Gessner, R., Kleinert, A., Koopman, R., Langen, J., López-Puertas, M., Mosner, P., Nett, H., Oelhaf, H., Perron, G., Remedios, J., Ridolfi, M., Stiller, G., and Zander, R.: MIPAS: an instrument for atmospheric and climate research, Atmos. Chem. Phys., 8, 2151-2188, 2008,

http://www.atmos-chem-phys.net/8/2151/2008/.

Flittner, D. E., Bhartia, P. K., and Herman, B. M.: $\mathrm{O}_{3}$ profiles retrieved from limb scatter measurements: Theory, Geophys. Res. Lett., 27(17), 2601-2604, doi:10.1029/1999GL011343, 2000.

Forbes, J. M., Russell, J., Miyahara, S., Zhang, X., Palo, S., Mlynczak, M., Mertens, C. J., and Hagan, M. E.: Tropospherethermosphere tidal coupling as measured by the SABER instrument on TIMED during July-September 2002, J. Geophys. Res., 111, A10S06, doi:10.1029/2005JA011492, 2006.

Fraser, A., Goutail, F., Strong, K., Bernath, P. F., Boone, C., Daffer, W. H., Drummond, J. R., Dufour, D. G., Kerzenmacher, T. E., Manney, G. L., McElroy, C. T., Midwinter, C., McLinden, C. A., Nichitiu, F., Nowlan, C. R., Walker, J., Walker, K. A., Wu, H., and Zou, J.: Intercomparison of UV-visible measurements of ozone and $\mathrm{NO}_{2}$ during the Canadian Arctic ACE validation campaigns: 2004-2006, Atmos. Chem. Phys., 8, 1763-1788, 2008, http://www.atmos-chem-phys.net/8/1763/2008/.

Froidevaux, L., Livesey, N. J., Read, W. G., Jiang, Y. B., Jimenez, C., Filipiak, M. J., Schwartz, M. J., Santee, M. L., Pumphrey, H. C., Jiang, J. H., Wu, D. L., Manney, G. L., Drouin, B. J., Waters, J. W., Fetzer, E. J., Bernath, P. F., Boone, C. D., Walker, K. A., Jucks, K. W., Toon, G. C., Margitan, J. J., Sen, B., Webster, C. R., Christensen, L. E., Elkins, J. W., Atlas, E., Lueb, R. A., and Hendershot, R.: Early validation analyses of atmospheric profiles from EOS MLS on the Aura satellite, IEEE Trans. Geosci. Remote Sens., 44(5), 1106-1121, doi:10.1109/TGRS.2006.864366, 2006.

Froidevaux, L., Jiang, Y. B., Lambert, A., Livesey, N. J., Read, W. G., Waters, J. W., Browell, E. V., Hair, J. W., Avery, M. A., McGee, T. J., Twigg, L. W., Sumnicht, G. K., Jucks, K. W., Margitan, J. J., Sen, B., Stachnik, R. A., Toon, G. C., Bernath, P. F., Boone, C. D., Walker, K. A., Filipiak, M. J., Harwood, R. S., Fuller, R. A., Manney, G. L., Schwartz, M. J., Daffer, W. H., Drouin, B. J., Cofield, R. E., Cuddy, D. T., Jarnot, R. F., 
Knosp, B. W., Perun, V. S., Snyder, W. V., Stek, P. C., Thurstans, R. P., and Wagner, P. A.: Validation of Aura Microwave Limb Sounder stratospheric ozone measurements, J. Geophys. Res., 113, D15S20, doi:10.1029/2007JD008771, 2008.

Fu, D., Walker, K. A., Mittermeier, R. L., Strong, K., Sung, K., Fast, H., Bernath, P. F., Boone, C. D., Daffer, W. H., Fogal, P., Kolonjari, F., Loewen, P., Manney, G. L., and Mikhailov, O.: Simultaneous atmospheric measurements using two Fourier transform infrared spectrometers at the Polar Environment Atmospheric Research Laboratory during spring 2006, and comparisons with the Atmospheric Chemistry Experiment-Fourier Transform Spectrometer, Atmos. Chem. Phys. Discuss., 8, 53055358, 2008,

http://www.atmos-chem-phys-discuss.net/8/5305/2008/.

Fussen, D., Vanhellemont, F., Dodion, J., Bingen, C., Walker, K. A., Boone, C. D., McLeod, S. D., and Bernath, P. F.: Initial intercomparison of ozone and nitrogen dioxide number density profiles retrieved by the ACE-FTS and GOMOS occultation experiments, Geophys. Res. Lett., 32, L16S02, doi:10.1029/2005GL022468, 2005.

Glatthor, N., von Clarmann, T., Fischer, H., Funke, B., Gil-López, S., Grabowski, U., Höpfner, M., Kellmann, S., Linden, A., López-Puertas, M., Mengistu Tsidu, G., Milz, M., Steck, T., Stiller, G. P., and Wang, D.-Y.: Retrieval of stratospheric ozone profiles from MIPAS/ENVISAT limb emission spectra: a sensitivity study, Atmos. Chem. Phys., 6, 2767-2781, 2006, http://www.atmos-chem-phys.net/6/2767/2006/.

Godin, S., Carswell, A. I., Donovan, D. P., Claude, H., Steinbrecht, W., McDermid, I. S., McGee, T. J., Gross, M. R., Nakane, H., Swart, D. P. J., Bergwerff, H. B., Uchino, O., von der Gathen, P., and Neuber, R.: Ozone differential absorption lidar algorithm intercomparison, Appl. Optics, 38(30), 6225-6236, 1999.

Goldman, A., Paton-Walsh, C., Bell, W., Toon, G. C., Blavier, J. F., Sen, B., Coffey, M. T., Hannigan, J. W., and Mankin, W. G.: Network for the Detection of Stratospheric Change Fourier transform infrared intercomparison at Table Mountain Facility, November 1996, J. Geophys. Res., 104(D23), 3048130503, 1999.

Griffith, D. W. T., Jones, N. B., and Matthews, W. A.: Interhemispheric ratio and annual cycle of carbonyl sulphide (OCS) total column from ground-based FTIR spectra, J. Geophys. Res., 103(D7), 8447-8454, 1998.

Gunson, M. R., Abbas, M. M., Abrams, M. C., Allen, M., Brown, L. R., Brown, T. L., Chang, A. Y., Goldman, A., Irion, F. W., Lowes, L. L., Mahieu, E., Manney, G. L., Michelsen, H. A., Newchurch, M. J., Rinsland, C. P., Salawitch, R. J., Stiller, G. P., Toon, G. C., Yung, Y. L., and Zander, R.: The Atmospheric Trace Molecule Spectroscopy (ATMOS) experiment: Deployment on the ATLAS Space Shuttle missions, Geophys. Res. Lett., 23(17), 2333, doi:10.1029/96GL01569, 1996.

Haley, C. S., Brohede, S., Sioris, C. E., Griffioen, E., Murtagh, D. P., McDade, I. C., Eriksson, P., Llewellyn, E. J., Bazureau, A., and Goutail, F.: Retrievals of stratospheric $\mathrm{O}_{3}$ and $\mathrm{NO}_{2}$ profiles from Odin/OSIRIS limb-scattered sunlight measurements, J. Geophys. Res., 109, D16303, doi:10.1029/2004JD004588, 2004.

Haley, C. S. and Brohede, S.: Status of the Odin/OSIRIS Stratospheric $\mathrm{O}_{3}$ and $\mathrm{NO}_{2}$ Data Products, Can. J. Phys., 85(11), 11771194, 2007.

Hase, F.: Inversion von Spurengasprofilen aus hochaufgelösten bodengebundenen FTIR-Messungen in Absorption, Wissenschaftliche Berichte Forschungszentrum Karlsruhe, FZKA 6512, ISSN 0947-8620, 2000.

Hase, F., Hannigan, J. W., Coffey, M. T., Goldman, A., Höpfner, M., Jones, N. B., Rinsland, C. P., and Wood, S. W.: Intercomparison of retrieval codes used for the analysis of high-resolution, ground-based FTIR measurements, J. Quant. Spectrosc. Radiat. Transfer, 87, 25-52, 2004.

Hauchecorne, A., Godin, S., Marchand, M., Heese, B., and Souprayen, C.: Quantification of the transport of chemical constituents from the polar vortex to midlatitudes in the lower stratosphere using the high-resolution advection model MIMOSA and effective diffusivity, J. Geophys. Res., 107(D20), 8289, doi:10.1029/2001JD000491, 2002.

Hegglin, M. I., Boone, C. D., Manney, G. L., Shepherd, T. G., Walker, K. A., Bernath, P. F., Daffer, W. H., Hoor, P., and Schiller, C.: Validation of ACE-FTS satellite data in the upper troposphere/lower stratosphere (UTLS) using non-coincident measurements, Atmos. Chem. Phys., 8, 1483-1499, 2008, http://www.atmos-chem-phys.net/8/1483/2008/.

Iyer, N., Zawodny, J. M., Thomason, L. W., and Burton, S. P.: Recent advances in SAGE II data processing: Version 6.2, Eos Trans. AGU, 84(46), Fall Meet. Suppl., Abstract A42C-0771, 2003.

Jarnot, R. F., Perun, V. S., and Schwartz, M. J.: Radiometric and spectral performance and calibration of the $\mathrm{GHz}$ bands of EOS MLS, IEEE Trans. Geosci. Remote Sens., 44(5), 1131-1143, doi:10.1109/TGRS.2005.863714, 2006.

Jégou, F., Urban, J., de La Noë, J., Ricaud, P., Le Flochmoën, E., Murtagh, D. P., Eriksson, P., Jones, A., Petelina, S., Llewellyn, E. J., Lloyd, N. D., Haley, C., Lumpe, J., Randall, C., Bevilacqua, R. M., Catoire, V., Huret, N., Berthet, G., Renard, J. B., Strong, K., Davies, J., Mc Elroy, C. T., Goutail, F., and Pommereau, J. P.: Technical Note: Validation of Odin/SMR limb observations of ozone, comparisons with OSIRIS, POAM III, ground-based and balloon-borne instruments, Atmos. Chem. Phys., 8, 33853409, 2008, http://www.atmos-chem-phys.net/8/3385/2008/.

Jiang, Y. B., Froidevaux, L., Lambert, A., Livesey, N. J., Read, W. G., Waters, J. W., Bojkov, B., Leblanc, T., McDermid, I. S., Godin-Beekman, S., Filipiak, M. J., Harwood, R. S., Fuller, R. A., Daffer, W. H., Drouin, B. J., Cofield, R. E., Cuddy, D. T., Jarnot, R. F., Knosp, B. W., Perun, V. S., Schwartz, M. J., Snyder, W. V., Stek, P. C., Thurstans, R. P., Wagner, P. A., Allaart, M., Andersen, S. B., Bodeker, G., Calpini, B., Claude, H., Coetzee, G., Davies, J., DeBacker, H., Dier, H., Fujiwara, M., Johnson, B., Kelder, H., Leme, N. P., König-Langlo, G., Kyrö, E., Laneve, G., Fook, L. S., Merrill, J., Morris, G., Newchurch, M., Oltmans, S., Parrondos, M. C., Posny, F., Schmidlin, F., Skrivankova, P., Stubi, R., Tarasick, D. W., Thompson, A. M., Thouret, V., Viatte, P., Vomel, H., von der Gathen, P., Yela, M., and Zablocki, G.: Validation of the Aura Microwave Limb Sounder ozone by ozonesonde and lidar measurements, J. Geophys. Res., 112, D24S34, doi:10.1029/2007JD008776, 2007.

Johnson, D. G., Jucks, K. W., Traub, W. A., and Chance, K. V.: Smithsonian stratospheric far-infrared spectrometer and data reduction system, J. Geophys. Res., 100(D2), 3091-3106, doi:10.1029/94JD02685, 1995.

Jones, A., Murtagh, D., Urban, J., Eriksson, P., and Rösevall, J.: Intercomparison of Odin/SMR ozone measurements with MIPAS 
and balloonsonde data, Can. J. Phys., 85, 1111-1123, 2007.

Jucks, K. W., Johnson, D. G., Chance, K. V., Traub, W. A., Margitan, J. M., Stachnik, R., Sasano, Y., Yokota, T., Kanzawa, H., Shibasaki, K., Suzuki, M., and Ogawa, T.: Validation of ILAS v5.2 data with FIRS-2 balloon observations, J. Geophys. Res., 107(D24), 8207, doi:10.1029/2001JD000578, 2002.

Kaiser, J. W. and Burrows, J. P.: Fast weighting functions for retrievals from limb scattering measurements, J. Quant. Spectrosc. Radiat. Transfer, 77(3), 273-283, 2003.

Kaiser, J. W., von Savigny, C., Eichmann, K. U., Noël, S., Bovensmann, H., Frerick, J., and Burrows, J. P.: Satellite-pointing retrieval from atmospheric limb-scattering of solar UV-B radiation, Can. J. Phys., 82(12), 1041-1052, 2004.

Kar, J., Trepte, C. R., Thomason, L. W., Zawodny, J. M., Cunnold, D. M., and Wang, H. J.: On the tropospheric measurements of ozone by the Stratospheric Aerosol and Gas Experiment II (SAGE II, version 6.1) in the tropics, Geophys. Res. Lett., 29(24), 2208, doi:10.1029/2002GL016241, 2002.

Kar, J., McElroy, C. T., Drummond, J. R., Zou, J., Nichitiu, F., Walker, K. A., Randall, C. E., Nowlan, C. R., Dufour, D. G., Boone, C. D., Bernath, P. F., Trepte, C. R., Thomason, L. W., and McLinden, C.: Initial comparison of Ozone and $\mathrm{NO}_{2}$ profiles from ACE-MAESTRO with Balloon and Satellite Data, J. Geophys. Res., 112, D16301, doi:10.1029/2006JD008242, 2007.

Kasai, Y. J., Kagawa, A., Jones, N., Fujiwara, A., Seki, K., Murayama, Y., and Murcray, F.: Seasonal Variations of $\mathrm{CO}$ and $\mathrm{HCN}$ in the Troposphere Measured by Solar Absorption Spectroscopy Over Poker Flat, Alaska, Geophys. Res. Lett., 32, L19812, doi:10.1029/2005GL022826, 2005.

Kazil, J., Kopp, E., Chabrillat, S., and Bishop, J.: The University of Bern Atmospheric Ion Model: Time-dependent modeling of the ions in the mesosphere and lower thermosphere, J. Geophys. Res., 108(D14), 4432, doi:10.1029/2001JD001276, 2003.

Keckhut, P., McDermid, S., Swart, D., McGee, T., GodinBeekmann, S., Adriani, A., Barnes, J., Baray, J.-L., Bencherif, H., Claude, H., di Sarra, A. G., Fiocco, G., Hansen, G., Hauchecorne, A., Leblanc, T., Lee, C. H., Pal, S., Mégie, G., Nakane, H., Neuber, R., Steinbrecht, W., and Thayer, J.: Review of ozone and temperature lidar validations performed within the framework of the Network for the Detection of Stratospheric Change, J. Environ. Monit., 6, 721-733, doi:10.1039/b404256e, 2004.

Kerzenmacher, T., Walker, K. A., Strong, K., Berman, R., Bernath, P. F., Boone, C. D., Drummond, J. R., Fast, H., Fraser, A., MacQuarrie, K., Midwinter, C., Sung, K., McElroy, C. T., Mittermeier, R. L., Walker, J., and Wu, H.: Measurements of $\mathrm{O}_{3}, \mathrm{NO}_{2}$ and Temperature during the 2004 Canadian Arctic ACE Validation Campaign, Geophys. Res. Lett., 32, L16S07, doi:10.1029/2005GL023032, 2005.

Kobayashi, J. and Toyama, Y.: On various methods of measuring the vertical distribution of atmospheric ozone: (III) - Carbon iodine type chemical ozone sonde, Pap. Met. Geophys., 17, 113126, 1966.

Komhyr, W. D., Barnes, R. A., Brothers, G. B., Lathrop, J. A., and Opperman, D. P.: Electrochemical concentration cell ozonesonde performance evaluation during STOIC 1989, J. Geophys. Res., 100(D5), 9231-9244, doi:10.1029/94JD02175, 1995.

Kouker, W., Offermann, D., Küll, V., Reddmann, T., Ruhnke, R., and Franzen, A.: Streamers observed by the CRISTA experi- ment and simulated in the KASIMA model, J. Geophys. Res., 104(D13), 16405-16418, doi:10.1029/1999JD900177, 1999.

Kuttippurath, J., Bremer, H., Burrows, J., Kleinböhl, A., Küllmann, H., Künzi, K., Notholt, J., Sinnhuber, M., von Savigny, C., Lautié, N., Murtagh, D., Urban, J., Milz, M., Stiller, G., Petelina, S., de La Noë, J., Le Flochmoën, E., and Ricaud, P.: Intercomparison of ozone profile measurements from ASUR, SCIAMACHY, MIPAS, OSIRIS, and SMR, J. Geophys. Res., 112, D09311, doi:10.1029/2006JD007830, 2007.

Kyrölä, E., Tamminen, J., Leppelmeier, G. W., Sofieva, V., Hassinen, S., Bertaux, J.-L., Hauchecorne, A., Dalaudier, F., Cot, C., Korablev, O., Hembise, O., Barrot, G., Mangin, A., Théodore, B., Guirlet, M., Etanchaud, F., Snoeij, P., Koopman, R., Saavedra, L., Fraisse, R., Fussen, D., and Vanhellemont, F.: GOMOS on Envisat: An overview, Adv. Space Res., 33, 1020-1028, doi:10.1016/S0273-1177(03)00590-8, 2004.

Kyrölä, E., Tamminen, J., Leppelmeier, G. W., Sofieva, V., Hassinen, S., Bertaux, J.-L., Hauchecorne, A., Dalaudier, F., Fussen, D., Vanhellemont, F., Fanton d'Andon, O., Barrot, G., Mangin, A., Théodore, B., Guirlet, M., Snoeij, P., Koopman, R., Saavedra, L., and Meijer, Y. J.: Nighttime ozone profiles in the stratosphere and mesosphere by the Global Ozone Monitoring by Occultation of Stars on Envisat, J. Geophys. Res., 111, D24306, doi:10.1029/2006JD00577193, 2006.

Lamsal, L. N., Weber, M., Tellmann, S., and Burrows, J. P.: Ozone column classified climatology of ozone and temperature profiles based on ozonesonde and satellite data, J. Geophys. Res., 109, D20304, doi:10.1029/2004JD004680, 2004.

Livesey, N. J., Van Snyder, W., Read, W. J., and Wagner, P. A.: Retrieval algorithms for the EOS Microwave Limb Sounder (MLS), IEEE Trans. Geosci. Remote Sens., 44(5), 1144-1155, doi:10.1109/TGRS.2006.872327, 2006.

Llewellyn, E. J., Lloyd, N. D., Degenstein, D. A., Gattinger, R. L., Petelina, S. V., Bourassa, A. E., Wiensz, J. T., Ivanov, E. V., McDade, I. C., Solheim, B. H., McConnell, J. C., Haley, C. S., von Savigny, C., Sioris, C. E., McLinden, C. A., Griffioen, E., Kaminski, J., Evans, W. F. J., Puckrin, E., Strong, K., Wehrle, V., Hum, R. H., Kendall, D. J. W., Matsushita, J., Murtagh, D. P., Brohede, S., Stegman, J., Witt, G., Barnes, G., Payne, W. F., Piché, L., Smith, K., Warshaw, G., Deslauniers, D.-L., Marchand, P., Richardson, E. H., King, R. A., Wevers, I., McCreath, W., Kyrölä, E., Oikarinen, L., Leppelmeier, G. W., Auvinen, H., Mégie, G., Hauchecorne, A., Lefèvre, F., de La Nöe, J., Ricaud, P., Frisk, U., Sjoberg, F., von Scheele, F., and Nordh, L.: The OSIRIS instrument on the Odin spacecraft, Can. J. Phys., 82(6), 411-422, 2004.

Lucke, R. L., Korwan, D. R., Bevilacqua, R. M., Hornstein, J. S., Shettle, E. P., Chen, D. T., Daehler, M., Lumpe, J. D., Fromm, M. D., Debrestian, D., Neff, B., Squire, M., König-Langlo, G., and Davies, J.: The Polar Ozone and Aerosol Measurement (POAM) III instrument and early validation results, J. Geophys. Res., 104(D15), 18785-18800, doi:10.1029/1999JD900235, 1999.

Lumpe, J. D., Bevilacqua, R. M., Hoppel, K. W., and Randall, C. E.: POAM III retrieval algorithm and error analysis, J. Geophys. Res., 107(D21), 4575, doi:10.1029/2002JD002137, 2002.

Lumpe, J. D., Fromm, M., Hoppel, K. W., Bevilacqua, R. M., Randall, C. E., Browell, E. V., Grant, W. B., McGee, T., Burris, J., Twigg, L., Richard, E. C., Toon, G. C., Margitan, J. J., Sen, B., 
Pfeilsticker, K., Boesch, H., Fitzenberger, R., Goutail, F., and Pommereau, J. P.: Comparison of POAM III ozone measurements with correlative aircraft and balloon data during SOLVE, J. Geophys. Res., 108(D5), 8316, doi:10.1029/2001JD000472, 2003.

Manney, G. L., Zurek, R. W., O'Neill, A., and Swinbank, R.: On the motion of air through the stratospheric polar vortex, J. Atmos. Sci., 51, 2973-2994, 1994.

Manney, G. L., Toon, G. C., and Zawodny, J. M.: Comparison of satellite ozone observations in coincident air masses in early November 1994, J. Geophys. Res., 106(D9), 9923-9944, doi:10.1029/2000JD900826, 2001.

Manney, G. L., Daffer, W. H., Zawodny, J. M., Bernath, P. F., Hoppel, K. W., Walker, K. A., Knosp, B. W., Boone, C. D., Remsberg, E. E., Santee, M. L., Harvey, V. L., Pawson, S., Jackson, D. R., Deaver, L., McElroy, C. T., McLinden, C. A., Drummond, J. R., Pumphrey, H. C., Lambert, A., Schwartz, M. J., Froidevaux, L., McLeod, S. D., Takacs, L. L., Suarez, M. J., Trepte, C. R., Cuddy, D. C., Livesey, N. J., Harwood, R. S., and Waters, J. W.: Solar occultation satellite data and derived meteorological products: sampling issues and comparisons with Aura MLS J. Geophys. Res., 112, D24S50, doi:10.1029/2007JD008709, 2007.

Manney, G. L., Daffer, W. H., Strawbridge, K. B., Walker, K. A., Boone, C. D., Bernath, P. F., Kerzenmacher, T., Schwartz, M. J., Strong, K., Sica, R. J., Krüger, K., Pumphrey, H. C., Lambert, A., Santee, M. L., Livesey, N. J., Remsberg, E. E., Mlynczak, M. G., and Russell III, J. R.: The high Arctic in extreme winters: vortex, temperature, and MLS and ACE-FTS trace gas evolution, Atmos. Chem. Phys., 8, 505-522, 2008, http://www.atmos-chem-phys.net/8/505/2008/.

Mauldin III, L. E., Zaun, N. H., McCormick, M. P., Guy, J. H., and Vaughn, W. R.: Stratospheric Aerosol and Gas Experiment II instruments: A functional description, Opt. Eng., 24, 307-312, 1985.

McElroy, C. T.: A spectroradiometer for the measurement of direct and scattered solar irradiance from on-board the NASA ER2 high-altitude research aircraft, Geophys. Res. Lett., 22(11), 1361-1364, doi:10.1029/95GL01391, 1995a.

McElroy, C. T., Midwinter, C., Barton, D. V., and Hall, R. B.: A comparison of J-values from the composition and photodissociative flux measurement with model calculations, Geophys. Res. Lett., 22(11), 1365-1368, doi:10.1029/95GL01392, 1995b.

McElroy, C. T., Nowlan, C. R., Drummond, J. R., Bernath, P. F., Barton, D. V., Dufour, D. G., Midwinter, C., Hall, R. B., Ogyu, A., Ullberg, A., Wardle, D. I., Kar, J., Zou, J., Nichitiu, F., Boone, C. D., Walker, K. A., and Rowlands, N.: The ACEMAESTRO instrument on SCISAT: Description, performance, and preliminary results, Appl. Optics, 46(20), 4341-4356, 2007.

McHugh, M., Magill, B., Walker, K. A., Boone, C. D., Bernath, P. F., and Russell III, J. M.: Comparisons of atmospheric retrievals from ACE and HALOE, Geophys. Res. Lett., 32, L15S10, doi:10.1029/2005GL022403, 2005.

McPeters, R. D., Janz, S. J., Hilsenrath, E., Brown, T. L., Flittner, D. E., and Heath, D. F.: The retrieval of $\mathrm{O}_{3}$ profiles from limb scatter measurements: Results from the Shuttle Ozone Limb Sounding Experiment, Geophys. Res. Lett., 27(17), 2597-2600, doi:10.1029/1999GL011342, 2000.

Meijer, Y. J., Swart, D. P. J., Allaart, M., Andersen, S. B., Bodeker,
G., Boyd, I., Braathen, G., Calisesi, Y., Claude, H., Dorokhov, V., von der Gathen, P., Gil, M., Godin-Beekmann, S., Goutail, F., Hansen, G., Karpetchko, A., Keckhut, P., Kelder, H. M., Koelemeijer, R., Kois, B., Koopman, R. M., Kopp, G., Lambert, J.C., Leblanc, T., McDermid, I. S., Pal, S., Schets, H., Stubi, R., Suortti, T., Viscont G., and Yela, M.: Pole-to-pole validation of Envisat GOMOS ozone profiles using data from groundbased and balloon sonde measurements, J. Geophys. Res., 109, D23305, doi:10.1029/2004JD004834, 2004.

Mertens, C. J.: Retrieval of mesospheric and lower thermospheric kinetic temperature from measurements of $\mathrm{CO}_{2} 15 \mu \mathrm{m}$ Earth limb emission under non-LTE conditions, Geophys. Res. Lett., 28(7), 1391-1394, doi:10.1029/2000GL012189, 2001.

Mertens, C. J., Schmidlin F. J., Goldberg R. A., Remsberg E. E., Pesnell W. D., Russell III, J. M., Mlynczak M. G., Wintersteiner P. P., Picard R. H., Winick J. R., and Gordley, L. L.: SABER observations of mesospheric temperatures and comparison with falling spheres measurements taken during the 2002 summer MaCWAVE campaign, Geophys. Res. Lett., 31, L03105, doi:10.1029/2003GL018605, 2004.

Moreau, G., Robert, C., Catoire, V., Chartier, M., Camy-Peyret, C., Huret, N., Pirre, M., Pomathiod, L., and Chalumeau, G.: SPIRALE: a multispecies in situ balloon-borne instrument with six tunable diode laser spectrometers, Appl. Optics, 44(28), 59725989, 2005.

Morris, G. A., Gleason, J. F., Russell III, J. M., Schoeberl, M. R., and McCormick, M. P.: A comparison of HALOE V19 with SAGE II V6.00 ozone observations using trajectory mapping, J. Geophys. Res., 107(D13), 4177, doi:10.1029/2001JD000847, 2002.

Murtagh, D. P., Frisk, U., Merino, F., Ridal, M., Jonsson, A., Stegman, J., Witt, G., Eriksson, P., Jiménez, C., Mégie, G., de la Noë, J., Ricaud, P., Baron, P., Pardo, J. R., Hauchecorne, A., Llewellyn, E. J., Degenstein, D. A., Gattinger, R. L., Lloyd, N. D., Evans, W. F. J., McDade, I. C., Haley, C. S., Sioris, C., von Savigny, C., Solheim, B. H., McConnell, J. C., Strong, K., Richardson, E. H., Leppelmeier, G. W., Kyrölä, E., Auvinen, H., and Oikarinen, L.: An overview of the Odin atospheric mission, Can. J. Phys., 80, 309-319, 2002.

Nakajima, H., Suzuki, M., Matsuzaki, A., Ishigaki, T., Waragai, K., Mogi, Y., Kimura, N., Araki, N., Yokota, T., Kanzawa, H., Sugita, T., and Sasano, Y.: Characteristics and performance of the Improved Limb Atmospheric Spectrometer (ILAS) in orbit, J. Geophys. Res., 107(D24), 8213, doi:10.1029/2001JD001439, 2002.

Nazaryan, H. and McCormick, M. P.: Comparisons of Stratospheric Aerosol and Gas Experiment (SAGE II) and Solar Backscatter Ultraviolet Instrument (SBUV/2) ozone profiles and trend estimates, J. Geophys. Res., 110, D17302, doi:10.1029/2004JD005483, 2005.

Parrish, A., Connor, B. J., Chu, W. P., Tsou, J.-J., and McDermid, I. S.: Ground-based microwave monitoring of stratospheric ozone, J. Geophys. Res., 97(D2), 2541-2546, doi:10.1029/91JD02914, 1992.

Parrish, A.: Millimeter-wave remote sensing of ozone and trace constituents in the stratosphere, Proc. IEEE, 82, 1915-1929, 1994.

Paton-Walsh, C., Bell, W., Gardiner, T., Swann, N., Woods, P., Notholt, J., Schutt, H., Galle, B., Arlander, W., and Mellqvist, 
J.: An uncertainty budget for ground-based Fourier transform infrared column measurements of $\mathrm{HCl}, \mathrm{HF}, \mathrm{N}_{2} \mathrm{O}$, and $\mathrm{HNO}_{3}$, deduced from results of side-by-side instrument intercomparisons, J. Geophys. Res., 102, 867-887, 1997.

Petelina, S. V., Llewellyn, E. J., Degenstein, D. A., Lloyd, N. D., Gattinger, R. L., Haley, C. S., von Savigny, C., Griffioen, E., McDade, I. C., Evans, W. F. J., Murtagh, D. P., and de La Noë, J.: Comparison of the Odin/OSIRIS stratospheric ozone profiles with coincident POAM III and ozonesonde measurements, Geophys. Res. Lett., 31, L07105, doi:10.1029/2003GL019299, 2004.

Petelina, S. V., Llewellyn, E. J., Walker, K. A., Degenstein, D. A., Boone, C. D., Bernath, P. F., Haley, C. S., von Savigny, C., Lloyd, N. D., and Gattinger, R. L.: Validation of ACE-FTS stratospheric ozone profiles against Odin/OSIRIS measurements, Geophys. Res. Lett., 32, L15S06, doi:10.1029/2005GL022377, 2005a.

Petelina, S. V., Degenstein, D. A., Llewellyn, E. J., Lloyd, N. D., Mertens, C. J., Mlynczak, M. G., and Russell III, J. M.: Thermal conditions for PMC existence derived from Odin/OSIRIS and TIMED/SABER data, Geophys. Res. Lett., 32, L17813, doi:10.1029/2005GL023099, 2005b.

Pickett, H. M.: Microwave Limb Sounder THz module on Aura, IEEE. Trans. Geosci. Remote Sens., 44(5), 1122-1130, 2006.

Pommereau, J. P. and Piquard, J.: Ozone, nitrogen dioxide and aerosol vertical distributions by UV-visible solar occultation from balloons, Geophys. Res. Lett, 21(13), 1227-1230, 1994.

Pougatchev, N. S. and Rinsland, C. P.: Spectroscopic study of the seasonal variation of carbon monoxide vertical distribution above Kitt Peak, J. Geophys. Res., 100, 1409-1416, 1995.

Pougatchev, N. S., Connor, B. J., and Rinsland, C. P.: Infrared measurements of the ozone vertical distribution above Kitt Peak, J. Geophys. Res., 100, 16689-16697, 1995.

Randall, C. E., Rusch, D. W., Bevilacqua, R. M., Hoppel, K. W., Lumpe, J. D., Shettle, E., Thompson, E., Deaver, L., Zawodny, J., Kyrö, E., Johnson, B., Kelder, H., Dorokhov, V. M., KönigLanglo, G., and Gil, M.: Validation of POAM III ozone: comparison with ozonesonde and satellite data, J. Geophys. Res., 108(D12), 4367, doi:10.1029/2002JD002944, 2003.

Raspollini, P., Belotti, C., Burgess, A., Carli, B., Carlotti, M., Ceccherini, S., Dinelli, B. M., Dudhia, A., Flaud, J.-M., Funke, B., Höpfner, M., López-Puertas, M., Payne, V., Piccolo, C., Remedios, J. J., Ridolfi, M., and Spang, R.: MIPAS level 2 operational analysis, Atmos. Chem. Phys., 6, 5605-5630, 2006, http://www.atmos-chem-phys.net/6/5605/2006/.

Reber, C. A., Trevathan, C. E., McNeal, R. J., and Luther, M. R.: The Upper Atmosphere Research Satellite (UARS) Mission, J. Geophys. Res. 98(D6), 10643-10647, 1993.

Redelsperger, J.-L., Thorncroft, C. D., Diedhiou, A., Lebel, T., Parker, D. J., and Polcher, J.: African Monsoon Multidisciplinary Analysis: An international research project and field campaign, Bull. Amer. Meteor. Soc., 87, 1739-1746, doi:10.1175/BAMS87-12-1739, 2006.

Ridolfi, M., Carli, B., Carlotti, M., von Clarmann, T., Dinelli, B. M., Dudhia, A., Flaud, J.-M., Höpfner, M., Morris, P. E., Raspollini, P., Stiller, G., and Wells, R. J.: Optimised forward model and retrieval scheme for MIPAS near-real-time data processing, Appl. Optics, 39(8), 1323-1340, 2000.

Rinsland, C. P., Jones, N. B., Connor, B. J., Logan, J. A., Pougatchev, N. S., Goldman, A., Murcray, F. J., Stephen, T. M., Pine, A. S., Zander, R., Mahieu, E., and Demoulin, P.: Northern and southern hemisphere ground-based infrared spectroscopic measurements of tropospheric carbon monoxide and ethane, J. Geophys. Res., 103, 28197-28217, 1998.

Rodgers, C. D.: Inverse Methods for Atmospheric Sounding - Theory and Practise, in: Series on Atmospheric, Oceanic and Planetary Physics, World Scientific (publisher), vol. 2, 2000.

Rodgers, C. D. and Connor, B. J.: Intercomparison of remote sounding instruments, J. Geophys. Res., 108(D3), 4116 , doi:10.1029/2002JD002299, 2003.

Roth, C. Z., Degenstein, D. A., Bourassa, A. E., and Llewellyn, E. J.: The retrieval of vertical profiles of the ozone number density using Chappuis band absorption information and a multiplicative algebraic reconstruction technique, Can. J. Phys., 85(11), 1225-1243, 2007.

Rothman, L. S., Jacquemart, D., Barbe, A., Benner, D. C., Birk, M., Brown, L. R., Carleer, M. R., Chackerian Jr., C., Chance, K., Coudert, L. H., Dana, V., Malathy Devi, V., Flaud, J.M., Gamache, R. R., Goldman, A., Hartmann, J.-M., Jucks, K. W., Maki, A. G., Mandin, J.-Y., Massie, S. T., Orphal, J., Perrin, A., Rinsland, C. P., Smith, M. A. H., Tennyson, J., Tolchenov, R. N., Toth, R. A., Vander Auwera, J., Varanasi, P., and Wagner, G.: The HITRAN 2004 molecular spectroscopic database, J. Quant. Spectrosc. Radiat. Transfer, 96, 139-204, doi:10.1016/j.jqsrt.2004.10.008, 2005.

Russell III, J. M., Gordley, L. L., Park, J. H., Drayson, S. R., Hesketh, W. D., Cicerone, R. J., Tuck, A. F., Frederick, J. E., Harries, J. E., and Crutzen, P. J.: The Halogen Occultation Experiment, J. Geophys. Res., 98(D6), 10777-10797, doi:10.1029/93JD00799, 1993.

Russell III, J. M., Mlynczak, M. G., Gordley, L. L., Tansock, J., and Esplin, R.: An overview of the SABER experiment and preliminary calibration results, Proc. SPIE Int. Soc. Opt. Eng., 3756 , 277-288, 1999.

SAGE III ATBD Team: SAGE III Algorithm Theoretical Basis Document (ATBD) for transmission level $1 \mathrm{~b}$ products version 2.1, NASA Langley Res. Cent. (LaRC), Hampton, Virginia, 2002a.

SAGE III ATBD Team: SAGE III Algorithm Theoretical Basis Document (ATBD): Lunar and solar algorithm, NASA Langley Res. Cent. (LaRC), Hampton, Virginia, 2002b.

Schneider, M., Redondas, A., Hase, F., Guirado, C., Blumenstock, T., and Cuevas, E.: Comparison of ground-based Brewer and FTIR total column $\mathrm{O}_{3}$ monitoring techniques, Atmos. Chem. Phys., 8, 5535-5550, 2008a,

http://www.atmos-chem-phys.net/8/5535/2008/.

Schneider, M., Hase, F., Blumenstock, T., Redondas, A., and Cuevas, E.: Quality assessment of $\mathrm{O}_{3}$ profiles measured by a state-of-the-art ground-based FTIR observing system, Atmos. Chem. Phys., 8, 5579-5588, 2008b,

http://www.atmos-chem-phys.net/8/5579/2008/.

Schneider, N., Selsis, F., Urban, J., Lezeaux, O., de La Noë, J., and Ricaud, P.: Seasonal and diurnal ozone variations: observations and modeling, J. Atmos. Chem., 50, 25-47, 2005.

Schoeberl, M. R., Douglass, A. R., Hilsenrath, E., Bhartia, P. K., Beer, R., Waters, J. W., Gunson, M. R., Froidevaux, L., Gille, J. C., Barnett, J. J., Levelt, P. F., and DeCola, P.: Overview of the EOS Aura mission, IEEE Trans. Geosci. Remote Sens., 44(5), 1066-1074, 2006.

Senten, C., De Mazière, M., Dils, B., Hermans, C., Kruglanski, 
M., Neefs, E., Scolas, F., Vandaele, A. C., Vanhaelewyn, G., Vigouroux, C., Carleer, M., Coheur, P. F., Fally, S., Barret, B., Baray, J. L., Delmas, R., Leveau, J., Metzger, J. M., Mahieu, E., Boone, C., Walker, K. A., Bernath, P. F., and Strong, K.: Technical Note: New ground-based FTIR measurements at Île de La Réunion: observations, error analysis, and comparisons with independent data, Atmos. Chem. Phys., 8, 3483-3508, 2008, http://www.atmos-chem-phys.net/8/3483/2008/.

Sica, R. J., Izawa, M. R. M., Walker, K. A., Boone, C., Petelina, S. V., Argall, P. S., Bernath, P., Burns, G. B., Catoire, V., Collins, R. L., Daffer, W. H., De Clercq, C., Fan, Z. Y., Firanski, B. J., French, W. J. R., Gerard, P., Gerding, M., Granville, J., Innis, J. L., Keckhut, P., Kerzenmacher, T., Klekociuk, A. R., Kyrö, E., Lambert, J. C., Llewellyn, E. J., Manney, G. L., McDermid, I. S., Mizutani, K., Murayama, Y., Piccolo, C., Raspollini, P., Ridolfi, M., Robert, C., Steinbrecht, W., Strawbridge, K. B., Strong, K., Stübi, R., and Thurairajah, B.: Validation of the Atmospheric Chemistry Experiment (ACE) version 2.2 temperature using ground-based and space-borne measurements, Atmos. Chem. Phys., 8, 35-62, 2008,

http://www.atmos-chem-phys.net/8/35/2008/.

Smit, H. G. J., Sträter, W., Johnson, B. J., Oltmans, S. J., Davies, J., Tarasick, D. W., Hoegger, B., Stubi, R., Schmidlin, F. J., Northam, T., Thompson, A. M., Witte, J. C., Boyd, I. S., and Posny, F.: Assessment of the performance of ECC-ozonesondes under quasi flight conditions in the environmental simulation chamber: insights from the Jülich Ozone Sonde Intercomparison Experiment (JOSIE), J. Geophys. Res., 112, D19306, doi:10.1029/2006JD007308, 2007.

Steck, T., von Clarmann, T., Fischer, H., Funke, B., Glatthor, N., Grabowski, U., Höpfner, M., Kellmann, S., Kiefer, M., Linden, A., Milz, M., Stiller, G. P., Wang, D. Y., Allaart, M., Blumenstock, Th., von der Gathen, P., Hansen, G., Hase, F., Hochschild, G., Kopp, G., Kyrö, E., Oelhaf, H., Raffalski, U., Redondas Marrero, A., Remsberg, E., Russell III, J., Stebel, K., Steinbrecht, W., Wetzel, G., Yela, M., and Zhang, G.: Bias determination and precision validation of ozone profiles from MIPAS-Envisat retrieved with the IMK-IAA processor, Atmos. Chem. Phys., 7, 36393662, 2007, http://www.atmos-chem-phys.net/7/3639/2007/.

Stratospheric Processes And their Role in Climate (SPARC): Assessment of trends in the vertical distribution of ozone, SPARC report No. 1, in: WMO Global Ozone Res. and Monit. Project Rep. 43, edited by: Harris, N., Hudson, R., and Phillips, C., World Meteorol. Org., Geneva, 1998.

Sung, K., Skelton, R., Walker, K. A., Boone, C. D., Fu, D., and Bernath, P. F.: $\mathrm{N}_{2} \mathrm{O}$ and $\mathrm{O}_{3}$ arctic column amounts from PARISIR observations: Retrievals, characterization and error analysis, J. Quant. Spectrosc. Rad. Transfer, 107, 385-406, 2007.

Sung, K., Strong, K., Mittermeier, R. L., Walker, K. A., et al.: Partial and total column SFIT2 retrievals from Eureka DA8 spectra in spring 2004 and 2005, including comparisons with PARIS-IR and ACE Satellite measurements, Atmos. Chem. Phys. Discuss., in preparation, 2009.

Sussmann, R. and Borsdorff, T.: Technical Note: Interference errors in infrared remote sounding of the atmosphere, Atmos. Chem. Phys., 7, 3537-3557, 2007,

http://www.atmos-chem-phys.net/7/3537/2007/.

Thompson, A. M., Witte, J. C., McPeters, R. D., Oltmans, S. J., Schmidlin, F. J., Logan, J. A., Fujiwara, M., Kirch- hoff, V. W. J. H., Posny, F., Coetzee, G. J. R., Hoegger, B., Kawakami, S., Ogawa, T., Johnson, B. J., Vömel, H., and Labow, G.: Southern Hemisphere Additional Ozonesondes (SHADOZ) 1998-2000 tropical ozone climatology: 1. Comparison with Total Ozone Mapping Spectrometer (TOMS) and ground-based measurements, J. Geophys. Res., 108(D2), 8238, doi:10.1029/2001JD000967, 2003a.

Thompson, A. M., Witte, J. C., Oltmans, S. J., Schmidlin, F. J., Logan, J. A., Fujiwara, M., Kirchhoff, V. W. J. H., Posny, F., Coetzee, G. J. R., Hoegger, B., Kawakami, S., Ogawa, T., Fortuin, J. P. F., and Kelder, H. M.: Southern Hemisphere Additional Ozonesondes (SHADOZ) 1998-2000 tropical ozone climatology: 2. Tropospheric variability and the zonal wave-one, J. Geophys. Res., 108(D2), 8241, doi:10.1029/2002JD002241, 2003b.

Thompson, A. M., Witte, J. C., Smit, H. G. J., Oltmans, S. J., Johnson, B. J., Kirchhoff, V. W. J. H., and Schmidlin, F. J.: Southern Hemisphere Additional Ozonesondes (SHADOZ) 1998-2004 tropical ozone climatology: 3. Instrumentation, station-to-station variability, and evaluation with simulated flight profiles, J. Geophys. Res., 112, D03304, doi:10.1029/2005JD007042, 2007a.

Thompson, A. M., Stone, J. B., Witte, J. C., Miller, S. K., Pierce, R. B., Chatfield, R. B., Oltmans, S. J., Cooper, O. R., Loucks, A. L., Taubman, B. F., Johnson, B. J., Joseph, E., Kucsera, T. L., Merrill, J. T., Morris, G. A., Hersey, S., Forbes, G., Newchurch, M. J., Schmidlin, F. J., Tarasick, D. W., Thouret, V., and Cammas, J.-P.: Intercontinental Chemical Transport Experiment Ozonesonde Network Study (IONS) 2004: 1. Summertime upper troposphere/lower stratosphere ozone over northeastern North America, J. Geophys. Res., 112, D12S12, doi:10.1029/2006JD007441, 2007b.

Thompson, A. M., Stone, J. B., Witte, J. C., Miller, S. K., Oltmans, S. J., Kucsera, T. L., Ross, K. L., Pickering, K. E., Merrill, J. T., Forbes, G., Tarasick, D. W., Joseph, E., Schmidlin, F. J., McMillan, W. W., Warner, J., Hintsa, E. J., and Johnson, J. E.: Intercontinental Chemical Transport Experiment Ozonesonde Network Study (IONS) 2004: 2. Tropospheric ozone budgets and variability over northeastern North America, J. Geophys. Res., 112, D12S13, doi:10.1029/2006JD007670, 2007c.

Urban, J., Lautié, N., Le Flochmoën, E., Jiménez, C., Eriksson, P., de La Noë, J., Dupuy, E., Ekström, M., El Amraoui, L., Frisk, U., Murtagh, D., Olberg, M., and Ricaud, P.: Odin/SMR observations of stratospheric trace gases: Level 2 processing of $\mathrm{ClO}, \mathrm{N}_{2} \mathrm{O}, \mathrm{O}_{3}$, and $\mathrm{HNO}_{3}$, J. Geophys. Res., 110, D14307, doi:10.1029/2004JD005741, 2005.

Vigouroux, C., De Mazière, M., Errera, Q., Chabrillat, S., Mahieu, E., Duchatelet, P., Wood, S., Smale, D., Mikuteit, S., Blumenstock, T., Hase, F., and Jones, N.: Comparisons between groundbased FTIR and MIPAS $\mathrm{N}_{2} \mathrm{O}$ and $\mathrm{HNO}_{3}$ profiles before and after assimilation in BASCOE, Atmos. Chem. Phys., 7, 377-396, 2007, http://www.atmos-chem-phys.net/7/377/2007/.

von Clarmann, T., Grabowski, U., Höpfner, M., Kellmann, S., Kiefer, M., Linden, A., Mengistu Tsidu, G., Milz, M., Steck, T., Stiller, G. P., Wang, D. Y., Fischer, H., Funke, B., GilLópez, S., and López-Puertas, M.: Retrieval of temperature and tangent altitude pointing from limb emission spectra recorded from space by the Michelson Interferometer for Passive Atmospheric Sounding (MIPAS), J. Geophys. Res., 108(D23), 4736, doi:10.1029/2003JD003602, 2003. 
von Clarmann, T.: Validation of remotely sensed profiles of atmospheric state variables: strategies and terminology, Atmos. Chem. Phys., 6, 4311-4320, 2006, http://www.atmos-chem-phys.net/6/4311/2006/.

von Koenig, M., Bremer, H., Eyring, V., Goede, A., Hetzheim, H., Kleipool, Q., Kuellmann H., and Künzi, K.: An airborne submm radiometer for the observation of stratospheric trace gases: Microwave Radiometry and Remote Sensing of the Earth's Surface and Atmosphere, edited by: Pampaloni, P. and Paloscia, S., VSP Utrecht, 409-415, 2000.

von Savigny, C., Haley, C. S., Sioris, C. E., McDade, I. C., Llewellyn, E. J., Degenstein, D., Evans, W. F. J., Gattinger, R. L., Griffioen, E., Kyrölä, E., Lloyd, N. D., McConnell, J. C., McLinden, C. A., Mégie, G., Murtagh, D. P., Solheim, B., and Strong, K.: Stratospheric ozone profiles retrieved from limb scattered sunlight radiance spectra measured by the OSIRIS instrument on the Odin satellite, Geophys. Res. Lett., 30(14), 1755-1758, doi:10.1029/2002GL016401, 2003.

von Savigny, C., Rozanov, A., Bovensmann, H., Eichmann, K.-U., Noël, S., Rozanov, V. V., Sinnhuber, B.-M., Weber, M., and Burrows, J. P.: The ozone hole break-up in September 2002 as seen by SCIAMACHY on ENVISAT, J. Atmos. Sci., 62(3), 721-734, 2005a.

von Savigny, C., Kaiser, J. W., Bovensmann, H., Burrows, J. P., McDermid, I. S., and Leblanc, T.: Spatial and temporal characterization of SCIAMACHY limb pointing errors during the first three years of the mission, Atmos. Chem. Phys., 5, 2593-2602, 2005b, http://www.atmos-chem-phys.net/5/2593/2005/.

Walker, K. A., Randall, C. E., Trepte, C. R., Boone, C. D., and Bernath, P. F.: Initial validation comparisons for the Atmospheric Chemistry Experiment (ACE-FTS), Geophys. Res. Lett., 32, L16S04, doi:10.1029/2005GL022388, 2005.

Wang, H. J., Cunnold, D. M., Thomason, L. W., Zawodny, J. M., and Bodeker, G. E.: Assessment of SAGE II version 6.1 ozone data quality, J. Geophys. Res., 107(D23), 4691, doi:10.1029/2002JD002418, 2002.

Wang, H. J., Cunnold, D. M., Thomason, L. W., and Zawodny, J. M.: SAGE III solar ozone measurements: Initial results, Geophys. Res. Lett., 33, L03805, doi:10.1029/2005GL025099, 2006.
Wang, P. H., Cunnold, D. M., Trepte, C. R., Wang, H. J., Jing, P., Brackett, V. G., Zawodny, J. M., and Bodeker, G. E.: Ozone variability in the midlatitude upper troposphere and lower stratosphere diagnosed from a monthly SAGE II climatology relative to the tropopause, J. Geophys. Res., 111, D21304, doi:10.1029/2005JD006108, 2006.

Waters, J. W., Froidevaux, L., Harwood, R. S., Jarnot, R. F., Pickett, H. M., Read, W. G., Siegel, P. H., Cofield, R. E., Filipiak, M. J., Flower, D. A., Holden, J. R., Lau, G. K., Livesey, N. J., Manney, G. L., Pumphrey, H. C., Santee, M. L., Wu, D. L., Cuddy, D. T., Lay, R. R., Loo, M. S., Perun, V. S., Schwartz, M. J., Stek, P. C., Thurstans, R. P., Boyles, M. A., Chandra, K. M., Chavez, M. C., Chen, G.-S., Chudasama, B. V., Dodge, R., Fuller, R. A., Girard, M. A., Jiang, J. H., Jiang, Y., Knosp, B. W., LaBelle, R. C., Lam, J. C., Lee, K. A., Miller, D., Oswald, J. E., Patel, N. C., Pukala, D. M., Quintero, O., Scaff, D. M., Van Snyder, W., Tope, M. C., Wagner, P. A., and Walch, M. J.: The Earth Observing System Microwave Limb Sounder (EOS MLS) on the Aura satellite, IEEE Trans. Geosci. Remote Sens., 44(5), 10751092, doi:10.1109/TGRS.2006.873771, 2006.

Wiacek, A., Taylor, J. R., Strong, K., Saari, R., Kerzenmacher, T., Jones, N. B., and Griffith, D. W. T.: Ground-Based solar absorption FTIR spectroscopy: characterization of retrievals and first results from a novel optical design instrument at a New NDACC Complementary Station, J. Atmos. Oceanic Technol., 24(3), 432-448, 2007.

WMO (World Meteorological Organization): Scientific assessment of ozone depletion: 2006, WMO Global Ozone Res. and Monit. Project, Rep. 50, World Meteorol. Org., Geneva, 2007.

Zander, R., Mahieu, E., Demoulin, P., Duchatelet, P., Roland, G., Servais, C., De Mazière, M., Reimann, S., and Rinsland, C. P.: Our changing atmosphere: Evidence based on long-term infrared solar observations at the Jungfraujoch since 1950, Sci. Total Environ., 391, 184-195, 2008. 